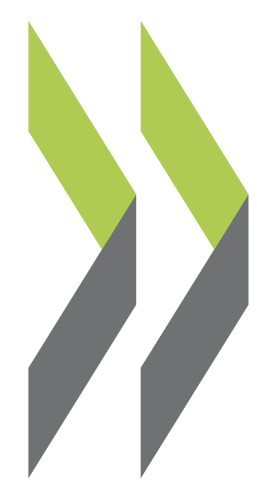

OECD Local Economic and Employment Development (LEED) Papers 2010/07

A Review of Local Economic and Employment Development Policy Approaches in OECD Jonathan Potter, Countries: Policy Transferability to Wales 


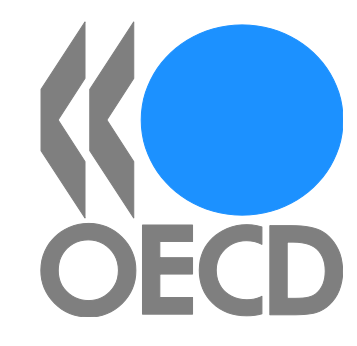

LEED Progganme

OECD Local Economic and Employment Development (LEED) Programme

\title{
A Review of Local Economic and Employment Development Policy Approaches in OECD Countries
}

\author{
Part II: \\ Policy Transferability to Wales
}




\section{Contact details}

OECD Centre for Entrepreneurship, SMEs and Local Development (CFE) 2 rue Andre-Pascal, 75775 cedex 16, Paris, France www.oecd.org/cfe CFE's Local Economic and Employment development programme www.oecd.org/cfe/leed

OECD contact people for this report:

Jonathan Potter, Senior Economist, OECD LEED Programme jonathan.potter@oecd.org

Marco Marchese, Policy Analyst, OECD LEED Programme marco.marchese@oecd.org 


\section{NOTE ON THE REPORT SERIES}

This report forms part of a series of four reports from the project carried out by the OECD with collaboration from the Welsh Assembly Government (WAG) "A Review of Local Economic and Employment Development Policy Approaches in OECD countries". The review has intended to provide WAG with a set of policy options and learning models to consider in the design of future development policies and strategies. The full set of reports is as follows:

- $\quad$ Executive Summary \& Synthesis of Findings

- $\quad$ Part I: Policy Audits

- Part II: Policy Transferability to Wales

- Part III: Case Studies of Regional Economic Development Approaches

This report presents the results of Part II, which investigates the transferability to Wales of the twenty interventions analysed in the "policy audit" part of the review. 



\section{ACKNOWLEDGEMENTS}

This project was led by Jonathan Potter and Marco Marchese of the OECD Local Economic and Employment Development Programme. The work was undertaken in collaboration with the Welsh Assembly Government.

The OECD Secretariat gratefully acknowledges the contributions of the Welsh Assembly Government Steering Group for this project and the advice of the members of the Welsh Assembly Government Economic Research Advisory Panel.

The project Steering Group members were:

Jonathan Price, Chief Economist

Gareth Morgan, Head of Economic Research

Gareth Edwards, Economic Advice Division

Neill Paul, First Ministers Office

Kevin Griffiths, Education Division

Julian Revell, Statistics Division

Jarlath Costello, Economics and Transport Division

James Price and Tracey Burke of the Welsh Assembly Government Secretariat provided further useful support. 



\section{TABLE OF CONTENTS}

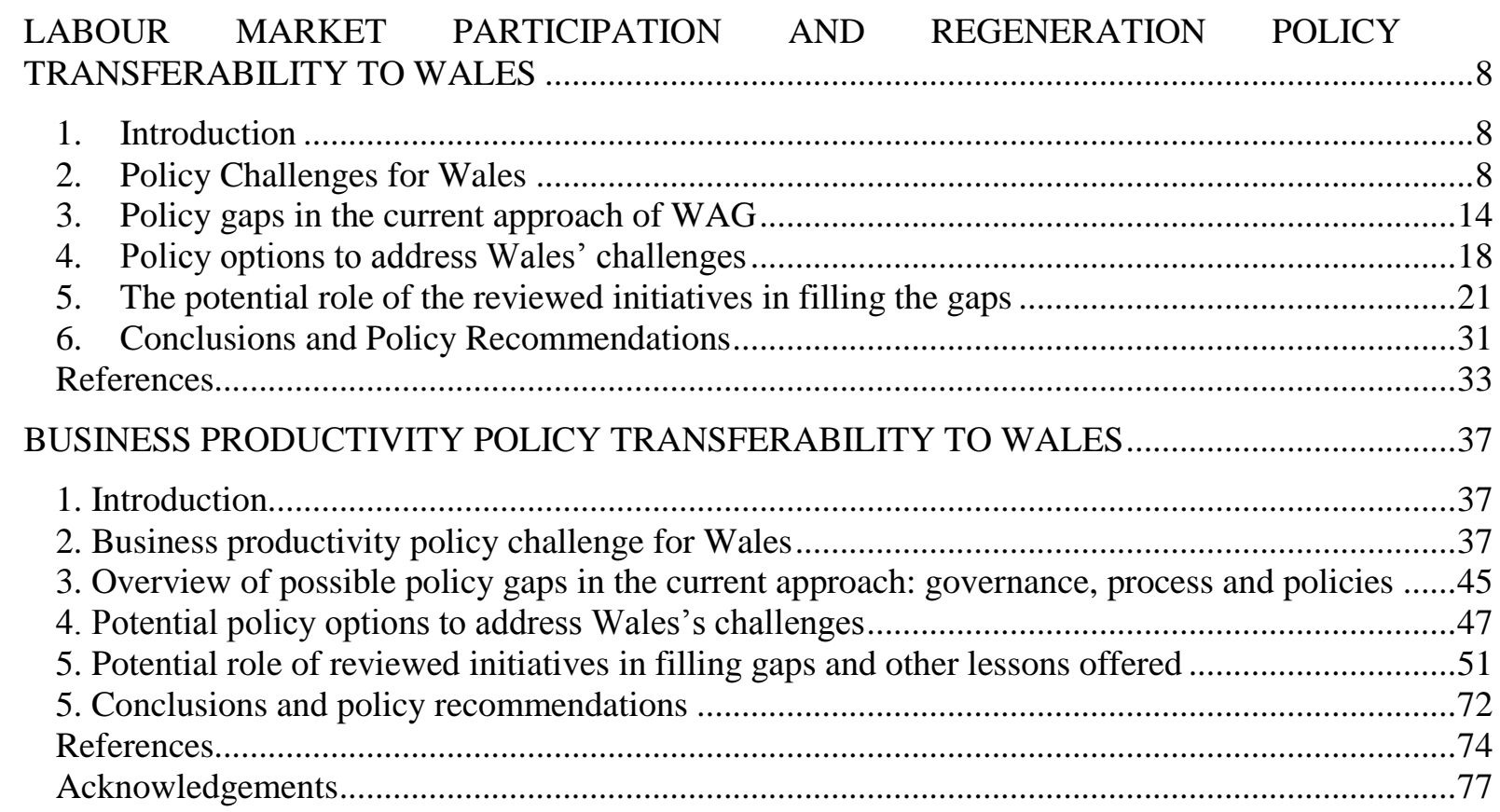




\title{
LABOUR MARKET PARTICIPATION AND REGENERATION POLICY TRANSFERABILITY TO WALES
}

\author{
Prof. P.J. Sloane \\ WELMERC, School of Business and Economics, Swansea University.
}

\section{Introduction}

This paper is written in the context of a coalition government ${ }^{1}$ in the Welsh Assembly which is committed to full employment (defined as an employment rate of $80 \%$ ) based on quality jobs. ${ }^{2}$ At the outset it should be noted that not all activities relevant to the subject matter of this report have been devolved to the Welsh Assembly. Though the Assembly has powers relating to education and training it does not have responsibility for employment issues. It should also be emphasised that the Welsh Assembly has introduced many new policies and strategies and has recently integrated bodies such as Education and Learning Wales (ELWa) and the Welsh Development Agency into Government Departments. This report considers the transferability of ten policy audits focusing on specific policy interventions in different OECD countries in the fields of labour market participation, skills development and economic and physical regeneration. First, it considers the main policy challenges for Wales in relation to the labour market. It then examines evidence of policy gaps in the current approach of the Welsh Assembly Government. This leads on to an assessment of the policy options that might be considered in relation to the challenges facing Wales. The next section attempts to consider the potential role of the reviewed initiatives in filling these gaps. A final section draws conclusions and makes some policy recommendations.

\section{Policy Challenges for Wales}

During its first term, beginning in 1999, the Welsh Assembly Government (WAG) set out the key challenges facing Wales and set targets for improvements in A Winning Wales (2002), a national economic development strategy. The principle aim was to close the Gross Domestic Product (GDP) gap between Wales and the rest of the UK. ${ }^{3}$ For the next ten years the targets were to raise employment initially by 135000 , improve enterprise and innovation, raise skill levels and improve information and communications technology. It was believed that skilled, good quality and well paid jobs would assist in this process, but it was also recognised that the Welsh economy was highly dependent on the performance of the economy elsewhere in the UK.

Further flesh was put on these aims in Wales: A Better Country and Wales: A Vibrant Economy (2005). The latter recognised that there had been improvements in employment, unemployment, real earnings and economic growth in Wales compared to 1999, but also noted that economic inactivity remained high and was not confined to certain areas such as the Heads of the Valleys where long term illness was at a high level. Gaps in the provision of childcare and in transport deterred some from entering work. Some emphasis was placed on regeneration projects supported by the EU Structural Funds programmes and WAG "Communities First" initiatives which attempt to regenerate deprived communities. 
UK-wide policies such as Pathways to Work pilots and the Welsh Want2Work initiative, also supported by EU Structural Funds, were designed to encourage those on incapacity benefits to enter the workforce. ${ }^{4}$ Building on New Deal: Local Solutions Meeting Individual Needs, by the UK Department of Work and Pension (June 2004), outlined a fivefold strategy for Britain as a whole, incorporating macro-economic stability, flexible labour markets, tax and benefit policies to make work pay, education, skills and training policies to produce a more productive labour force and active labour market policies to prevent long-term unemployment and inactivity. Since 1997 employment had increased by 1.9 million, with higher employment rates than the OECD average for all major groups, and with an average cost per unemployed person, as a ratio of GDP, below the OECD average.

Research had also identified the absence of a large city or urban area, with a consequential lack of agglomeration economies, as a factor underlying the lower earnings found in $\mathrm{Wales}^{5}$; but appropriate policies to alleviate this problem were far from obvious. Business growth has been supported by WAG's Innovation Action Plan which supports innovation in firms and encourages stronger links with higher education, notably through the Technium network which provides incubator space for high technology enterprises. There is a separate Entrepreneurship Action Plan and a Knowledge Bank for Business. The Wales Spatial Plan, People, Places, Futures divides Wales into six Spatial Plan areas and builds on regional development strategies by considering economic, social and environmentally sustainable aspects. The annual National Learning and Skills Assessments seek to highlight priority areas for change including consideration of examples of market failure, where evidence suggests that the learning market is not moving quickly enough or a further growth of skilled manpower is required. Six priorities for change are learning pathways for 14-19 year olds, basic skills training (where Wales performs noticeably badly ${ }^{6}$ ), apprenticeships in construction, e-skills, the childcare sector and NVQs in customer care in selected sectors. However, higher education is not considered in this framework. Concerns have also been expressed about the impact of migrant labour on the learning system and the importance of management and leadership training has been recognised as well.

Research into inactivity rates in Wales has been conducted by Swansea University for the Welsh Assembly Government (D. Blackaby et al. Identifying Barriers to Economic Activity in Wales, Stages 1 and 2). It was noted that the economically inactive are a diverse group - early retired, students and sick or disabled - that vary in their closeness to the labour market. The growth in inactivity has increasingly been concentrated on the low skilled and those classified as long-term ill or disabled with a suggestion that the social security system encourages early retirement. There are high levels of inactivity among social housing residents which may reflect reduced potential residential mobility, neighbourhood effects, and peripheral locations. Particularly for youths, the scarring effects of nonemployment may be severe and in the case of those from workless households, labour market disadvantage may result in the transmission of non-employment to later cohorts through intergenerational influences. The government's strategy for reducing joblessness has been two pronged providing assistance to enter work (New Deal) and increasing relative rewards from work such as Working Families Tax Credits (WFTC). The impact of the New Deal for young workers in particular has been positive, but does not take into account the costs of the programme, while for WFTC the incentives appear to be positive for lone parents and male single earners, but negative for married females. All of this points to the need for careful targeting.

Interviews carried out by WELMERC, Swansea University with 1300 inactive persons in Welsh areas with diverse working conditions, confirmed that around one half of inactive men and nearly one half of inactive women had not worked for at least ten years, over two thirds had no formal qualifications, and a similar proportion reported a long term health problem. There was generally severe disengagement from the labour market and of the $20 \%$ who wanted a job some had unrealistic wage aspirations. The barriers to employment were multi-faceted including childcare and transportrelated problems. There was severe ignorance about in-work benefits. From the policy view point 
there were advantages to be gained from focusing on those who wanted a job in the short-term by making them more aware of in-work benefits, enhancing the current range of easements and having more effective early interventions for inactive young men.

Want2Work was a Wales specific strategy introduced to deal with the problem of inactivity. Voluntary Want2Work pilots have been conducted through WAG and Job Centre Plus in four locations - Cardiff, Neath Port Talbot, Merthyr Tydfil and Denbighshire. The pilots support all inactive residents in these locations, but the prime target is the stock of invalidity benefit recipients. The key features are a network of community based advisers, the availability of health professionals, return to work subsidies of $£ 60$ per week for the first four months, $£ 40$ for the next four months and $£ 20$ for the following four months. There is also discretionary funding to overcome other barriers, a job preparation premium and funding for training. Interim evaluation of the pilots has been carried out by researchers from Sheffield University, who surveyed 3500 recipients over a two year period (20052006). Individuals who enrolled on the Want2Work scheme were 8.4 percentage points more likely to have moved into employment compared to a control group of those initially out of work in the Quarterly Labour Force Survey (QLFS), which was a statistically large and significant effect. These results were largely confirmed using a propensity score matching approach, limiting the analysis to invalidity benefit recipients and restricting the analysis to more comparable time periods over the two data sets. While there was some suggestion that pay was lower among those entering employment from Want2Work, there was no hard evidence that the quality of jobs was inferior for those obtaining a job than the average for those employed in Wales. Preliminary results of additional health outcome research suggests that getting a job and actively looking for a job are both associated with positive health benefits. However, these results need to be confirmed over a longer time period and information on cost per job compared to that on other forms of labour market intervention needs to be provided.

Wales, however, is not a homogeneous country as is recognised by West Wales and the Valleys having EU Objective One status from 2000 and Convergence Funding from 2008-2013. Thus the aim is not simply for Wales to close the GDP gap with the rest of the UK, but also for West Wales and the Valleys to close the GDP gap with East Wales, which itself performs more closely to the UK average. Between 1995 and 2004 GVA per head in Wales fell, relatively to the UK, from 84 to $78 \%$; though the decline was concentrated in the earlier part of the period prior to the introduction of Objective One funding. When we split Wales into the two regions we observe that GVA per head in East Wales has been identical to that of the UK as a whole, while the position of West Wales and the Valleys deteriorated from $74 \%$ of the UK average in 1995 to $65 \%$ in 2004. In absolute terms the position is better since the position of the UK has been improving relative to the EU average as measured by GDP per head. Thus according to Eurostat figures, using purchasing power parities, the UK figure rose from $111 \%$ of the EU average in 1999 to $117 \%$ in 2005. The problem for Wales is how to break the historical link with the rest of the UK in a positive as opposed to a negative direction.

When we turn to the labour market, the situation is somewhat brighter for Wales. According to WELMERC data $^{7}$ the overall performance of the Welsh labour market improved, relative to that of Great Britain, over the period 2000 to 2006 and the improvement was more marked in the Objective One area than in the rest of Wales. This was true of all three domains - employment, earnings and human capital. The relative decline in product market performance and improvement in labour market performance is suggestive of a deterioration in the quality of jobs. In part, full-time male jobs appear to have been substituted by female part-time jobs. Table II. 1 shows changes since 2000 in a number of indicators for the Objective One area and Objective Three (East Wales) area using the most recent available data. Economic activity is shown to have improved relative to the UK in the Objective One area, but fallen in the Objective 3 area. Unemployment has fallen in both areas and is actually lower in the Objective One area than in the rest of the UK. There have also been substantial reductions in both areas, in long-term unemployment as a percentage of total unemployment. Thus it is on inactivity as 
opposed to unemployment that policy needs to be focused. Turning to qualifications, there have been improvements in both areas in the proportion of working age people with NVQ level 3 or more as a percentage of all working age people, and the same applies to those with NVQ level 4 qualifications or better. But in both cases the percentages are lower in the Objective One area than in the Objective 3 area.

TABLE II.1: Key indicators for Welsh Objective One \& Objective Three

\begin{tabular}{|c|c|c|c|c|c|}
\hline & & \multicolumn{2}{|c|}{$\begin{array}{c}\text { Welsh Objective } \\
\text { One Area }\end{array}$} & \multicolumn{2}{|c|}{$\begin{array}{c}\text { Welsh Objective } \\
\text { Three Area }\end{array}$} \\
\hline & & Number & $\%$ & Number & $\%$ \\
\hline Long-term (12 months+) & Jan-00 & 8765 & 19.9 & 3910 & 19.6 \\
\hline \multirow[t]{2}{*}{ unemploymenta } & Jan-08 & 3330 & 12.0 & 1100 & 8.1 \\
\hline & & & $\%$ & & $\%$ \\
\hline \multirow{3}{*}{$\begin{array}{l}\text { Unemployment - Working age } \\
\text { people }\end{array}$} & Mar 1999-Feb 2000b & 61000 & 7.8 & 33000 & 6.6 \\
\hline & Apr 2006-Mar 2007c & 47900 & 4.8 & 24300 & 5.9 \\
\hline & & & $\begin{array}{c}\text { Index } \\
(\mathrm{UK}=100)\end{array}$ & & $\begin{array}{c}\text { Index } \\
(\mathrm{UK}=100)\end{array}$ \\
\hline \multirow[t]{3}{*}{ Economic Activity } & Mar 1999-Feb 2000b & 781000 & 71.6 & 492000 & 79.2 \\
\hline & Apr 2006-Mar 2007c & 814000 & 73.8 & 507100 & 77.2 \\
\hline & & & $\%$ & & $\%$ \\
\hline $\begin{array}{l}\text { Working-age people with NVQ } \\
\text { level } 3+\text { as } \% \text { of all working } \\
\text { age people }\end{array}$ & Mar 1999-Feb 2000b & 379000 & 34.8 & 265000 & 42.1 \\
\hline \multirow[t]{2}{*}{ \% with NVQ3+ - working age } & Jan 2006-Dec 2006c & 443400 & 40.2 & 307200 & 47.2 \\
\hline & & & $\%$ & & $\%$ \\
\hline $\begin{array}{l}\text { Work-age people in } \\
\text { employment with NVQ 4+ as } \\
\% \text { of all working age in } \\
\text { employment }\end{array}$ & Mar 1999-Feb 2000b & 202000 & 18.6 & 163000 & 25.9 \\
\hline$\%$ with NVQ4+ - working age & Jan 2006-Dec 2006c & 242300 & 22.0 & 183100 & 28.1 \\
\hline
\end{tabular}

Wales has set itself targets of closing the GDP gap per head with the rest of the UK, which implies raising productivity while at the same time achieving convergence between West Wales and the Valleys and East Wales. Further, in order to achieve this objective, it implies that Wales will need to achieve a faster growth rate than the rest of the UK over a number of years. This involves a classic potential trade-off, since any attempt to frustrate market forces by inducing resources to move from East Wales and transfer them to West Wales and the Valleys may reduce the overall rate of economic growth. ${ }^{8}$ East Wales, and particularly Cardiff, as the largest population centre in Wales, is closer to England both in location and performance and appears to benefit from agglomeration economies more than the rest of Wales.

The most recent figure for gross value added per head in East Wales is 99 (UK = 100) with Cardiff at 113 and Monmouthshire and Newport at 104. West Wales and the Valleys stand at 65 and, whilst stable during the period from when Objective One funding was introduced, are lower than they were in the mid 1990s. ${ }^{9}$ If Cardiff, and to a lesser extent Newport, gains from agglomeration economies and closeness to the English market, the only significant population centres are Swansea, which is in the Objective One region and Wrexham in North Wales (which at least is adjacent to the market of North West England including Liverpool and Manchester). One would expect that migration of labour to Cardiff and other areas of high activity would serve as an alternative to the movement of physical resources, but particularly in the Valleys labour tends to be relatively immobile and the effect of outward mobility (mainly of younger workers) would leave a residue of less employable individuals in the less busy regions. An alternative approach is to encourage more commuting from say the 
Valleys, in particular, to Cardiff and elsewhere - transport links have an important role to play here. The only other alternative is a regeneration strategy to improve the local infrastructure, making make it more attractive for firms to relocate. But that needs to be accompanied by policies to improve the quality of the local potential workforce.

Here Want2Work is the flagship policy to improve activity rates in Wales, and while there has been some relative success, it is in part-time work that the main increase has occurred and this fits uneasily with WAG's desire to improve the quality of jobs. Further, there may also be a trade-off between raising activity rates and improving productivity, given the unfavourable skill composition of the inactive. There is, in fact, only a small difference between the overall activity rates for the nondisabled in Wales and the rest of the UK. It is among the disabled that the activity rates diverge with a figure of around $28 \%$ in Wales compared to around $36 \%$ in the UK as a whole and the disabled in employment tend to work much shorter hours than the non-disabled. Getting those who have been sick long term back into the labour market remains a formidable challenge, which is exacerbated by the greater incidence of disability in Wales. Jones, Latreille and Sloane $(2006)^{10}$ have shown that the marginal effects of increasing education on the likelihood of the disabled having employment are substantial. This points to the importance of upgrading for the disabled and other inactive groups. Whilst the qualifications of the workforce in Wales as a whole are rising, there are substantial differences across unitary authorities with less than 10\% achieving NVQ level 4 or more in Blaenau Gwent compared to 33\% in Cardiff. Improving skill levels requires a prior improvement in basic skills of literacy and numeracy if individuals are to fully benefit from various forms of skill acquisition. This emphasises the importance of the basic skills strategy.

There is, in addition, a demographic challenge as birth rate effect mean that the percentage of the population in younger age groups (up to age 24) is declining and the percentage over 55 increasing. Wales already has the second lowest proportion of the population aged between 15 and 65 of any region in the UK. Further, net immigration is concentrated among those aged between 45 and 64, while there is net outmigration in the 16-24 age group. This implies that there is a need to encourage more workers to remain in employment beyond the standard age of retirement, encourage in-migration and discourage outmigration of working age individuals and this applies a fortiori to those with higher level skills. Though there is an increasing trend of those in employment in the 50 to retirement age group there remains a gap of six percentage points between Wales and Great Britain in the employment rate for this group. Again there are substantial differences among unitary authorities in Wales in the percentage of the population aged 15-64, ranging from just over 60 in Conwy to over $68 \%$ in Cardiff. This reflects differences in migration patterns according to the attractiveness of the location.

If there is a simple lesson it is that there is a need for realism in setting targets. It is questionable whether the GDP gap per head between Wales and the UK or between West Wales and the Valleys and East Wales can be eliminated as opposed to being reduced. A target employment rate of $80 \%$ is very challenging. However, short-term targets for lifelong learning in Wales seem more feasible, such as raising the percentage of working age adults with level 1 in literacy from $75 \%$ in 2004 to $80 \%$ by 2010 and those with a qualification equivalent to level4 from $26 \%$ to $30 \%$ in 2006 , but even these targets will not be attained unless the necessary resources are put in place. There may also be a need to encourage policy makers to consider the interaction of each policy with other policies to ensure that they are mutually consistent. Often Departmental structures within government militate against this.

There is a comprehensive range of policies to deal with the issues referred to above, and many of these are in the process of renewal and adaptation. Questions might be raised, however, as to whether these are sufficient to achieve the objectives laid down by WAG. Further, many of the policy documents such as the Wales Spatial Plan are merely aspirational, lacking in any detail of how 
objectives are to be attained or where the resources are to come from. A situation in which DWP is responsible for employment and WAG for training is not helpful to the integration of policies. Also within Wales the fact that the Department for Children, Education, Lifelong Learning and Skills (DCELLS), the Department of Education and Training (DET), Job Centre Plus and the Sector Skills Councils (SSCs) are in different locations emphasises the need for more linking of programmes.

\section{Box II.1: Main policy issues and lessons for Wales}

How to deal with the trade-off between raising labour productivity to the UK average and achieving convergence between West Wales and the Valleys and East Wales.

Current policies

- Objective One and Convergence Funding

- Upgrading the workforce (Basic Skills Strategy, Modern Apprenticeships, Work-Based Learning Programmes, Individual Learning Accounts, The Welsh Baccalaurate)

How to deal with the trade-off between raising activity rates and raising levels of productivity?

Current policies

- Upgrading the Labour Force

- New Deals for Young People, 25 Plus, Lone Parents, and Disabled People (Want 2 Work)

- Childcare provision

- Transport improvements

- Increasing awareness of in-work benefits

- Equal Opportunities Policies

How to upgrade the labour force as a basis for raising the quality of jobs?

Current policies

- Sector Skills Councils

How to meet the demographic challenge?

Current policies

- NEET Strategy

- New Deal 50 Plus

- Age Discrimination Legislation

How to overcome the locational disadvantages arising from the lack of major population centres (and resulting absence of aggregation economies?)

Current policies

- Transport improvements

- Regeneration strategies. 


\section{Policy gaps in the current approach of WAG}

There is no shortage of policies directed at the Welsh Labour market and there are no obvious areas where there are major gaps in policy provision. Questions might be asked, however, about whether sufficient resources have been provided to produce the desired outcomes or whether some change of emphasis might produce better results. Despite the focus on New Deal Programmes in the UK as a whole the DWP paper, Building a New Deal, June, 2004, noted that there were still some key challenges as improvements had not been felt by all groups or across all geographical areas to the same extent.

In particular:

- The disabled and those with health conditions, lone parents, ethnic minorities, people aged over 50, people with no or low qualifications and some specific groups with multiple disadvantages had not benefited to the same degree.

- The number of households without any wage earners was comparatively high and contributed to the UK's relatively high levels of child poverty.

- Skills shortages persisted in some sectors and across most sectors at level 2 (GSCE grades $\left.A^{*}-\mathrm{C}\right)$.

- There remained differences in employment rates among regions and even greater differences within them.

The latest New Deal Statistics for Wales show that between January 1998 and February 2008 105000 people started on the New Deal for Young People (aged 18-24 years) of whom 51000 (49\%) had secured jobs. Over the same period 48500 people started on the New Deal 25 Plus, of whom 15700 (32\%) secured jobs and 91400 people started on the New Deal for Lone Parents of whom $37200(41 \%)$ secured jobs. Over all three programmes 38800 disabled people started, of whom $11800(30 \%)$ secured jobs and 5800 members of ethnic minorities of whom 1600 (14\%) secured jobs. These figures confirm the difficulties these groups, and particularly members of ethnic minorities, have in obtaining employment even when they are involved in New Deal programmes. In the case of the disabled, not only does this group have a higher incidence rate in Wales than in all other regions of Great Britain (apart from the North) but the inactivity rate is higher than in any other region. Further, the disabled are much more likely to be located in low income households than the non-disabled. ${ }^{11}$ This indicates that further measures are required in Wales to assist this group in particular, which is far more numerous than the ethnic minorities group.

The National Learning and Skills Assessment Update, October 2007, notes that following consultation with a range of stakeholders (including learning providers, Community Consortia for Education and Training - CCETS - and Sector Skills Council Organisations - SSCO) the following key themes emerged:

- The need for a greater emphasis on basic skills.

- Concerns about the impact of migrant labour on the learning system.

- The importance of higher level skills.

- The importance of management and leadership training.

- The need to increase the provision of vocational pathways for 14-19 year olds. 
- The importance of the Welsh language (though this is more for social than economic reasons).

- The need for reconfiguration of the learning system.

Other key elements are the ageing population, the need to retain a higher proportion of graduates in Wales and encouragement of entrepreneurship.

In the Basic Skills Strategy "Words Talk, Numbers Count" a target was set for $80 \%$ of adults to have reached level one literacy and 55\% of adults to have reached level 1 numeracy by 2010 . The Strategy identifies three priority groups - the economically inactive or unemployed, those in full-time employment who require additional support to improve their skills to level 2 and other groups at risk of social exclusion such as young people not in learning or employment (NEET). But it is not clear as to whether there are sufficient adult basic skills teachers to enable these targets to be achieved. Little is known about the extent to which low basic skills lowers productivity and the relative importance of these and other forms of basic skills, such as communication skills, team working and flexibility. DCELLS is, however, developing a NEETs strategy (see Skills that Work for Wales, 2008).

One way of overcoming labour shortages, particularly in jobs which are not attractive to the native population (either by nature or because of low pay), is to hire migrants. Although Welsh immigration, particularly from Western Europe, has increased in recent years, Wales has attracted a relatively small share of migrants $(2.5 \%$ compared to Wales' population which is $5 \%$ roughly of the UK). Moreover, recent immigration has not been evenly distributed across Wales, with the largest inflows occurring in Cardiff, Wrexham, Merthyr Tydfil and Carmarthenshire. Drinkwater and Blackaby $(2008)^{12}$ suggest that not only can immigration increase labour market flexibility and efficiency, but it has particularly relevance in Wales since many rural areas have seen an outflow of young and educated residents to other parts of Wales and the UK. Furthermore, for Wales as a whole this is a matter of concern because of its potential effects on the current and future performance of the Welsh economy. While around $42 \%$ of Welsh born working age individuals living in other parts of the UK have degrees, only $14 \%$ of the Welsh born and $27 \%$ of the non-Welsh born living in Wales are similarly qualified. It is not clear that adequate policies are in place to deal with this problem.

The Annual Learning and Skills Assessment 2006-2009 suggested that the number of migrant workers employed in Wales was 55000 and increasing. Many of these workers, it suggests, will require support for basic skills. However, many of the immigrants appear to be well educated and may benefit more from higher level English language skills training (ESOL). Further, the estimated number may include a wide margin of error and little is known about the average duration of stay and hence the willingness of migrants to undertake further training. Higher level skills research from e-skills UK Sector Skills Council indicates that $25 \%$ of the workforce in Wales has an IT user skills gap and that IT skills of 424000 people need to be improved in order to eliminate the gaps and meet future skills needs. It is recommended that support should be given to the implementation of the ITQ - a competence based qualification for IT users. Other identified priorities are customer services in selected sectors (such as hospitality and catering, retail, food and drink, leisure and tourism). However, the Leitch review concluded that there was no consensus among employers as to where the main skill deficiencies lay and there was considerable debate over the extent to which reported skill deficiencies accurately portrayed the UK labour market even though $32 \%$ of organisations reporting the presence of internal skills gaps claimed that this prevented them from moving up-market. As regards graduates, there is concern that many move out of Wales on graduation, though Wales is a net importer of undergraduates. In part this may reflect the branch factory syndrome, which means that many job opportunities for graduates are in head offices of companies located outside Wales or in research and development in which Wales is under-represented. At present there are no policies or 
strategies to deal with this problem. DCELLS has an important role to play in ensuring that the data produced by the Sector Skills Councils are on a consistent basis and take into account the results of the activities of the other SSCs. The plans of the SSCs will have important implications for learning providers, including both further-education and higher-education institutions, and DCELLS should be an important link between the employers and learning providers.

The National Learning and Skills Assessment Update 2007 notes that at the end of 2004 only $40 \%$ of the "managers and senior officials" occupational group was qualified to NVQ Level 4+, this figure is much lower than for professional groups. While it recognises that qualifications may not be a good proxy for skills in this group, management and leadership training may be needed, particularly in knowledge intensive work, to better utilise the growing number of graduates entering these occupations, particularly in SMEs. Here the Go Wales initiative could be helpful in aligning graduates with small employers without previous experience of employing graduates. ${ }^{13}$

Learning Pathways for 14-19 year olds have ambitious targets to ensure that no pupil will leave full-time education without an approved qualification, with a target for the percentage in education or training to reach $93 \%$ by 2010 . But this will not assist those who have already left full-time education and are not in employment or training (NEETS). The latest data for Wales (2003/4) suggest that just over 50000 people aged 16-24 fall into this category. While those who are long-term unemployed are a cause for concern, those who are inactive are even more so, and little is known about them.

There is a general presumption that upgrading the workforce will increase economic growth. Indeed, it seems likely that a higher proportion of skilled workers should raise productivity, as a skilled worker should possess more efficiency units of labour. What is less clear are what particular types of skills will be optimal for the Welsh economy and what is the most cost effective way of upgrading skills. As indicated by the Welsh index of multiple deprivation Wales possesses some of the poorest areas in the UK. Wales, as the rest of the UK, has faced an increase in the number of households in which no one is employed. This is likely to lead to the transmission of deprivation from one generation to another. Many studies (notably by James Heckman and others) point to the importance of early intervention in a child's life, particularly pre-school, and in terms of family environment and it is not clear that policies in this area are sufficiently well developed. ${ }^{14}$

In Economic Futures for Wales, the WAG Economic Research Advisory Panel (ERAP) suggested that there was no evidence of a major brain drain from Wales, but suggested that in view of demographic trends there may be scope for effective action in the field of childcare and flexible working. In relation to migration policies one might attempt to reduce the rate of out-migration for target groups such as the young. For example, incentives might be introduced to encourage more of the highly qualified school-leavers to attend Welsh Universities. There could also be measures to attract back highly qualified or key workers, and previous out-migrants or retain other desirable inmigrants, or measures to improve the attractiveness to migrants of less fashionable areas such as the Valleys. However, the introduction of such measures may not be straightforward given free mobility of labour in the EU.

Wales will face an ageing population in future years. As the assembly's Strategy for Older People in Wales, 2003 notes, over the next twenty years the overall population is projected to grow slowly by just 3\% (less than 100000 people), but the number of people of current retirement ages in Wales will increase by $11 \%$ (or by 650000 ). There are a number of existing measures to assist the employment of older workers. Thus the New Deal 50 Plus targets the older unemployed by offering access to training, work experience and funding. "Prime Cymru" has been established, as an autonomous Welsh arm of the Prime Initiative for Mature Enterprise, to support people over 50 into self employment. The Age Positive Initiative aims to attract 20000 additional older workers into 
employment, with an overall target of raising the number of over 50s in employment substantially by 2010. Nonetheless, it can be argued that there is still a need for further measures to attract more older workers into employment, perhaps by more specific policies directed at this age group in the Want2Work initiative. Alternatively, there is scope for greater flexibility over retirement ages and working hours, or as suggested by ERAP, increasing opportunities for older workers to be employed in non-traditional capacities (e.g. "downshifting"). It is much easier to implement measures to encourage older workers to remain in employment than it is to implement measures to attract them back into employment. Older workers may possess skills which are obsolescent, emphasising the need for retraining, but the return to training for older workers is reduced due to the shorter payback period. This may require subsidies to encourage employers to offer training to older workers, which in turn is likely to keep them in employment longer.

There are two major regeneration schemes underway. The first, Turning Heads - Regeneration Strategy for the Heads of the Valleys (HOV), covers the period up to 2020 and incorporates economic, social and environmental issues in an integrated way. Only 64\% of the working age population in HOV are in employment, compared to $69 \%$ in the lower valleys. There is a $30 \%$ sickness benefit claimant rate, relatively low life expectancy and low qualifications. Funding of £140 million is in place including EU Convergence Funds and this is complemented by $£ 360$ million from the private sector. The strategy includes transport improvements, landscape enhancement, housing renewal, skills and business development, and encouragement of tourism. On a smaller scale is the Mon a Menai Coastal Action plan established by WAG in 2006 in recognition of the economic problems facing Anglesey and North Gwynedd due to the uncertainty over the future of the Wylfa Nuclear Power Station and Anglesey Aluminium Metal. A total of $£ 15$ million has been allocated by WAG. The action plan identifies significant opportunities related to maritime, sporting, leisure and tourism activities. It also focuses on skills and training for the local workforce.

Another good example of a regeneration strategy is the recent upgrading of the previous freightonly Ebbw Valley railway line to accommodate passenger transport and link the Ebbw Valley to the coastal plain of Newport and Cardiff. This followed the closure of Corus's Ebbw Vale Works and the cessation of steel production at Llanwern. The scheme is part of a broader strategy of economic regeneration in an area with among the lowest household disposable income and lowest car ownership rates in the UK. This involved the regeneration of the Corus Ebbw Vale site through the development of a campus of the University of Wales Newport, a local hospital, housing and employment: the development of transport links between Ebbw Vale and Newport campuses, and strengthening Newport's role as a regional centre. An Economic Impact Report suggested that there would be effects on the labour market, vocational choices, and in helping Ebbw Vale to retain its population. Ebbw Vale suffers from deprivation, low educational attainment, a lack of modem (e.g. IT) skills and low economic activity rates. It was estimated that the proposed scheme would generate an economic net present value of $£ 31.4$ million and a benefit/cost ratio of around 1.5:1.

Regeneration strategies are being consolidated under a new minister. The evaluation of the Cardiff Bay project indicates that the project was not successful at attracting high profile companies as was originally hoped for. Regeneration in Newport was in the process of being evaluated, while the Swansea SA1 project was yet to be completed. An overall plan for transport is only now being developed, and the lack of agglomeration economies could be offset by transport improvements. If the rail time to London could be cut to two hours, this might have a significant impact on economic performance. Likewise, if the journey time between Swansea and Cardiff could be reduced to 45 minutes - this was a critical cut-off point according to the Eddington Review. There was a suggestion that widening the M4 - including the possibility of a new "user-pays" M4 motorway section around Newport ${ }^{15}$ - would have a bigger impact than other transport improvements, such as the new passenger rail link with Ebbw Vale. A recent report for $\mathrm{WAG}^{16}$ suggests that while transport is a 
constraint to employment, it is not the primary constraint for the economically inactive. However, making the inactive more aware of transport availability is important.

It should be noted that the institutions concerned with the Welsh labour market are in a process of change. The Sector Skills Councils ${ }^{17}$ are a recent development and the Wales Employment and Skills Board has only been set up this year. New policies include Careers Ladders Wales, a Credit and Qualifications Framework for Wales and Communities Next which is proposed for disadvantaged communities. At the UK level, Local Employment Partnership involving Job Centre Plus and local employers, is designed to support the entry of benefit claimants into the workforce and includes work trials, pre-employment training, mentoring by existing employees, reviews of recruitment processes and more flexible work patterns. Under the linked Train to Gain policy, additional financial contributions are available for firms with fewer than 50 employees to support the release of staff for training. For firms with between 10 and 250 employees there is also financial support to help develop the skills of key leaders and managers. Any new initiatives will therefore have to fit into a dynamic framework.

\section{Box II.2: Significant policy gaps in Wales}

- Specific policies to reduce the inactivity rate of the disabled to the UK average.

- Specific measures to retain a higher proportion of graduates from Welsh institutions in Wales.

* Early intervention (pre-school) measures to reduce inter-generational transmission of deprivation.

* Measures to encourage desirable in-migration to key areas.

* Directed measures to encourage more older workers to stay longer in employment or return to employment.

* A transport policy focusing on encouraging greater labour force participation.

\section{Policy options to address Wales' challenges}

Devolution has not yet reached the point where Wales has discretion over all policy levers, so that the main focus has to be on those policies over which the Welsh Assembly has some control. The next question is whether it is appropriate to introduce new policies or graft new ideas on to existing policies. Given the wide range of existing initiatives, the danger of introducing new policies is that the number of policies becomes too great to operate at minimal costs, or causes confusion. Therefore, strong arguments are needed for introducing new stand-alone policies. When considering the transferability of the ten policy audits, attention has to be paid not only to their intrinsic merits but also to whether they need adapting to Welsh circumstances. Even where there seems to be a good fit, there is the question of whether the scale of the operation or the size of any subsidies is appropriate to the Welsh situation.

The case for intervention is normally based on perceived market failures, which first need to be identified and then the causes of such failures established. It is generally believed that the two major market failures in Wales are levels of inactivity which are too high and levels of productivity which are too low. Appropriate comparisons are not, however, with London and the South-East, which is an outlier in relation to other regions. Thus, there are explanations for the productivity gap with London and the South-East which may not be amenable to change through policy intervention. Broadly speaking there are two choices in relation to labour market intervention. First one may operate on the 
demand side of the labour market by focusing on employers. Thus the Sector Skills Councils are employer led in belief that this will ensure that training provision is more closely allied to employer requirements. Alternatively, one may operate on the supply side of the labour market by focusing on individuals. This would seem appropriate where the policy is directed particularly at the most disadvantaged groups, though even here one might wish to persuade employers to give favourable treatment to such groups. Policies which operate on both supply and demand sides of the market are more likely to be successful and this is increasingly the case in Wales. There is also the question of whether policies should rely on voluntary participation or on a degree of compulsion. Thus, the Want2Work initiative relies on the voluntary participation of inactive individuals. However, criteria for the receipt of Job Seekers Allowance (JSA) benefits include being available for and actively seeking work. Otherwise benefits may be reduced or removed for a period of time. Additionally, Job Centre Plus may direct a customer to undertake a particular activity to enhance job prospects under the threat of benefit sanction. For those claiming out of work benefits (e.g. lone parents or Incapacity Benefit (IB) recipients) there are fewer and less stringent requirements, reflecting the extra barriers to work faced by members of these groups. Employers' actions may be circumscribed by legislation, such as Equality Laws or Minimum Wage legislation, backed up with fines for those who transgress. Individuals may be offered subsidies to encourage them to take certain initiatives. Thus there are return-to-work subsidies of $£ 40$ per week over 52 weeks for IB recipients who earn less than $£ 15000$ per annum. It is important to engender trust and this is a slow process. Want2Work was first introduced in the 12 most deprived wards in Wales and now covers 54, with plans to extend it to 120130 wards, which covers ten percent of the population base in Wales. There are 200000 individuals who have been out of the labour market for periods extending up to 20 years. Interventions are multifaceted including fitness regimes to make individuals feel better about themselves, the encouragement of volunteering and identifying particular training needs. It may be several years before such initiatives make substantial inroads into levels of inactivity.

Some policies may be nationwide while others are regional or local. The latter is the case with regeneration strategies which focus on run-down areas, usually in urban as opposed to rural settings. Transport initiatives also tend to be regionally or locally based. Given the objective of achieving convergence between West Wales and the Valleys and East Wales some policies will need to be regional, whilst raising labour productivity to the UK average implies that some policies will need to be pan-Wales. The difficulty is in obtaining the appropriate balance between the two. However, as shown in Table II.1 there are still substantial differences in the percentage of working age people with NVQ levels 3 and 4 between the two areas. Having a target of eliminating this gap should possibly be the most effective means of assisting convergence, while at the same time making it easier to raise inactivity rates and productivity in the Objective One area. However, this requires the demand side of the market to be able to absorb the more qualified labour, which may require attracting in new employers.

Whatever the policy is, there is a need for evaluation. In the case of Objective One Funding this normally means that the outcome is compared with what was promised in terms of the bid for funds. Economic evaluation, however, requires much more than this. In the above case, there is no counterfactual, i.e. what would have been the outcome without the scheme. If we take the case of a training initiative, those selected for training may not be a random subset of the total population, but those who are more motivated (a sample selection problem). There are also problems of replacement, displacement and deadweight. Replacement will raise the benefits and reduces the costs while displacement will have the reverse effect. Deadweight will increase the costs of any policy. Comparing the outcome after the initiative with the situation prior to the initiative which is sometimes done as an alternative to using a control group ignores environmental changes which may have affected the outcome. 
The obvious solution to these problems is to compare two groups one of which participated in the scheme and one which did not, controlling for personal characteristics (often referred to as treatment and control groups). These may be compared using a difference-in-difference approach or propensity score matching, under which a control group is selected which possesses as closely as possible the characteristics of the treatment group. Such studies tend, however, to be the exception rather than the norm. ${ }^{18}$ It is also crucial to set up the evaluation from the very start of the policy's introduction. Without proper economic evaluation it is extremely difficult to judge where extra resources should be put in order to equalise the marginal returns across policies.

Returning to the significant policy gaps in Wales outlined in the previous section what can be done? First, reducing the inactivity rate of the disabled may require active implementation of equality laws. Though increasing the costs of employment by requiring more workplace accommodation of the disabled may actually make it harder to increase employment for this group. Careful counselling which identifies the source of disability and the precise type of work which minimises comparative disadvantage seems to be important, as different types of disability have very different effects on employability. None of the 10 initiatives focus directly on this group.

Second, specific measures to retain a higher proportion of graduates in Wales are dependent on the availability of sufficient well paid graduate jobs. The public sector is important in this regard, but the relatively small number of large companies in the private sector and particularly the absence of a large financial sector and research and development capability militate against this. The encouragement of entrepreneurship might persuade a (small) number of graduates to remain in Wales. In addition a favourable fee structure may persuade more Welsh domiciled entrants to higher education to remain in Wales, but care needs to be taken to finance Welsh institutions sufficiently to maintain their quality relative to institutions in the rest of the UK if they are to remain attractive to potential entrants. Only the Portuguese Inov Contacto initiative seems relevant to this issue.

The third issue of early intervention has been comprehensively examined in a recent paper by James Heckman (2008). ${ }^{19}$ Summarising a large number of studies, he shows that early interventions promote education, reduce crime and foster workforce productivity. These interventions have high benefit-cost ratios and rates of return which are much higher than later interventions such as improved teacher-pupil ratios, job training and adult literacy programmes. The later the interventions in the lifecycle of a disadvantaged child, the more costly it is to remediate the disadvantage. Children living in families with never married mothers are at greatest risk; as such families are less likely to invest in their children. Given that Wales has areas with amongst the highest multiple rates of deprivation in the $\mathrm{UK}$, this suggests that greater investments designed to improve the quality of parenting for young children, such as home visits, will be of much greater long term benefit than increased investments in life-long learning or even in basic skills. None of the initiatives deal with these issues.

Directed measures to encourage desirable immigration to key areas should acknowledge that it may be difficult for Wales to attract a proportionate share of migrants, particularly from Eastern Europe, as they tend to be concentrated in particular regions, notably the South-East of England. However, the availability of low cost housing as well as appropriate employment opportunities may be helpful here and the physical regeneration of run-down areas could offset some of the deterrents to mobility. None of the initiatives deal with these issues.

Directed measures to encourage more older workers to stay longer in employment or return to employment should acknowledge that although employers do employ older workers, the latter are less likely to be hired (In fact, research suggests the probability is 0.6 which is significantly lower than full replacement). In Wales, employment rates up to age 55 are high compared to England, but they reduce sharply over 55 and even more so over 60 . Further, people over the age of 50 accounts for $35.9 \%$ of 
the total population in Wales compared to $33.3 \%$ in England. Thus closing this gap could make a significant contribution to raising activity rates in Wales. There is no evidence that the productivity of older workers is lower than that of younger workers and the health of older workers at a given age is likely to be higher than in the past. Therefore a policy directed at persuading employers of the benefits of retaining and hiring older workers, and reminding them of their obligations under the age discrimination legislation may be worthwhile. Here, the German Perspective 50 Plus Initiative is highly relevant. Finally, transport policies focusing on encouraging greater labour force participation may make a difference in extending the job search, particularly for those in lower income households.

\section{Box II.3: Policy options}

* Given the wide range of existing policies, ceteris paribus, the preference should be for adaptation rather than new stand-alone policies.

* Policies which operate on both the supply and demand sides of the market are likely to be more successful.

* There needs to be an appropriate mix of voluntary participation and degree of compulsion.

* There is a requirement for a mix of regional and pan-Wales policies.

* Appropriate economic evaluation strategies should be put in place from the very start of any new policy.

* Only some of the initiatives are relevant to dealing with the identified policy gaps.

\section{The potential role of the reviewed initiatives in filling the gaps}

\section{(a) Are the problems which the initiatives attempt to address relevant to Wales?}

As a starting point we must consider the problems that each initiative was designed to address and whether these are consonant with the problems facing Wales. The initiatives are summarised in Table II.2: three initiatives are concerned predominantly with labour market participation, though they may also include some elements of skills development. Skills development has a more central role in four of the initiatives. Finally three initiatives are concerned with economic and physical regeneration, though other elements may be involved here also.

Most of the initiatives focus on the supply side of the labour market and particularly on disadvantaged groups, which are evident in Wales. Thus the US Welfare-to-Work programme aims to help families in need of temporary assistance under the Needy Families programme. The client base consists mainly of women, the working poor, workers displaced by economic restructuring, those in part-time or temporary jobs or individuals for whom an appropriate job match is hard to find. Such cases seem typical of the Welsh Valleys. The JARC programme is similar in many respects as it focuses on immigrants and other disadvantaged groups which suffer from a lack of education, low skills, language difficulties and discrimination. It is designed to offer disadvantaged individuals a choice of vocational, literacy and numeracy skills, to help move individuals up the occupational hierarchy. This hints at the existence of a segmented labour market, but also is in line with the Welsh concern to raise basic skills. There is also a locational aspect, since the programme adopts a sectoral approach to industrial decline in an area in which a particular industry predominates. The intervention also looks to the demand side of the labour market by offering technical assistance and advocacy to firms in the sector of concern. However, it is concerned predominantly with a sector which is located 
in an area of decline, whereas the focus in Wales is on developing strategic industries which are likely to have a different skill composition.

Table II.2: Summaries of the policy audits

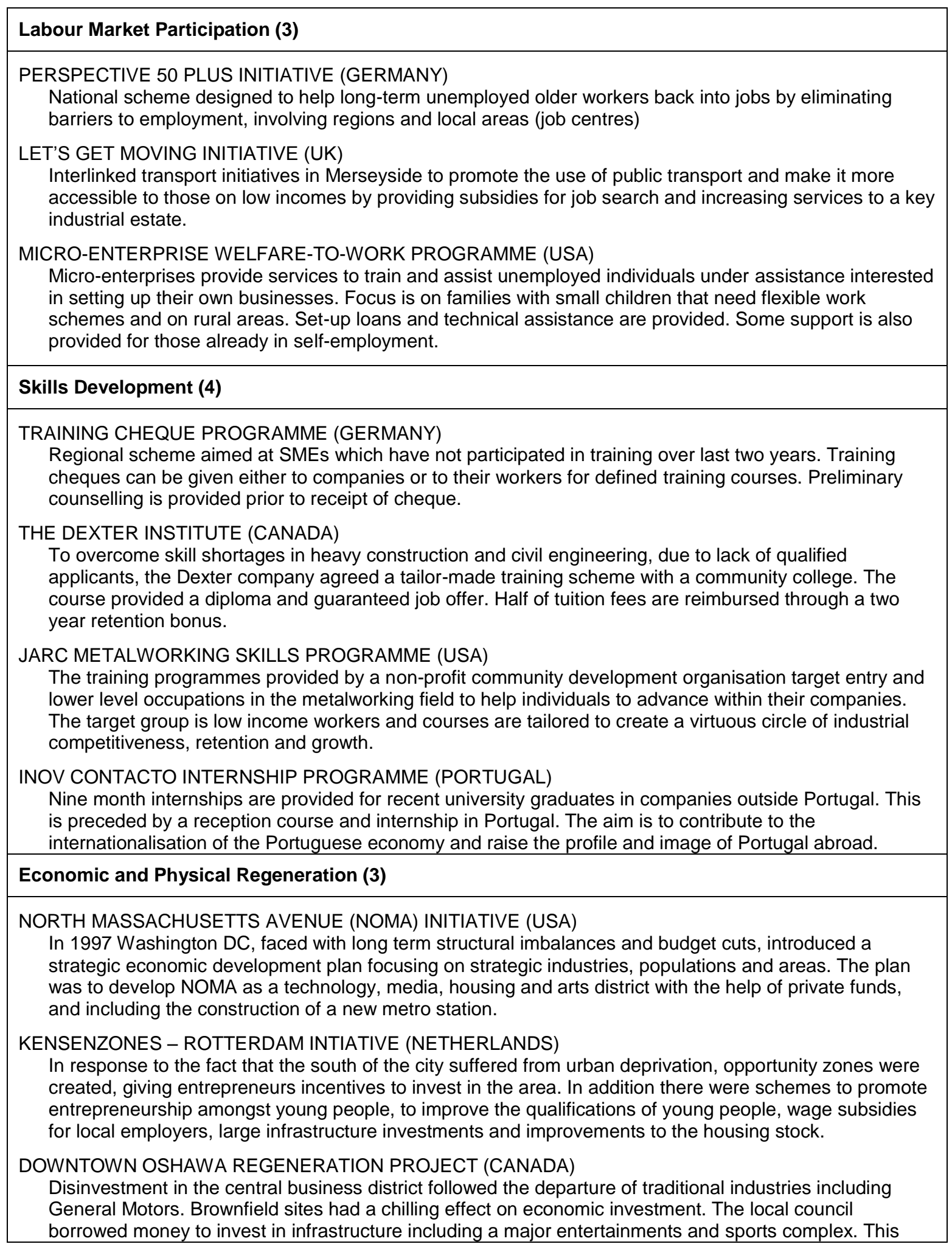


transformed the central business district.

The UK Let's Get Moving initiative is also concerned with disadvantaged workers lacking in skills, but is focused on those with limited travel horizons for whom lack of car ownership and poor public transport facilities raise the relative costs of transport. These issues have been raised in Wales, particularly in relation to the Welsh Valleys. Two of the initiatives focus on supply side issues, but not particularly in relation to disadvantaged groups. Thus, the Portuguese Inov Internship programme is concerned with the scarcity of professionals with specific expertise in internationalisation / globalisation; while the Dexter Institute initiative is concerned with critical skill shortages due to a lack of qualified young applicants in a particular industry (civil engineering), which is faced with an ageing workforce. Both of these issues are germane to the Welsh situation. The German Training Cheques initiative echoes the concern, with the problem of finding suitable young employees in an economy faced with low birth rates and where laws have been passed to make it more difficult shed older workers. Here, there is also concern with globalisation and the need to upgrade the labour force to remain competitive; hence, the requirement for lifelong learning, which has been emphasised in the UK Leitch Report.

In Germany, unlike Wales, the participation rate of employed people in vocational training has been declining and the participation rate of migrants is significantly lower than that of indigenous workers. The question of ageing is also to the fore in the other German initiative, Perspective 50 Plus ${ }^{20}{ }^{20}$ which operates on both the supply and demand sides of the labour market and focuses on older workers. These programmes seem particularly pertinent to Wales, faced as it is with an ageing population.

The remaining initiatives all focus on location issues, though not exclusively so. The Dutch Kensenzones initiative is concerned with the fact that the economic success of a city (Rotterdam) is unevenly spread with one part of the city (the South) faced with a high percentage of individuals with little or no education, long-term unemployment, low incomes, social housing, high crime rates and a large percentage of poor immigrants. There is an outward movement of both individuals and firms. At least some of these features can be found in the poorer areas of Swansea, Cardiff, Wrexham and the Welsh Valleys. The Washington NOMA initiative resulted from experience of slow job growth, insufficient new investment, population loss and a troubled low income neighbourhood, again similar in some respects to the experience of the Welsh Valleys. Finally, the Oshawa regeneration programme in Canada was a response to the downward spiral of a deteriorating urban core and the need to redevelop contaminated brownfield sites. Due to its industrial legacy, brownfield sites are plentiful in Wales; planning policy is designed to avoid development on greenfield sites, though unlike England, Wales does not set specific targets for brownfield development. Thus it seems that each of the initiatives has at least some elements which are relevant to the problems facing Wales.

\section{How successful have the initiatives been?}

In determining whether an initiative can be appropriately implemented in Wales, the first thing to ascertain is the degree of success that it has had in its country of origin, or failing that, to consider whether the degree of success could have been increased if the initiative had been formulated or implemented in a different way. Few of the initiatives have, in fact, been subject to formal scientific evaluation which makes judgement of their degree of success somewhat problematic. Formal analysis is, of course, expensive, so this may not always be appropriate if, for instance, the initiative is on a small scale. Thus, in the case of the US Micro-enterprise Welfare-to-Work programme, an experimental design was rejected because the budget did not allow for the composition of a control 
group. Also, in this case, the nature of the programme meant that there was no constant treatment across individuals which would have made such an approach difficult.

Some initiatives have yet to be fully evaluated (e.g. the two Canadian initiatives: Downtown Oshawa Regeneration and the Dexter Institute projects, as well as the Portuguese Inov Contacto Internship Programme). In some cases success was defined in terms of the goals set for the projects or seemed to be self evident. Thus in the case of the North Massachusetts Avenue (NOMA) initiative success was defined in terms of surpassing the goal of creating and attracting 5000 new jobs and generating one billion dollars of total private investment and similarly in the Oshawa project. But this gives no consideration to cost effectiveness or displacement effects.

In other cases, reliance was placed on responses to surveys by the respondents. Thus in the case of the Portuguese Internship programme annual surveys showed very positive responses by both the trainees and the firms involved and demand was increasing on both sides. In the case of the Dexter Institute project, feedback from the programme participants and College stakeholders, as well as some of the quantitative data on graduate employment rates, was said to point to a successful outcome. Neither of these cases considered the possibility of response bias.

In some initiatives evaluation took the form of a before and after approach. Thus, in the case of the JARC Metalworking Skills programme, two research institutes conducted longitudinal surveys of participants (though these covered other initiatives as well as JARC) which suggested that incomes had been raised, participants worked on a more constant basis, jobs were of higher quality (defined in terms of access to health insurance) and there was optimism about the individuals' working lives. Though the income improvements applied equally to JARC, controlling for response bias reduced the true effect from 15 to $5 \%$ when the baseline earnings of a follow-up group were considered. The sheer longevity of the programme was, however, taken as an indicator of success. The Microenterprise Welfare-to-Work programme evaluation involved the collection of data on employment and the welfare status of participants at the time the training course was completed and one and two years later. There was a strong increase in work engagement and earned income and a dramatic reduction in welfare assistance. The so called "income patchers", who were both employed and self employed, did much better than the rest.

Three initiatives did have elements of a more formal approach to evaluation. In the case of the Kensenzones Rotterdam initiative Ernst and Young conducted a mid-term review covering four dimensions of effectiveness, efficiency, integrality and customer satisfaction, which was combined with the collection of some output indicators. There was evidence of deadweight effects, since only $25 \%$ of investments made would not have taken place without the programme, though another $40 \%$ would have been postponed. Further, it was suggested that, at least so far, outcomes had been disappointing with employment effects not yet very encouraging. There was also reference to the programme causing market distortions. Deadweight effects were also considered in the German Training Cheques programme, defined as the extent of the supported training that would have been realised even in the absence of financial support. It was noted, however that this definition ignores further or additional training activities, which would not have come about without the initiative (a "push-start" effect). The presence of this would result in the deadweight being exaggerated. That is, the gross deadweight effect exceeds the net deadweight effect. In net terms, 13\% of employers and 9\% of employees said they would have undertaken the training even in the absence of the initiative. The third example is the German Perspective 50 Plus Initiative, in which the evaluation was carried out by the University of Duisburg-Essen, which conducted a propensity scores matching approach. Of those integrated into the labour market nearly all were long-term unemployed. Indeed, $45 \%$ of participants were unemployed for longer than four years. Notably, given the problem of long-term sickness in Wales, $36 \%$ had health problems, while $26 \%$ were migrants. It seems that a lack of qualified skilled 
workers was a major motivational factor in persuading employers to consider the employment of older workers. While the employment rate of older workers had increased by between 8 and 17 percentage points over the previous four years, much of this appeared to be due to the improved economic situation, which itself had been influenced by the Hartz reforms to the labour market and by the Government's Active Ageing Strategy and the Initiative 50 Plus legislation, of which Perspective 50 Plus was a part. ${ }^{21}$ The employers claimed that the majority of jobs created were new jobs. However, the propensity score matching approach suggested that the initiative had only a small effect on job creation in relation to all changes in the regional labour markets analysed. ${ }^{22}$

To conclude the NOMA, Let's Get Moving and Oshawa Initiatives only had rudimentary evaluation policies; and the Dexter, Jarc, Micro-enterprise Welfare-to-Work, Dexter and Inov Internship initiatives had more advanced evaluation policies. Only the Perspective 50 Plus, Training Cheques and Kensenzones initiatives attempted more formal evaluations. In terms of impact, the NOMA initiative was designated, in 2007 by the United Nations, as one of the Best Practices Worldwide to Improve the Living Environment and the Let's Get Moving Initiative obtained Beacon status and an associated special commendation. But such awards do not necessarily take into account cost effectiveness. The last of these initiatives suggests the cost per journey plan were high in relation to one aspect of the programme and the Oshawa project acknowledges that cost efficiency was not the objective. In the Kensenzones initiative it was acknowledged that the costs in terms of subsidy per new job were rather high and the same was true of operational costs. In contrast the report on the Dexter Institute notes that there were low set-up costs and the fact that the programme was based on a complete cost recovery model for the college, suggests that this was an efficient programme (financially) for the college. Likewise the evaluation for the Perspective 50 Plus Initiative suggests the cost-efficiency balance was positive. Costs, on average, were no higher than employment benefits and integration costs for unemployed older workers were no higher than those for all other age groups. Of course, incomplete evaluations should not be taken in themselves to imply that these initiatives were not successful, but they should indicate that a degree of caution is appropriate in recommending that they be extended elsewhere. Ignoring cost effectiveness, it seems that in the long run, each of these projects could be regarded as successful in reaching the objectives that had been set for them, though the Kensenzones initiative has yet to prove itself. We cannot currently rank these initiatives, however, in terms of value for money.

\section{(c) Implementation}

The initiatives are diverse in terms of their degree of complexity, ranging from the Dexter initiative which simply relies on an accord between a local community college and an individual company and the Training Cheques initiative which has a very lean administrative structure based on the principle of self declaration rather than documented evidence, to the 50 Plus Initiative which is one of a number of extensive measures for older workers in Germany. ${ }^{23}$ The 50 Plus Initiative adopts a multi-level approach, being conceived at the national (federal) level, managed at the regional level and implemented at both regional and local levels. This is not dissimilar to the DWP arrangements in the UK, which give a degree of autonomy to the local Job Centre Plus offices. The 50 Plus Initiative, however, goes beyond this in developing an ideas competition for the 435 local job centres across Germany and implementing 62 Employment Pacts, ${ }^{24}$ which include, on the demand side, regional and local companies, and on the supply side, active measures including the selection of individuals from among the long term unemployed for participation in the programme: there is a degree of discretion which means that in some job centres personal interviews are mandatory, whilst in other they are voluntary. It appears that those job centres which operated very closely with other external bodies during the entire matching process were the most successful. Partnership arrangements were also crucial in other initiatives. Thus in the Merseyside Let's Get Moving initiative partnerships between 
Job Centre Plus, the Learning and Skills Council, Connexions, St Helens Chamber of Commerce and voluntary organisations were said to lie at the heart of delivery. Partnership arrangements were also important in the JARC initiative where the organisation had established its credibility with employers, thereby helping the organisation to work with employers in the creation of job ladders. In the NOMA initiative it was public/private sector relationships which mattered; the body responsible for regeneration reached out to every major constituency among business, property owners and community residents. It was through these relationships that it was possible - despite initial rejection to obtain US 25 million dollars from private owners to enable the construction of the metro station. Another important aspect was the role played by individual counselling (an aspect which is particularly important in the work of Job Centre Plus in the UK). This was seen most strongly in the Training Cheques initiative, where the issuing of cheques was preceded by preliminary counselling in more than two hundred counselling centres associated with various institutions, the staff of which had received training in special workshops. The coaching of individuals was also important in the US Welfare-to-Work initiative which involved the screening of individuals, training in business skills and further help during start-up and operations. It also played an important part in the German 50 plus initiative.

Other elements of these initiatives point to the importance of raising awareness, which may be achieved by awarding companies that exemplify best practice. This is in accordance with the Basic Skills Employers' Pledge in Wales. Often existing institutions are utilised rather than creating new institutions. Thus in the Merseyside Let's Get Moving initiative the travel teams built on earlier experience. The use of incentives plays an important role. This is seen most clearly in the Oshawa regeneration programme which included increased assessment grants, building permit grants, façade improvement grants, study grant programmes, tax cancellation programmes and redevelopment grants. Clearly, in all initiatives, careful planning is required and the greater the number of bodies involved the more crucial this is.

\section{(d) Budgets.}

Most initiatives involved subsidies of one form or another. The exception was the Dexter Institute - based on cost recovery through tuition fees - which set higher than standard fees because of the special nature of the course. Several made use of European Funding which is available in the form of convergence funding for Wales. Thus, the Let's Get Moving initiative obtained $£ 3$ million under the European Regional Development Fund (ERDF) Objective One, measure 29(b). But this was used to lever other support from other sources via the local authority. Training Cheques are being supported by $€ 14$ million per annum of ESF funding over the period 2007-2013. Both ESF and private funding were available in the case of the Perspective 50 Plus initiative. The Inov Contacto programme which costs over $€ 25000$ per trainee is supported partly by European Union subsidies and partly by public sector support. The JARC initiative is reliant on donations from several sponsors - foundations, individual contributors, companies and government grants, which amount to just under one million dollars annually. The largest budget is for the German Perspective 50 Plus initiative which amounted to $€ 250$ million for the first two years and $€ 270$ million over the next three year period, although high, the costs per individual are lower than the costs of unemployment benefit. In addition costs have been substantially reduced in the later phase of the initiative by eliminating less successful types of approach and providing more rewards to those projects which are more successful. Further the Federal Ministry will not pay all the costs, but will encourage co-financing by other means (European Funding, German L $\ddot{a}$ nder and local authorities).

Regeneration projects are also costly, but not always easy to cost because of their complexity. Thus, in the case of the Oshawa project it was said to be difficult to provide a definitive budget 
because the strategy and implementation changed over time and involved multiple overlapping projects. However, costs in excess of 67 million Canadian dollars could be identified. In the NOMA project private owners, the Washington DC government and the US Congress each contributed 25 million US dollars to the costs of the construction of the metro station and in all contributions amounted to 110 million US dollars. In the case of the Kensenzones regeneration project $€ 24$ million came from state funding, but a similar amount was provided by the City of Rotterdam authorities for a larger regeneration scheme in the area. It is difficult to establish the precise extent to which these regeneration projects provided value for money. In the case of NOMA it was suggested that the Metro station produced an excellent return, but it should also be noted that there was displacement of some of the existing lower income population. In the case of Oshawa, the city estimated that over three quarters of a million Canadian dollars in value had been created and suggested that this was a ratio of ten to one (this has yet to be followed up). As a general proposition, the National Roundtable on Environment and Economy suggests that the general multiplier effect of expenditure on brownfields is 3.8 , having the highest of 12 activities compared and higher, for example, than education services with a multiplier of 2.7 or health care and social assistance (2.4), or utilities bringing up the rear at 1.9. Whilst these estimates are a function of the particular assumptions made, the relative sizes of the multipliers may be less subject to bias. Therefore, the development of brownfield sites may be a relatively efficient way of stimulating the economy. Clearly efficiency criteria should play a significant part in considering the possible implementation of these initiatives in Wales.

\section{(e) Strengths and Weaknesses}

Two things stand out in making for a successful initiative - partnership arrangements and flexibility. Thus in the Merseyside Let's Get Moving initiative strong partnership was regarded as the key strength. This was combined with a person-centred approach with advisers embedded in the local community, so that their services could be tailored to local needs. The advisers were also independent from the organisations associated with welfare benefits which increased the degree of trust. This issue has been raised in the context of the Want2Work project since individuals feared that the advisers were attempting to remove their benefits, whereas the objective was to inform recipients of the assistance available to them when making a return to work. In the NOMA initiative there was a process of consensus building, in trying to persuade participants that they were faced with a win-win situation rather than a zero-sum game. The Oshawa case efforts were also made to engage all stakeholders with particular stress on public/private sector partnerships. Flexibility was shown particularly in the German Perspective 50 Plus initiative with a successful combination of a relatively free budget with transfers from one year to the next, a regional approach and high flexibility of the investments. An individual approach was adopted to convince micro firms with up to ten employees and small firms with up to 50 employees of the potential of employing older workers. In the case of older unemployed, the emphasis was on coaching and mentoring. It was suggested that the best outcomes occurred when the "call" for participants for the information sessions and workshops was voluntary. In the follow-up activities, however, there was a more compulsory structure. In the Training Cheques initiative optional counselling, which precedes the issuing of cheques, broadens perceptions and prevents the misuse of the promotion instrument. Employees have two ways of accessing support, with individual as opposed to company access increasingly used for those in insecure employment. The lean administrative structure reduces people's inhibitions in using the scheme.

In some cases, the strengths of the initiatives were said to depend on a highly focused sectoral approach. Thus in the JARC initiative the focus is on hands-on vocational courses which are intensive, but of short duration. Tutors are also able to teach in native languages such as Spanish, Polish or Bosnian. The training focuses on incumbent workers, not the unemployed. In the US Welfare-to-Work programme the emphasis was on redirecting clients to self employment rather than dependent 
employment, thereby inducing a stronger attachment to work, and providing a sense of moving forward. Self employment was shown to be a viable way out of poverty and reliance on welfare support. The Inov Contacto programme benefited from specificity in relation to internationalisation and selectivity in choosing trainees, this was also true of the Dexter Institute.

Identified weaknesses included lack of coverage of all those in need of help and organisational flaws. The Perspective 50 Plus initiative did not provide any solution for those far from the labour market including those with health problems. The highest integration rate was for 51-54 year olds, while those over 58 were harder to reintegrate into the labour market. Women were also under represented. The Training Cheques scheme tended to be used by stronger companies and more educated employees. The Dexter Institute screening of candidates by the company limited the type of students enrolled in the course. It was suggested that smaller companies would not have the necessary resources to run similar programmes.

Scale of operations were said to be smaller than was desirable in the case of the Inov Contacto and the JARC initiatives, while the large scale of the Oshawa initiative was said to be crucial in ensuring a critical mass of new investment. In the Welfare-to-Work initiative the presence of ten different business providers, each adopting a different strategy, meant that there was not enough coordination between the organisations benefiting from the grants and those in charge of the evaluation. This was one reason why the evaluation was less than satisfactory.

\section{(f) Further Reflections on the Potential Transferability of the Initiatives to Wales.}

First, three regeneration schemes (NOMA, Oshawa and Kensenzones) were designed to deal with very specific problems. Wales already has a number of regeneration schemes of its own. Therefore, the schemes themselves may have little applicability though there may be important lessons to be learned from them. Oshawa in particular had to deal with the problem of brownfield sites and this is an important issue for Wales. It appears that what was important in Oshawa was the ability to compete against other municipalities for major Government investment and this required many years of effort. In the NOMA case, the stress was on proactively involving all parties and leveraging private sector investment in particular. In the Kensenzones case promoting entrepreneurship was seen as a major tool for economic regeneration, provided it was part of an integrated approach, but there is the potential for market distortions.

The background to the Oshawa project was that the province of Ontario was relatively undeveloped with an abundance of greenfield space, a situation not very different from Wales. While positive returns can be obtained on brownfield projects, the uncertainty of the process had left developers concerned that there might be hidden risks and costs associated with re-development relative to the limited risks on greenfield sites. This led the Council to take pro-active steps to invest in the clean-up of contaminated downtown sites long before introducing a selection of projects to developers. This was without consideration of a business case or economic efficiency arguments. A positive decision was also made to favour quality projects in the context of recognising the locational value of key sites. The fact that the Council was the developer or co-developer of some significant projects meant, for instance, that it was able to control the quality of the architecture and surrounding urban design. Some of the claimed success was attributed to the Council's use of strategic land swaps, purchases, acquisitions and expropriations designed to improve the quality of living in the downtown area. In addition, there were grant, tax cancellation and redevelopment programmes. However, on their own, these were not regarded as sufficient to create a market which would be attractive to developers. The willingness of the Council to make its own investments was critical. It was following this that the Province of Ontario decided to make a major investment in a Courthouse in Oshawa and further 
investment in brownfield locations there. The total investment by the City of Oshawa itself was some $\$ 77$ million (Canadian), but the total investments from public (excluding the City itself) and private sectors was ten times this amount. The Council was, therefore, the catalyst for a much greater investment in brownfield remediation and infrastructure. Wales does not appear to have a well developed strategy for brownfield re-development; this is an area that could be investigated further.

The NOMA and Kansenzones initiatives seem less applicable. The former is base on special needs (i.e. the construction of a new metro station), while the latter is concerned with attracting entrepreneurs into a run-down area of a City. The notion of offering subsidies to entrepreneurs sits uneasily as the function of an entrepreneur is to engage in risk and seize unexploited opportunities before they have been perceived by others.

The provision of tailor-made courses for particular companies by Further Education colleges is commonplace in Wales. What is novel about the Canadian Dexter Institute initiative is a combination of the award of a diploma, defined career paths, the ability to earn while learning and retention bonuses. It might be useful, therefore, for DCELLS to collect data on such courses in order to build up a data bank of best practice as suggested by the author of the report.

The US Micro-Enterprise Welfare-to-Work Programme, as the author notes, could contribute to spreading a business culture to the Valleys and elsewhere, and assist the better management of existing activities. There is already some experience of such policies in Wales. For example, Want2Work has been successful in getting some of those with long-term illness into self-employment, because of the flexibility it provides. Childcare is one of the most popular businesses entered into by US participants and this resonates well with Wales. It is also suggested that similar considerations could be applied to improvements in transport and communications infra-structure, perhaps through community based transport provision. Self employment would help to raise job quality as indicated by studies of job satisfaction for this group. It has been suggested, however, that in Wales the problem is not so much in generating new businesses as in ensuring their future growth. If this initiative were to be taken forward, there is, as the author of the report emphasises, a need for a well designed and robust evaluation using appropriate econometric techniques.

The success of the JARC initiative may be dependent on the prior existence of a community development organisation which had built up a strong rapport with the companies in its sector. If the approach was to be transferred to Wales the equivalent organisation may not exist or take several years to develop such a relationship. The JARC report notes that ESOL training is provided for immigrants in Wales, which implies that immigrants should first learn English. However, in the view of the author of this report, teaching vocational skills and competencies in the workers' own native language is often more effective. Delivering courses "from below" and "from within" and not from above, by organisations with a strong community ethos is emphasised. This is something that the Sector Skills Councils may wish to investigate.

It is suggested that the Training Cheques initiative fits in with ESF Priority 3, and is particularly relevant for high technology and knowledge-based growth sectors, where economic and social change makes retraining essential. There are, however, already a number of initiatives to deal with. These issues as outlined in Skills that Work for Wales and training needs analysis in the Work Based Learning Schemes allows for discretionary funding to firms.

There are three initiatives which seem to have considerable potential. The Perspective 50 Plus initiative focuses on raising the activity rate of older workers. Since 2005 all those not in employment in Germany can participate in active labour market programmes including upgrading, training, mediation processes, company internships and publicly subsidised work programmes. If inactive 
individuals do not participate they face sanctions including obligatory personal interviews. While this sounds very much like Want2Work, the latter does not have special provisions for older workers, however, it might be possible to incorporate such provisions allied to a campaign such as the Basic Skills Pledge, but applied to older workers. In considering the applicability to Wales it should be emphasised that Perspective 50 Plus is part of active labour market policy in Germany which has a number of elements designed to help older workers. For example, the Federal Government introduced legal measures to create 50000 additional publicly subsidised jobs for unemployed older people aged 58 and over (of which 30000 had been created by 2007). It deals with two particular challenges - to reduce the long-term unemployment rate of older people and to involve regional and local stakeholders, with local job centres playing a key role. In the Welsh context both Job Centre Plus and the SSCs would have to play a major role in this sort of initiative. It is also high profile, as it is necessary to raise awareness of the problem; identity best practice initiatives; identify appropriate instruments; and set up local networks and local Employment Pacts. It operates, therefore, on both sides of the labour market with the active involvement of employers. There is close co-operation between the managers in the job centres, training providers and employers. The initiative is multifaceted with wage subsidies of up to $€ 4000$ per person, in-company training, upgrading, coaching, health care activities, internships in companies, start-up initiatives for those who wish to start their own companies and mobility incentives. All of this is likely too intensive in resources.

Second, the Let's Get Moving Initiative seems to fit in well with current Welsh strategies. One Wales: Connecting the Nation; The Wales Transport Strategy, April 2008 has as twin objectives improving access to education, training and lifelong learning and improving access to employment opportunities. Poor access is regarded as one of the major barriers facing those without jobs, particularly in the Valleys and the rural areas of Wales. About $80 \%$ of those employed in Wales travel by car, but Blaenau Gwent and Merthyr Tydfil, for example, have the highest percentage of households without access to a car in Wales, making public transport a key to integrating the jobless into the labour market. Further, the transport strategy is to reduce dependence on the car as a means of reducing carbon emissions, particularly when the car is used by a single occupant for commuter journeys. This outcome, however, is dependent on significant improvements in public transport, in terms of its accessibility, frequency and integration. Working through the four Regional Transport consortia, local authorities are due to produce their first Regional Transport Plans in 2008/2009, which will set out a series of detailed steps to improve the integration of local transport. This is where the ideas and policies contained in the Let's Get Moving initiative could be incorporated. It has helped individuals to tackle barriers to participation in work and linked areas of need to areas of job opportunity. It is particularly relevant to young people, women who are constrained by household duties (in particular lone parents) and minorities, who can be targeted if they live in deprived wards. It is among such groups that knowledge of available transport may be most limited. Some may be lacking in basic skills or simply constrained in their job search activities by their low potential earnings capacity. It was suggested that the limited life experience of those who are inactive or unemployed needs to be better understood. There may also be a cultural problem. In Liverpool many individuals lived in families with a tradition of industries being on their doorstep (e.g. dockers). The idea of travelling ten miles or more to work was alien to them. Further, bus maps tend to not be user friendly. The number of bus stops varies depending on where passengers need to get off. Having a travel adviser (perhaps initially travelling with the individual concerned) can help to overcome such uncertainties. In fact, the availability of public transport was much better than many people from these groups realised. Though it applies largely to an urban environment, some elements could apply to rural areas. Further, there are already links between key personnel in Merseyside Travel concerned with the initiative and partners in North East Wales. There are three distinct projects under the Let's Get Moving Banner. The Neighbourhood Travel Teams arrangement would seem particularly well suited to the Valleys and other deprived areas. The same could be said of Workwise which provides financial assistance rather than information. Demand responsive transport services are much more expensive 
than the other parts of the initiative and may require longterm subsidies. It was suggested that such services will not be provided by the market because they are expensive and firms are reluctant to pay for them because they fear this will help their competitors more than themselves. This is despite the fact that car parking facilities on company premises are also expensive to provide. Such services also help to overcome the problem of labour shortages by helping firms to fill existing vacancies. Reference was also made to the Deeside Industrial Estate, a greenfield site where the only access was by car. Thus subsidised bus services could contribute to a significant reduction in car journeys. This again is consistent with the Welsh Transport Strategy.

Third, the Portuguese Inov Contacto initiative has been applied in a relatively peripheral, small open economy similar to Wales and faced both with the possibility of Multinational Enterprises (MNEs) relocating elsewhere and with SMEs often lacking critical mass to engage in export markets. Such an initiative could be linked to an expanded GO Wales scheme and help to encourage Welsh graduates to join Welsh companies. GO Wales provides project-based work in smaller companies (SMEs) and charitable organisations with recipients being paid a minimum of $£ 230$ per week. Placements are open to both under-graduates on vacation and graduates. Careers services already provide advice to graduates seeking opportunities overseas. It would be relatively straightforward, therefore, to apply a scheme such as Inov Contacto into this programme, but extend it to larger companies as well as SMEs, as larger multinationals in particular are likely to offer a broader experience. There is, however, a danger that graduates going abroad under such a scheme may not return and the value of such graduates acting as ambassadors for Wales has to be weighed against a possible loss of graduates.

\section{Conclusions and Policy Recommendations}

There is no shortage of ideas, policies or strategies to improve the operation of the Welsh economy and labour market. Institutions to deal with at least some of these issues are also in a state of flux and need time to implement new and emerging policies. This suggests that it may be more appropriate to incorporate elements of suitable initiatives into existing policies rather than setting them up as stand-alone policies. A prior need, however, is to consider the linkages between different existing programmes. For example, both Communities First and Want2Work aim to help the most deprived individuals in the most deprived wards, but it is not obvious how they link together. The Sector Skills Councils, which are now fully operational, need to have their role integrated with those of DCELLS, DET and Job Centre Plus. This should have priority over introducing any additional measures.

In the absence of careful economic evaluation for most of the ten initiatives considered in this draft report, it is difficult to assess the precise degree of their success, though there is much qualitative evidence that they have been successful. In nearly all cases there are also Welsh counterparts. Thus major regeneration schemes have already taken place in Wales or are already in progress. It is difficult to see how these could be altered in any substantial way as a result of the lessons of the three regeneration initiatives considered here.

The Canadian Dexter Institute, US Micro-enterprise Welfare-to-Work Programme and JARC initiatives deal with issues that are pertinent to Wales such as skill shortages, self employment and immigrant training; but in each case there are existing provisions in Wales, even if the format may not be the same. The same is true in relation to the German Training Cheques initiative.

There is, however, more potential in the remaining three initiatives. The German Perspective 50 Plus initiative has been remarkably successful in getting older persons who are out of the labour 
market back into it. While older workers on incapacity benefit are covered by the Want2Work initiative there is no special focus on their needs within the programme and there may be scope to increase their participation in it. This would also help to deal with the problem of disability which is higher among those over 50. A way forward might be through the involvement of the emerging Local Employment Partnerships. The Merseyside Let's Get Moving Initiative has also been successful in helping those from low income households to enter the labour market by providing information, assistance and encouraging better public transport links between deprived areas and job locations. This could be appropriate, at least for some parts of Wales. Finally, the Portuguese Inov Contacto Programme might encourage Welsh graduates to take up employment with Welsh companies and assist smaller Welsh firms to enter export markets. This could possibly be grafted on to the GO Wales scheme, which DCELLS is keen to expand.

\section{Box II.4: The potential role of the reviewed initiatives in filling the gaps}

* The context is one in which there are a large number of relevant policy initiatives and many changes in both the administrative apparatus and strategies.

* Most of the initiatives aim to help members of disadvantaged groups, which are visible in Wales.

* Some deal with raising skills, which is a key consideration in Wales.

* Some deal with older workers, which is an important group in Wales.

* Some deal with run-down locations in urban centres.

* It is not easy to establish just how successful these initiatives have been.

* The precise way in which schemes are implemented can be important.

* Some initiatives require a substantial input of financial resources.

* Partnership arrangements and flexibility are key features of success.

* Not all schemes are able to reach out to the most vulnerable.

* Brownfield site remediation can be a catalyst for encouraging private sector investment.

* The German Perspective 50 Plus initiative has lessons for dealing with long-term unemployed older workers.

* The Merseyside "Let's get Moving" initiative is a good fit in relation to the objectives of the Wales Transport Strategy.

* The Portuguese Inov Contacto scheme has some relevance for the desire to retain high quality graduates in Wales. 


\section{References}

Blackaby D., Jones M., Jones R., Latreille P., O’Leary N. and Sloane P.

Identifying Barriers to Economic Activity in Wales, Part 1, May 2003 and Part 2, September 2004, Report to the Welsh Assembly Government.

Czoski Murray C., Edlin R., Lindley J., McIntosh S. and Roberts J.

Evaluation of the "Want 2 Work" Pilot: Labour Market Outcomes, Interim Report for the National Assembly for Wales, October, 2007.

Department for Work and Pensions, Building on New Deal: Local Solutions Meeting Individual Needs, June, 2004.

Experian, Commuting in and Around Wales, Final Report, The National Assembly for Wales, undated.

Goos M. and Manning A., Lousy and Lovely Jobs: The Rising Polarisation of Work in Britain, CEP Discussion Paper, 604, LSE, December 2003.

Heckman J.S., School, Skills and Synapses, IZA Discussion Paper No. 3515, May, 2008.

Henley A., On Regional Growth Convergence in Great Britain, Regional Studies, vol. 39(9), 2005, pp 1245-1260.

HM Treasury, Prosperity for All in the Global Economy: World Class Skills, Final Report (Chair Lord Leitch) December, 2006.

Jones M.K., The Dynamic Benchmarking of Labour Markets, Regional Studies, vol. 38(5), July, 2004, pp 493-506.

Jones M.K., Latreille P.L. and Sloane P.J., Disability, Gender and the Labour Market in Wales, Regional Studies, vol. 40(8), November, 2006, pp 823-845.

Jones M.K. and Henley A., Welsh Economic Performance: Recent Experience and Future Challenge, WELMERC Discussion Paper No. 2007-03, Swansea University, July, 2007.

Jones M.K. Kidd M.P. and Sloane P.J., Disability in the Living in Wales Survey, Report for the Welsh Assembly Government, May, 2008.

Labour and Plaid Cymru, One Wales: A Progressive Agenda for the Government of Wales, 27 June 2007.

Revell J., Statistics on Job Quality in Wales, 2001-2006, Welsh Assembly Government, 25 October 2007.

Rice P. and Venables A.J., Spatial Determinants of Productivity: Analysis for the Regions of Great Britain, CEP Discussion Paper No. 642, LSE, 2004.

Rosenbaun P.R. and Rubin D.B., the Central Role of the Propensity Score in Observational Studies for Causal Effects, Biometrika, vol. 70, 1983, pp 41-55. 
Sloane P.J., O’Leary N. and Watson D.

The Long Tail of Low Skills in Wales and the UK - A Review of the Evidence, Report to the Economic Research Unit, Welsh Assembly Government, September, 2006.

Transport and Travel Research Ltd, Scope for Public Transport Improvements to Contribute to Increases in Economic Activity, Report for the Welsh Assembly Government, undated.

WELMERC, Welsh Labour Market Benchmarking Update, WELMERC Newsletter, Swansea University, Winter, 2007.

Welsh Assembly Government, Wales A Better Country, The Strategic Agenda of the Welsh Assembly Government, undated.

Welsh Assembly Government, A Winning Wales: The National Economic Strategy of the Welsh Assembly Government, http/www.wales.gov.uk

Welsh Assembly Government, Wales: A Vibrant Economy; The Welsh Assembly Government's Strategic Framework for Economic Development, November 2005.

Welsh Assembly Government, The National Basic Skills Strategy for Wales, undated.

Welsh Assembly Government, The Entrepreneurship Action Plan for Wales, undated.

Welsh Assembly Government, Knowledge Bank for Business, undated

Welsh Assembly Government, Wales for Innovation: The Welsh Assembly Government's Action Plan for Innovation, undated.

Welsh Assembly Government, Learning Country: Learning Pathways 14-19, undated.

Welsh Assembly Government, "Turning Heads" - The Regeneration Strategy for the Heads of the Valley for the Period up to 2020, undated.

Welsh Assembly Government, Action Plan for Môn a Menai, February 29, 2008.

Welsh Assembly Government, Economic Futures for Wales, Economic Research Advisory Panel, undated.

Welsh Assembly Government, The Strategy for Older People in Wales, January, 2003.

Welsh Assembly Government, People, Places Futures - The Wales Spatial Plan, undated.

Welsh Assembly Government, Skills and Employment Action Plan for Wales 2005, Department of Education and Training, 11 January 2005.

Welsh Assembly Government, Annual Learning and Skills Assessment 2006-2009, May 2006.

Welsh Assembly Government, National Learning and Skills Assessment Update: Statement of Priorities for Change - 2007-2010, DCELLS, October 2007.

Welsh Assembly Government, Skills that Work for Wales: A Skills and Employment Strategy, DCELLS, 17 January, 2008. 


\section{ENDNOTES}

${ }^{1}$ See One Wales; a progressive agenda for the government of Wales - an agreement between the Labour and Plaid Cymru Groups in the National Assembly, $27^{\text {th }}$ June, 2007.

${ }^{2}$ This begs the question of what we mean by job quality. Using an approach based on earnings levels J. Revell, Statistics on Job Quality in Wales, 2001-2006, Welsh Assembly Government, 25 October, 2007, finds between 2001 and 2006 there was strong growth in the higher occupational groups, combined with a switch between machine-based jobs and people based jobs at the lower end, consistent with the hollowing out effect identified by Goos and Manning, Lousy and Lovely Jobs: the Rising Polarisation of Work in Britain, CEP Discussion Paper 604, LSE, December 2003. While the relative share of the lowest paid jobs fell, the absolute number in them rose slightly.

${ }^{3}$ An initial set of ten sectors were identified as being important to future economic growth; namely automotive; aerospace; agri-food; high technology; pharmaceuticals/bio-chemicals; financial services; creative industries; construction; hospitality, leisure and tourism; and social care. Each of these is covered by a Sector Skills Council which has the responsibility to ensure sufficient training of the right type is provided. But, the precise extent to which the growth potential of these sectors is greater than elsewhere is unclear and there is a need to monitor their development over time.

${ }^{4}$ Employment policy is not devolved and is the responsibility of the Department of Work and Pensions, though there is some scope, with the DWPs agreement, for some local initiatives. Training is, however, a devolved activity.

${ }^{5}$ See, for instance, Rice P. and Venables A.J., Spatial Determinants of Productivity: Analysis for the Regions of Great Britain, CEP Discussion Paper no. 642, LSE, 2004.

${ }^{6}$ Statistics from the Basic Skills Agency suggest that $25 \%$ of adults in Wales have poor literacy skills and around $53 \%$ have poor numeracy skills relative what one would expect from an eleven year old child (i.e. level 1).

${ }^{7}$ See Welsh Labour Market Benchmarking Update, WELMERC Newsletter, Swansea University, Winter 2007, pp 2-9. For details of the methodology used in this study see M.K. Jones, The Dynamic Benchmarking of Labour Markets, Regional Studies, vol. 38(5), July, 2004, pp 493-506.

${ }^{8}$ Of course attracting resources from outwith Wales does not suffer from this problem but is made more difficult by the inability of WAG to offer financial inducements such as tax breaks.

${ }^{9}$ We should allow for regional and sub-regional differences in the cost of living, but A. Henley (On Regional Growth Convergence in Great Britain, Regional Studies, vol. 39(9), 2005, pp 1245-1260) found limited evidence of regional convergence since the late 1970s even after controlling for regional differences in the cost of living.

${ }^{10}$ Disability, Gender and the Labour Market in Wales, Regional Studies, 40(8), November 2006, pp 823-845.

${ }^{11}$ See M.K. Jones, M.P.Kidd and P.J.Sloane, Disability in the Living in Wales Survey, Report for the Welsh Assembly Government, May, 2006.

${ }^{12}$ Paper presented to the Welsh Assembly Government Workshop on Migration, Cardiff, March, 2008.

${ }^{13}$ Skills that Work for Wales, 2008, reports plans to expand GO Wales subject to employer demand. 
${ }^{14}$ See, for example, Sloane P.J., O’Leary N.C. and Watson D.L. The Long Tail of Low Skills in Wales and the $U K-A$ Review of the Evidence, WELMERC Report to the Economic Research Unit, Welsh Assembly Government, 2005.

${ }^{15}$ See Experian, Commuting in and Around Wales, Report to the Welsh Assembly Government.

16 Tranport Travel Research Ltd, Scope for Public Transport Improvements to Contribute to Increases in Economic Activity, Report for the Welsh Assembly Government, August, 2005.

17 There are 25 Sector Skills Councils covering England and Wales. All of these have now concluded Sector Skills Agreements, each with Welsh specific components.

${ }^{18}$ Such an approach was, however, adopted in the evaluation of the Want2Work pilot.

${ }^{19}$ James J. Heckman, Schools, Skills and Synapses, IZA Discussion Paper No. 3515, May 2008.

${ }^{20}$ This was part of a larger programme including Initiative 50 Plus, which provides subsidies to SMEs to provide in-company training for older workers.

${ }^{21}$ It was suggested that the programme would have succeeded even under less favourable circumstances through behaviour change on the part of individuals who had been out of the labour market for a long time and on the part of small firms which reduced their prejudice against older workers. It was also believed that the higher the local demand for labour the lower the employability of those who remain unemployed. This is a consequence of the fact that the more employable of the long-term unemployed will already have been absorbed into the labour market in the busier regions. This implies that such a policy should be more successful in areas of low demand in Wales such as the Valleys.

${ }^{22}$ Adopting the Rosenbaum and Rubin (1983) approach control groups were selected from comparable regions. In addition there was a financial analysis of inputs and outputs, case studies of 20 Employment Pacts, telephone interviews with 1000 participants (randomly chosen) and extended process analysis of data for most of the participants.

${ }^{23}$ Likewise the Dutch Kensenzones initiative does not work in isolation, but is part of a larger regeneration package.

24 There are substantial differences in the way in which these pacts operate. Thus, while some attracted in leading companies and installed steering groups, others operated in a more informal way. It was suggested that larger companies were interested in public relations campaigns for older workers rather than hiring them, while micro and small enterprises were more likely to change their hiring strategies. These pacts have features in common with the new Local Employment Partnerships in the UK. 


\title{
BUSINESS PRODUCTIVITY POLICY TRANSFERABILITY TO WALES
}

\author{
David Pickernell \\ Business School, University of Glamorgan, Wales
}

\section{Introduction}

As part of the OECD project 'A Review of Local Economic and Employment Development Policy Approaches in OECD Countries', carried out in partnership with the Welsh Assembly Government (WAG), a "transferability paper" is required on the broad field of business productivity policies. This paper will therefore directly link to the previous policy audits stage of the project, in which 10 specific interventions from different OECD member countries were investigated in the broad policy field of business productivity improvement. In undertaking this task, existing academic and policy documents on policy challenges and options in Wales are analysed, as are the papers related to the 10 policy interventions whose potential transferability to Wales should be investigated. In addition, interviews were conducted with experts on the Welsh situation, from academia and government, to obtain their views on existing policy issues, transferability and lessons of the initiatives. Further feedback was also obtained from the experts who have written the original 10 policy interventions in OECD member countries (to further inform the lessons for Wales).

The paper has the following structure. In the first section, the Business Productivity Policy challenge for Wales is examined in terms of the causes of low business productivity in Wales, the current policy context this creates in Wales, and potential strengths and weaknesses of current policies. Potential gaps in the current approach of the Welsh Assembly Government and its partners are then identified, in terms of governance, policy-making process and specific policy areas. This is followed by a broad examination of policy options potentially available to address Wales's challenges, and a more specific narrowing to the key areas in which the 10 identified initiatives sit. The potential role of 10 identified initiatives in filling policy gaps or offering policy lessons are then explored. Finally, conclusions are drawn and policy recommendations offered in terms of the principal lessons for future policy development in Wales.

\section{Business productivity policy challenge for Wales}

Wales has a long standing and on some measures growing relative productivity and thus economic growth problem. Business Productivity Issues are a sub-set of more general productivity issues (which include unemployment and economic inactivity for example).

Business Productivity Issues generally revolve around capital and labour quantity and quality and speed of technological advancement, creating a strong policy focus on innovation as a driver of productivity as well as skills, entrepreneurship and investment.

The business productivity gap in Wales has historically been strongly linked to lower levels of capital and related industry structure issues, geographic peripheral location, as well as less use of 
management technology, and likely lower levels of entrepreneurial, innovative, and networked activity, particularly as they relate to new technological creation, dissemination and utilisation.

Wales has had productivity related policies for many years, with a focus on unemployment and inactivity issues; the business productivity-related policies focused on issues of industrial structures, connectivity and place, skills and qualifications, entrepreneurship, and networking and innovation.

Current policy areas highlighted for examination focusing on insufficient industry-led network organisations, issues surrounding business assistance policy delivery mechanisms, the focus for entrepreneurship policy, and the appropriateness of the operation of the Technium innovation strategy.

\section{(a) The productivity problem in Wales}

Productivity is a widely used, though not unchallenged measure of economic prosperity. It is also seen, therefore, as a key determinant of standards of living. There have been several examinations of the issues surrounding it in Wales, most notably, Bristow (1999), Boddy (2006) and Crafts (2007). At its most basic, Boddy (2006) defined productivity as a measure of the value of goods and services produced, expressed in a standardised format. The standardised format commonly used now to compare regions and nations in terms of productivity is Gross Value Added (GVA) per head, which measures the volume of GVA relative to the population size of a given area. In other studies (e.g. Crafts, 2007) Gross Domestic Product (GDP) per head, which measures total income received from the production of goods and services per head of an area's population, is also used to measure productivity. Using this terminology, it is possible to illustrate the long-term nature of the broad productivity problem in Wales, when measured against the UK as a whole. Crafts (2007) for example highlighted that Wales has suffered from a relative productivity problem, compared with the UK as a whole, since at least the latter part of the $19^{\text {th }}$ century. This problem has worsened in the past 20 years. Boddy (2006) further estimated that by 2004 Wales's GVA per head figure was only 79\% of the UK figure but that this hides considerable variations within Wales's Unitary Authorities (UAs); with Cardiff and the Vale of Glamorgan being significantly above the UK average, South Eastern (Monmouthshire and Newport) and North Eastern (Flintshire and Wrexham) areas close to parity with the UK and all other parts of Wales considerably below the UK average. This highlights the (at least partially) spatial nature of the problem, and that policies to reduce productivity differences may also require a spatially targeted approach. Before examining the policies utilised, the causes of the business productivity differentials and reasons for these causes need to be explored. In order to do this, however, a more precise definition of productivity itself is required. Whilst GVA per head is the commonly-used 'headline' measure, it includes within it issues such as economic activity and unemployment rates. Crafts's (2007) analysis, for example, illustrates that the 2005 GDP per head level in Wales, $76 \%$ of the UK average, can partly be explained by a combination of lower hours worked per person employed, a lower level of employment, and lower activity rates.

$$
\begin{array}{llll}
\mathrm{GDP} / \mathrm{P} & =((\mathrm{GDP} / \mathrm{HW}) *(\mathrm{HW} / \mathrm{E}) *(\mathrm{E} / \mathrm{LF}) * & (\mathrm{LF} / \mathrm{P})) \\
0.765 & =((0.899) *(0.949) * & (0.995) * & (0.901)
\end{array}
$$

$\mathrm{P}=$ Population, HW = Hours Worked, E = Employment Levels, and LF = Total Labour Force)

Table II.3 below - for the more specifically business productivity related measure of GVA per hour worked for Wales against other regions and nations of the UK over the period 1996-2004 further illustrates that relative business productivity, specifically, is also a problem that has been getting progressively worse over the past decade or so, relative to the UK as a whole. 
Boddy (2006) recommend the use of business level data to allow calculation of output (in relation) to the size of the workforce, allowing measurement of productivity at the level of individual business units (effectively an output per worker measure). This enables business level productivity to be related to a wide variety of other characteristics at the level of the individual business units and to characteristics of the local area such as qualifications, though it does not account for mixes between full and part-time work. Where possible therefore, we use Boddy's (2006) analysis, and highlight where data collected from other sources and use of other definitions was necessary.

Table II.3: GVA per hour worked (Index, UK $=100)^{1,2}$

\begin{tabular}{lrrrr}
\hline Region / Nation & $\mathbf{1 9 9 6}$ & $\mathbf{1 9 9 9}$ & $\mathbf{2 0 0 2}$ & $\mathbf{2 0 0 4}$ \\
\hline North East & 97.9 & 95.7 & 94.9 & 93.6 \\
\hline North West & 94.0 & 94.6 & 93.0 & 92.5 \\
\hline Yorkshire and Humberside & 94.1 & 94.1 & 93.0 & 91.4 \\
\hline East Midlands & 98.1 & 93.9 & 97.1 & 98.5 \\
\hline West Midlands & 91.3 & 93.6 & 93.7 & 94.0 \\
\hline East of England & 100.0 & 98.7 & 98.6 & 101.2 \\
\hline London & 118.8 & 116.6 & 117.5 & 118.8 \\
\hline South East & 102.2 & 105.4 & 105.2 & 105.5 \\
\hline South West & 93.7 & 95.8 & 95.9 & 95.1 \\
\hline England & 100.5 & 100.8 & 101.2 & 101.3 \\
\hline Wales & 93.9 & 93.0 & 92.0 & 90.7 \\
\hline Scotland & 101.1 & 99.2 & 96.4 & 98.1 \\
\hline Northern Ireland & 89.5 & 86.7 & 85.7 & 81.9 \\
\hline UK & 100.0 & 100.0 & 100.0 & 100.0 \\
\hline
\end{tabular}

Notes: 1 . The annual hours figure that is used in the compilation of the GVA per hour worked index is an average of the four quarters and includes Employees, Self employed and Government Supported Trainees data provided by the Labour Force Survey, and Her Majetsy's (HM) Forces data provided by the Ministry of Defence. 2. GVA per hour worked has been calculated using the smoothed regional GVA figures as published in the Regional Accounts First Release on 21 December 2005.

Source: Employment, Earnings \& Productivity Division, Office for National Statistics (ONS)

\section{(b) Theoretical reasons for business productivity differences}

In order to evaluate the Welsh situation, it is first necessary to revisit the theoretical reasons for business productivity differences. These can be seen as having been generally focused around the amount and quality of factors of production (with a specific focus on physical and human capital), technological progress and the economic environment. Stiroh's (2001) analysis, for example, highlights an approach in which physical capital, human capital, public (infrastructure) capital and technological progress, embodied as Research and Development (R\&D) investment and Information and Communications Technology (ICT) investment can all be seen as different types of capital investments that can impact upon productivity. Haskel's (2001) analysis breaks the issues down into physical capital, human capital and technological advance, but points out, importantly, that identifying the components of growth, does not explain why firms and individuals invest as they do in the first place.

Hall and Jones's (1999) examination of the issue, is therefore of importance because it splits the problem into three, namely physical capital, human capital (education and skills) and what they called "social infrastructure", made up of the institutions and government policies that determine the 
economic environment within which individuals accumulate skills, and firms accumulate capital and produce output. A social infrastructure favourable to high levels of output per worker provides an environment that supports productive activities and encourages capital accumulation, skill acquisition, invention, and technology transfer. Etzkowitz and Leyesdorff (2000) see a particularly strong role for the government via innovation, through the triple helix of government-industry-institution interaction, and emphasises the importance of network and collaborative activities between these three groups of stakeholders. Whilst these can be seen as highlighting a positive role for government and policy in raising productivity, Gwartney et al. (1998) also highlight, the potential for excessively large government activity to have a negative impact on growth and productivity: if it goes beyond creating the legal and physical infrastructure and public good necessary for economic activity, if taxes are too high, if government engages in activities to which it is not suited or substitutes for market activities more efficient in allocating resources. Breunig and Wong's (2007) examination of the role of firm exit also highlights that competitive processes in which less efficient firms leave the industry are also beneficial to national productivity, re-emphasising the role of the market, and entrepreneurship which creates more efficient firms to enter the economy. Thus, there are particularly important roles for innovation, skills, entrepreneurship and investment as drivers of business productivity, and thus a need for policy to focus in these areas.

\section{(c) Causes of the business productivity gap in Wales}

Bristow's (1999) study highlighted that the competitiveness of individual firms is important, as well as the industrial structure of the economy more widely. She highlighted key roles, therefore, for more effective leadership, technical and management ability at the level of the firm, as well as a need for changes in the structure of the Welsh economy more generally. Boddy (2006) further decomposed the Welsh $42 \%$ output per employee (GDP/E) productivity gap relative to London. In addition to Full time- Part Time mix (HW/E), differences highlighted as an issue above, they also found that: lower capital levels per worker; a less advantageous industrial sectoral composition; the deleterious consequences of a peripheral location (in travel time); and a combination of the public/private sector ownership mix, skills level, population density (and the full-time-part time mix) each accounted for about a fifth of the difference. This left a fifth of the difference initially unexplained. In exploring this unexplained difference, examination of how labour is used is of clear importance. Crafts (2007) argues that technological progress is the most important underlying determinant of labour productivity generally and over time. It is logical, therefore, to evaluate differences in technological progress as another potential cause of the relative difference in overall productivity. Coe and Helpman (1995) see such technological progress for relatively small countries, such as Wales, as occurring mainly via technology transfer from abroad, rather than via internal means. This may be directly via inward investment and establishment of foreign companies within the economy, producing knowledge transfer via supply chains and proximity (Pickernell, 1999). Factoring in public/private ownership structures, use of ICT in websites, and multinational/non-multinational ownership mixes (which can be seen in terms of links to innovation take-up and profit-focus), only reduced the level of productivity difference explained by $1 / 8^{\text {th }}$ of the unexplained difference. Technology transfer may also occur via indirect means (e.g. via education and training programmes aimed at raising knowledge and skill levels generally). Diffusion and utilisation of existing new technologies (for Crafts (2007) particularly in the growing service sector, as illustrated by van Ark (2007)) are also of value. The issues for this, however, will be the speed of diffusion and adoption, given that such technologies will be available to other regions as well. Bristow (1999) for example, found that whilst there was a significant difference in GVA per head between foreign and UK owned manufacturing firms, that there was little difference between foreign-owned firms in Wales compared with the rest of the UK, reemphasising the relative nature of the issue. 
In terms of the overall $40 \%$ GVA gap, therefore, Boddy (2006) identified the following as of importance. In terms of within Wales differences, Boddy's analysis identifies that, relative differences are largely explained by differences in the capital stock, industrial structure, the full-time/part time employment mix and population density, and to a lesser extent qualification levels. Boddy (2006) also highlights that very high levels of productivity difference remain unexplained for Swansea and the Gwent Valleys in particular, hypothesising that these two areas contain the majority of the unexplained differences between Wales, as a whole, and London.

In addition, whilst issues related to agglomeration and clustering in space are partly accounted for by both travel time and population density measures, there are also important additional potential impacts from both entrepreneurship and innovation that explain the remaining differences in relative productivity levels, which also require a policy focus. Existing research, for example, suggests that it is also necessary to integrate individual and firm-level entrepreneurial processes with newly created knowledge and processes at a range of spatial levels, in order to maximise the utilisation of knowledge and innovation (Acs et al., 2007). This can also be seen as fitting within the Regional Innovation Systems literature, Cooke (2003), highlighting for example, that more successful core regions tend to have 'entrepreneurial' innovation systems, whilst more peripheral regions have 'institutional' ones. Specific internal, firm-level processes of relevance to knowledge spillovers (from university spinout activities in her example) have also been highlighted by Senyard et al. (2007) as related to entrepreneurial orientation, knowledge and relationship management and knowledge asymmetry. These entrepreneurship and innovation-related issues can therefore be seen as potentially falling within the realms of the "unexplained" element of Table II.4.

Table II.4: Explanations of the 40\% GVA per employee gap between Wales and London

\begin{tabular}{|c|c|}
\hline Explanation & Proportion of Gap "Explained" \\
\hline Capital Stock Levels & $8 / 40$ \\
\hline Travel time to London and Main Cities & $8 / 40$ \\
\hline Industry Structure & $6 / 40$ \\
\hline Qualifications & $6 / 40$ \\
\hline Population Density & $3 / 40$ \\
\hline Full Time /Part Time Mix & $1 / 40$ \\
\hline $\begin{array}{l}\text { Public/Private Ownership, Multinational } \\
\text { Ownership, No web site for external use }\end{array}$ & $1 / 40$ \\
\hline Unexplained & $7 / 40$ \\
\hline
\end{tabular}

Source: Boddy (2006)

Highlighting these causes of the productivity gap in Wales, however, does not explain why they exist, i.e. why there have historically been low levels of innovation, investment in relevant skills, business investment and entrepreneurship. As Morgan (1997) points out, Wales was forced to make the transition from an economy heavily dependent on large externally owned coal and steel employers, to one more diversified into manufacturing and (to a lesser extent until recently) services, the changes being accompanied by high unemployment necessitating consequential government intervention. In the 1930s, for example, Wales was one of the first parts of the UK to receive regional policy assistance because of the unemployment problem. Brooksbank et al. (2001) point out, that Wales has had access, for many years, to UK business grants schemes such as Regional Development Grants (RDGs) and Regional Selective Assistance (RSA) for the same reason. In pre-devolution times the focus of these resources was on particular areas of economic need, such as the South Wales Valleys (Brooksbank et al., 1998). The resources were used in particular to attract foreign inward investment. At this time the unemployment gap between Wales and the rest of the UK were seen as of particular importance in the regional competitiveness and productivity debate and inward investment attraction was therefore viewed largely as a means of creating valuable employment (though Pickernell (1999) also identified a 
variety of mechanisms by which knowledge and new working practices, of use in raising productivity, were also being transferred into the Welsh economy).

As Morgan (1997) also points out, however, the lack of a strong indigenous entrepreneurial business base (not least because of the concentration in coal and steel) led to a reliance on public sector investment in the long declining coal and steel industries and attraction of manufacturing investment from foreign-owned multinationals, often in relatively low-skilled areas. Morgan (1997) thus points out that it was only when the foreign inward investment began to become more difficult to attract, in the early to mid 1990s, that policy began to focus more heavily on business support, technology transfer, skills development and indigenous entrepreneurship. Hall and Jones's (1999) "social infrastructure" idea is thus of particular importance here, given that it highlights the importance of the economic environment within which individuals accumulate skills, firms accumulate capital and produce output, and the economy generally acquires and generates innovation through invention, and technology transfer. Wales, traditionally, has not had an economy conducive to this, partly because its history and the changes in its economic structure have created an environment and consequent focus for productivity-related policy which has been strongest in terms of unemployment and inactivity, rather than business productivity specifically.

\section{(d) Business productivity policy in Wales}

There thus seems unambiguous benefit to be gained from policies which focus on promoting enterprise and networks in general and innovation in particular as the central themes for a business productivity-based policy. This can be seen in elements of the more recent policy document (WAG, 2005) "Wales: A Vibrant Economy" (WAVE) the latest strategy document following the 2001 "A Winning Wales", under which there are a range of specifically identified drivers and strategies, such as:

1. Innovation: which includes highlighting the Innovation Action Plan, as well as a specific focus on encouraging innovation firms, links with universities and the Technium incubator network, (with related relevance to Centres of Excellence in Technology and Industrial Collaboration (CETICs), and Manufacturing Advisory Scheme). Discussions also reveal a focus on tapping the "latent" potential of universities in this regard, through research commercialisation, spinouts, graduate start-ups, university-industry links etc., with a particular interest in promoting graduate "stay-on" in a region following graduation.

2. Entrepreneurship: including the Entrepreneurship Action Plan and Knowledge Bank for Business.

3. Skills: focused through the Skills and Employment Action Plan.

4. Investment: focused through RSA (as well as the Single Investment Fund / Knowledge Bank for Business / RSA).

5. Sectoral Foci: through Energy Partnerships, Hi Technology Automotive, Aerospace, AgriFood, Tourism, Financial Services, Creative Industries; further discussions revealing specific foci on "core" sectors of ICT, energy, environmental management and transport as levers for the wider economy.

6. Spatial elements: via Wales Spatial Plan, Wales Transport Strategy / Regional Transport Strategies and Broadband Wales initiatives.

As an illustration to assist the examination of the range of Welsh productivity-related policies that do exist, Table II.5 identifies, against each of the broad causal factors, a basic proportion of the gap (with London) that can be attributed to them (derived from the Boddy, 2006 analysis above), and the 
Welsh policy strategies identified as being focused on that area from WAG (2005) "Wales: A Vibrant Economy.

Table II.5: Identified business productivity issues, estimated importance and WAG based resources spending 2007-11

\begin{tabular}{|c|c|c|c|}
\hline $\begin{array}{l}\text { Business } \\
\text { Productivity Issue: }\end{array}$ & $\begin{array}{l}\text { Area and estimated \% } \\
\text { "contribution" to the Welsh } \\
\text { business productivity gap } \\
\text { with London"1 }\end{array}$ & $\begin{array}{l}\text { Specifically Identified resources } \\
\text { from WAG } 2008-11 \text { budget (and } \\
\% \text { of total identified productivity- } \\
\text { related policies) }\end{array}$ & $\begin{array}{l}\text { Author-identified WAG policies of potential } \\
\text { relevance from WAG 2008-2011 budget }{ }^{2}\end{array}$ \\
\hline 1. Structure & $\begin{array}{l}\text { Capital Stock (20.0\%) } \\
\text { Industry Structure }(15.0 \%) \\
\text { Full Time / Part Time Mix } \\
\text { (2.5\%) } \\
\text { Total: } 37.5 \%\end{array}$ & $\begin{array}{l}\text { Flexible Business Solutions - } \\
\text { (Grants Programme, etc.) } \\
£ 370494000 \\
\text { Total: } 5.94 \%\end{array}$ & $\begin{array}{l}\text { Regional Selective Assistance: Single } \\
\text { Investment Fund ; Broadband Wales } \\
\text { Programme (High Bandwidth ICT); Attraction } \\
\text { of HQs; Stable overall business environment; } \\
\text { High Bandwidth ICT ; Single Investment Fund } \\
\text { : Knowledge Bank for Wales; Regional } \\
\text { Selective Assistance: Single Investment } \\
\text { Fund; Sectoral Foci on Energy Partnerships, } \\
\text { Hi Technology; Automotive, Aerospace, Agri- } \\
\text { Food, Tourism, Financial Services, Creative } \\
\text { Industries }\end{array}$ \\
\hline $\begin{array}{l}\text { 2. Connectivity } \\
\text { and Place }\end{array}$ & $\begin{array}{l}\text { Travel time to London and } \\
\text { major cities }(20.0 \%) \\
\text { Population density (7.5\%) } \\
\text { Total: } 27.5 \%\end{array}$ & $\begin{array}{l}\text { Regeneration (including Cardiff } \\
\text { Bay) } \\
\text { EU funding and matched } \\
\text { (assumed } 25 \% \text { of total) } \\
\text { Improving trunk roads, rail and } \\
\text { air } \\
\text { Wales Spatial Plan } \\
£ 1448781000 \\
\text { Total:23.23\% }\end{array}$ & $\begin{array}{l}\text { Improvements in transport infrastructure ; } \\
\text { Wales Spatial Plan; Wales Transport } \\
\text { Strategy; Broadband Wales programme (High } \\
\text { Bandwidth ICT) }\end{array}$ \\
\hline $\begin{array}{l}\text { 3. Skills and } \\
\text { Qualifications }\end{array}$ & Total:15.0\% & $\begin{array}{l}\text { 14-19 Learning } \\
\text { Skills For a Prosperous Wales } \\
\text { HEFCW (Reaching Higher and } \\
\text { Capital Budget) } \\
\text { Strategic investment } \\
\text { EU funding and matched } \\
\text { (assumed } 33 \% \text { of total) } \\
\text { £ } 140675000 \\
\text { Total: } 66.38 \%\end{array}$ & $\begin{array}{l}\text { Skills and Employment Action Plan (including } \\
\text { Graduate opportunity Wales); Broadband } \\
\text { Wales Programme (High Bandwidth ICT); } \\
\text { Tailored Policy through Department for } \\
\text { Education and Lifelong Learning; Supporting } \\
\text { Key drivers for individual businesses (skills) }\end{array}$ \\
\hline $\begin{array}{l}\text { 4. Enterprise, } \\
\text { Networks and } \\
\text { Innovation }\end{array}$ & $\begin{array}{l}\text { Web site for external use, } \\
\text { Multinational Ownership, } \\
\text { Public/Private Ownership } \\
\text { (2.5\%) } \\
\text { Unexplained (Innovation, } \\
\text { Enterprise and Geography) } \\
\text { (17.5\%) } \\
\text { Total: } 20.0 \%\end{array}$ & $\begin{array}{l}\text { Innovation and Technology } \\
\text { Enterprise } \\
\text { International Business Promotion } \\
\text { EU funding and matched } \\
\text { (assumed } 42 \% \text { of total) } \\
£ 277433200 \\
\text { Total: } 4.45 \%\end{array}$ & $\begin{array}{l}\text { Business Advice and Support:- RSA } \\
\text { attraction of inward investment: Single } \\
\text { Investment Fund: Knowledge Bank for Wales; } \\
\text { Trade promotion; Public Sector Reform; } \\
\text { Innovation and Enterprise ; Wales: Spatial } \\
\text { Plan: Techniums; Knowledge transfer } \\
\text { initiatives : Support for business innovation } \\
\text { and R\&D; Maximising the economic impact of } \\
\text { academia; Support for Innovation \& R\&D } \\
\text { Centres; Implementation of new technologies } \\
\text { including ICT; Sectoral activities; Innovation } \\
\text { Action Plan; Entrepreneurship Action Plan; } \\
\text { Knowledge Bank for Wales: Single } \\
\text { Investment Fund; Broadband Wales } \\
\text { Programme (High Bandwidth ICT) }\end{array}$ \\
\hline
\end{tabular}

Note: 1. From Boddy (2006) 2. Whilst these may impact upon more than one productivity issue for budget allocation purposes have been allocated to that deemed most relevant;

Source: WAG (2008) 


\section{(e) Business productivity-related policy in Wales: potential strengths and weaknesses}

Discussion with Welsh productivity policy experts highlighted that the Welsh Assembly Government's (WAG) current policies can be seen as having strengths in terms of gathering information and focusing policy on those industries offering strong growth prospects for the Welsh economy, such as opto-electronics, automotive components, aerospace, agri-food and media. Discussions also revealed, however, that the traditional facilitating role of the industry association has (often by default) largely been taken over by default by Government itself, which has established its own forums to bring together participants in the various sectors, e.g. the Wales Aerospace Forum. Comment was made, however, that currently the WAG input into sectoral policy foci, for example, may be concentrating disproportionately on data gathering / sector mapping exercises, relative to network development activity. Policy managers are often perceived as being more like data managers who outsource much of the data gathering activities, representing more "virtual" data hubs than having the in-depth industry linkages able to facilitate network development.

Discussions with policy experts also revealed, that whilst the One Stop Shop approach to business support was likely to be favoured by business organisations - such as the Confederation of British Industry (CBI) and Federation of Small Business (FSB) - because of the greater clarity that it created, concerns were raised that the $90 \%$ of new-firm referrals previously generated by networks such as Business in Focus and Venture Wales - might be undermined by the new approach. Indeed, the danger implied was of a "One door only" approach developing, which might still be ignored by many businesses, particularly small and micro ones. The highlighting of Unitary Authority-based consortia currently looking to administer grants under $£ 5000$ - which might be expected to impact on many micro-level businesses - was also seen as evidence of a gap in the approach, as well as the tendency for support programmes to multiply, making a One Stop shop difficult to maintain. Related to this was an expressed perception that the WAVE strategy implied a much greater focus on growing existing businesses (e.g. through the Knowledge Bank for Business (KB4B) programme) rather than creating new ones; a view confirmed by discussions with policy-making representatives, who argued that Wales's problem was not of too little start-up activity, but rather of growth in existing businesses.

Discussions also highlighted that whilst, for example, the Entrepreneurship Action Plan (EAP) had initial success in raising total entrepreneurial activity, and in terms of lifestyle and low-growth businesses (from specific policy foci on groupings such as female, ethnic minority, Welsh speaking, and youth entrepreneurship); overall growth in firm creation does not seem to have been sustained, and there have been particular difficulties in policy producing high growth firms. Related to this, the view that Wales's problems were not one of entrepreneurship per se, but of growing businesses, was challenged for a number of reasons. First, the high number of sub-Value Added Tax (VAT) registered firms and overall near equivalence of entrepreneurial rates with the UK as a whole was seen as being down to the large rural areas of Wales, the Valleys continuing to have low levels of entrepreneurship. Second, Wales's good recent record regarding entrepreneurship was seen as more linked to UK rates going down than Wales ones going up. Third, it was argued that for small nations like Wales, UK comparisons were less relevant than those with other small countries such as Ireland or Norway. Finally, it was estimated that up to $1 / 3$ of Wales Total Entrepreneurship Activity (TEA) could be attributed to government policy, and thus that there continued to be a need for focused policy in this area, which may not be the case in future.

In terms of Techniums, Abbey et al. (2008) argue that, along with other linked developments at Swansea University, Technium is helping generate a distinct sub-regional innovation system in SouthWest Wales, incorporating many features identified as critical to successful localised collective learning and innovation. There has also been criticism, however, that Techniums constitute more property development and are expensive in terms of cost per direct job. WAG data show that thus far 
the cost has been nearly $£ 190000$ per job created using total cash values (Bristow et al., 2007). In relation to Technium specifically, comment was also made that whilst the early facilities were very successful in recruiting firms, later ones are slower to fill up, raising the question of whether there are diminishing returns given the existing research base in West Wales and the Valleys. Discussions with policy-making actors also identified a need to track the progress of those firms which had left the Technium facilities, and also to ensure that those currently in the Techniums were most suitable. This also related to other comments that whilst the hi-tech related Techniums (e.g. in photo voltaic technology) had had some measure of success, other types had been much less successful, and the absence of Techniums related to sectorally focused policies (e.g. food) was a potential weakness. There was also some questioning of the appropriateness of the Technium approach, given that recent successes in Wales in bio-fuels for example, had been much more via knowledge networks than physical spaces such as Techniums.

\section{Overview of possible policy gaps in the current approach: governance, process and policies}

- Key Gaps may exist in the Governance of Policy formulation (with regard to stakeholders) and the lack of an overall specific business productivity strategy.

- Consequently there may also be gaps in the processes by which policies are created and priorities and resources allocated. Different policy options will have different returns in terms of time, GDP per policy £ spent etc. and this needs to be taken into account when formulating overall policy.

- Specific policy areas where gaps may exist are in areas attached to the role of stakeholders (such as universities and industry) in networked industrial sector organisations, a need for more focus on medium sized firms and possibly specific groups in entrepreneurship policy, and a broadening of the Technium and related innovation promotion policies.

\section{(a) Policy governance gaps}

There is therefore much debate about current policy areas in which policy may be absent, ineffective, or resource inefficient. There has, for example, been much debate as to the coherence and effectiveness of productivity and competitiveness policy in general (see for example, Bristow, 2005), and the role of regional and spatial planning, particularly in the advent of devolution in the UK (see Alden, 2006). Specifically, the advent of Welsh devolution post 1997, problems with inward investment attraction, access to substantial EU Objective One resources post 2001, and increasing importance attached to entrepreneurship promotion all contributed to a change in policy focus over the last decade. Brooksbank et al. (2001) highlighted the increased importance placed on entrepreneurship and skills development in the Welsh Objective One Programme, but also raised issues over its links with previous policy, and the need for spatial targeting given the very different nature of different parts of Wales. They highlighted the very different governance approaches required for "top-down" inward investment attraction and more "bottom-up" entrepreneurship and skills development. Adams and Robinson (2005) criticised the initial economic development strategy document- A Winning Wales, as being weaker than comparator documents in Scotland or Ireland, due partly to less well developed policy-making communities. According to Adams and Robinson (2005), the Welsh Assembly Government has continued to give great emphasis to increasing levels of employment and, particularly more recently, reducing economic inactivity; the focus on inactivity was also reinforced by discussions with policy-making actors. This can be seen as an entirely logical approach in light of both Wales's history and because of its historic importance amongst the reasons for Wales's poor overall relative productivity performance, but it may mean that less specific emphasis has been put on raising business productivity as a result. 
This further highlights that the policy making process requires, in many areas, a collaborative networked approach - both between different tiers of government and also with industry and institutional stakeholders (such as universities) - in terms of both policy formulation and implementation; an area where WAG policy has focused but still faces problems with obtaining effective stakeholder engagement (see Bristow et al., forthcoming). In addition, WAG business productivity policy emphases need to be seen in the light of more restricted resources in some areas, and greater resources in others (particularly the areas of skills, entrepreneurship and innovation, where additional EU Objective One funding is available).

\section{(b) Policy making process gaps}

Unsurprisingly, therefore, when evaluating existing strategy, policy making, and implementation a number of key gaps exist. Discussion with policy-making actors in Wales highlighted recognition that the resources available at the Wales level were limited, both relative to those at the UK government level, and relative to the business productivity problem itself. It was also acknowledged that a specific focus (and degree of success) for resources had been on inactivity in Wales, with relatively small resources available for the other business support activities that may assist in productivity improvements. Currently, however, policy is also often fragmented (i.e. productivity is referred to in various documents, developed at different times, and sometimes in unconnected ways) and is often programme as opposed to policy driven. As a result, there is a lack of clarity in terms of Wales's specific business productivity policy agenda, and how the different policies fit together specifically as a coherent whole. Producing a specific strategy would have a range of benefits in terms of:

- Allowing evaluation of the relative merits of resources focused on the different sets of issues, given a finite resource budget (i.e. "bang for the buck"). If we accept Boddy's (2006) analysis, for example, then it may be theoretically possible to cost different sets of policies against their impact, and thus establish the most efficient way to spend scarce resources.

- Placing relative importance on each of the sets of factors in terms of resources set aside for each policy.

- Acknowledgement of the differing degrees to which policies are within the control of WAG, which would also assist with resource allocation

- Specific evaluation criteria against which to measure success or failure, and from which any need to change policy direction can be discerned.

Table II.5 clearly shows a very strong focus of resources on the education and skills agenda. This could be seen as disproportionate, but there are a number of factors that mitigate this. First, the focus is understandable given the resources available in this area. Second, this concentration becomes even more understandable given that skills and education improvements will also be important factors in reducing unemployment and inactivity in the general productivity gap, as well as assisting in beneficial structural change, and that specifically focused unemployment and economic inactivity resources are largely controlled at the UK level. Indeed, it would be logical to treat skills and qualifications, and unemployment and inactivity as part of the same set of policy issues. Table II.5 also indicates a broadly proportionate focus on connectivity and space issues. It is therefore in the "Structure" and "Enterprise, Innovation and Networks" policy areas where there appears to be a potential relative importance to productivity-resources mismatch or gap. To an extent this may be explained by lower policy effectiveness, given that it is industry and institutional stakeholders themselves who ultimately need to effect change, with government playing a much more facilitating 
and much less directing role. Crucially, however, it also highlights a need to enact policies which will maximise the impact from these limited resources.

\section{(c) Policy focus gaps}

Interviews with policy experts in Wales, however, highlighted a number of areas where gaps in existing policy might exist. In terms of sector policy for example, some policy experts argued that there needed to be increased facilitation of the emergence of stronger representative organisations across Welsh industrial sectors (i.e. to replace the often government dominated forums that currently exist - e.g. see Clifton et al. (2008) for aerospace), to create enhanced co-operation capital between companies as well as with higher education institutions and government.

Comment was also made that current entrepreneurship policy in Wales, whilst it gave support to new and young businesses and large well established businesses, may be less focused on the middle sized (£5m - £20m turnover) firms upon which much growth was likely to depend; the danger being that these firms continued to fall between policies, unless sufficient advisors were employed and the mid-sized firms identified. There was also some questioning of the move towards "mainstreaming" entrepreneurship policy as opposed to focusing on specific groups, as had happened originally.

Potential gaps were also highlighted in terms of innovation policy. For example, given that Technium was never intended to be a wholesale innovation policy, it was suggested that Wales could benefit from a kind of sub-technium programme aimed at getting start-ups from these institutions, in firms not necessarily at the cutting edge of technology but which still contribute to the economy's overall knowledge profile. The importance of developing and growing hi-tech entrepreneurial capacity (e.g. as Israel was said to have done via an influx of scientists) also raised the question as to whether more attention should now switch to complementary activities such as training, mentoring, business planning etc., as well as attracting in more Technium tenants from outside Wales.

\section{Potential policy options to address Wales's challenges}

* Relevant Policy options revolve mainly around skills development and enterprise, innovation and network development.

* Specifically identified areas for development are as follows:

- An overall policy making process that successfully incorporates the full range of stakeholders involved in a regional economic development process, in ways that improve business productivity outcomes.

- Effective industrial sector / cluster activities that build a viable networked approach between industry, universities and government to achieve business productivity raising outcomes.

- Inter-related innovation creation, knowledge transfer and entrepreneurial utilisation activities that improve overall business productivity for the firms effected.

- Best practice business development policy delivery mechanisms that promote improved entrepreneurial outcomes in terms of both the number and growth of these firms.

* The 10 interventions discussed focus on one or more of these areas. 
Table II.6: Broad range of possible business productivity policies

\begin{tabular}{|c|c|c|c|}
\hline $\begin{array}{l}\text { Productivity } \\
\text { issue: }\end{array}$ & $\begin{array}{l}\text { Boddy (2006) } \\
\text { calculated effects } \\
\text { of policies on } \\
\text { productivity gap }\end{array}$ & $\begin{array}{l}\text { Broad additional potential policy areas (derived from previous } \\
\text { research into the Welsh productivity issue by Boddy (2006) and } \\
\text { Crafts (2007) }\end{array}$ & $\begin{array}{l}\text { Policy } \\
\text { suggestion } \\
\text { source }\end{array}$ \\
\hline \multirow[t]{3}{*}{$\begin{array}{l}\text { Structure: } \\
\text { (Economic } \\
\text { Capital) }\end{array}$} & \multirow[t]{3}{*}{$\begin{array}{l}10 \% \text { capital stock } \\
\text { increase produces a } \\
2.9 \% \text { increase in } \\
\text { productivity }\end{array}$} & $\begin{array}{l}\text { Encourage altered industrial structure or ownership towards more } \\
\text { capital intensive businesses via more specific business support, or } \\
\text { encouraging investment, including IT, by businesses in specific, } \\
\text { under-capitalised sectors (such as hotels and catering, small } \\
\text { businesses in the tourism) via specific policy measures. }\end{array}$ & Boddy (2006) \\
\hline & & $\begin{array}{l}\text { Promotion of high productivity sectors such as construction via } \\
\text { government demand policy. }\end{array}$ & Boddy (2006) \\
\hline & & $\begin{array}{l}\text { Greater Freedom over fiscal and industrial policy to incentivise } \\
\text { increased capital stock. }\end{array}$ & Crafts (2007) \\
\hline $\begin{array}{l}\text { Connectivity and } \\
\text { Place } \\
\text { (Public Capital) }\end{array}$ & $\begin{array}{l}10 \% \text { reduction in } \\
\text { travel time increase } \\
\text { productivity by } \\
0.6 \% \text { ) } \\
100 \% \text { increase in } \\
\text { population density } \\
\text { increases } \\
\text { productivity by } \\
1.1 \% \text { ) }\end{array}$ & $\begin{array}{l}\text { Improvements in transport infrastructure. } \\
\text { Policies focused on the Cardiff-city region to increase its connectivity } \\
\text { to surrounding areas, and its locational attractiveness for inward } \\
\text { investments in higher value added activities, and as a location for } \\
\text { "creative-class". } \\
\text { Renewed focus for infrastructure development and urban renewal on } \\
\text { Swansea (and Newport) as the next largest urban areas. }\end{array}$ & Boddy (2006) \\
\hline $\begin{array}{l}\text { Skills and } \\
\text { Qualifications } \\
\text { (Human Capital) }\end{array}$ & $\begin{array}{l}10 \% \text { increase in } \\
\text { NVQ } 4 \text { qualifications } \\
\text { produces } 1.2 \% \\
\text { increase in } \\
\text { productivity; } 10 \% \\
\text { increase in NVQ } 2 / 3 \\
\text { increases } \\
\text { productivity by } \\
1.6 \% \text { ) }\end{array}$ & $\begin{array}{l}\text { Medium and higher levels skills development simultaneously } \\
\text { required, but must be related to improved demand conditions for such } \\
\text { labour to avoid loss of such labour to other areas. NVQ } 4 \text { level } \\
\text { qualifications in particular must be linked to higher employment } \\
\text { opportunities creation \& graduate retention- linked to improvements in } \\
\text { location both from aesthetic and employment opportunity perspective } \\
\text { General NVQ } 2 \text { / } 3 \text { for existing workforce through part-time and } \\
\text { distance learning, and tied specifically to needs of local business to } \\
\text { upgrade performance of existing business. }\end{array}$ & $\begin{array}{l}\text { Boddy et al. } \\
(2006)\end{array}$ \\
\hline \multirow{5}{*}{$\begin{array}{l}\text { Enterprise, } \\
\text { Networks and } \\
\text { Innovation } \\
\text { (Change Capital) }\end{array}$} & & $\begin{array}{l}\text { Identification of management style and qualities in MNEs that may } \\
\text { account for productivity differences and are transferable. }\end{array}$ & Boddy (2006) \\
\hline & & $\begin{array}{l}\text { Strong focus on rapid diffusion and then utilisation of innovations } \\
\text { related to products, processes and technology and managerial } \\
\text { approaches which have been shown to improve business } \\
\text { productivity, both singly and in combination. }\end{array}$ & $\begin{array}{l}\text { Adams and } \\
\text { Robinson (2005) }\end{array}$ \\
\hline & & $\begin{array}{l}\text { Potential economies of scale from larger public sector agencies may } \\
\text { suggest promotion of these types of public sector activities, as well as } \\
\text { public sector focus on value added. }\end{array}$ & Crafts (2007) \\
\hline & & $\begin{array}{l}\text { Encouragement and funding of R\&D into leading edge innovation of } \\
\text { relevance to business productivity (but of secondary importance to } \\
\text { dissemination and utilisation of existing innovations), also linking in } \\
\text { with entrepreneurship issues. }\end{array}$ & Boddy (2006) \\
\hline & & $\begin{array}{l}\text { Regional Collaborative Measures designed to both improve business } \\
\text { productivity directly and also develop networks for the future in this } \\
\text { regard. } \\
\text { Examples include: Industry Collaborative Measures; Developing New } \\
\text { Innovation; R\&D Loans Programme; Developing Collaborative R\&D } \\
\text { Centres; Inter-University Institutes; Internal and External Networks; } \\
\text { Promoting Supply-Chain led Innovation; Supporting Innovation } \\
\text { Networks in Services Cluster-based Policies }\end{array}$ & Roper et al. (2007) \\
\hline
\end{tabular}

It must be recognised, however, that some of the potential policies highlighted in Table II.6 are unrealistic for WAG implementation given the current political settlement (e.g. those related to having different fiscal policies in Wales compared with the rest of the UK). Table II.7 indicates the proportion of devolvement that Adams and Robinson (2005) identified in their study in areas that could be linked to factors important to business productivity. Adams and Robinson (2005) also identified a range of 
business productivity-related policies, focused on clusters policies, science parks, and the knowledge economy in particular (specifically focused on in the last set of issues in Table II.6), into which the UK (and EU) also has significant input and thus control.

Table II.7: Proportion of devolvement of activities 2004 spending review

\begin{tabular}{llc}
\hline \multicolumn{1}{c}{ Area } & \% Devolvement to Wales \\
\cline { 2 - 3 } & Health & $99.6 \%$ \\
\cline { 2 - 3 } & Education and skills & $93.5 \%$ \\
\hline & Culture media and sport & $89.1 \%$ \\
\cline { 2 - 3 } & Environment and rural affairs & $80.4 \%$ \\
\cline { 2 - 3 } & Transport & $63.8 \%$ \\
\cline { 2 - 3 } & Trade and industry & $18.6 \%$ \\
\cline { 2 - 3 } Work and pensions & $6.4 \%$ \\
\hline \multirow{2}{*}{ Derived from Adams and Robinson (2005) }
\end{tabular}

Boddy (2006) argue, further, that little is possible in the way of direct policy leverage in overall capital stock investment and thus that indirect policy, such as encouraging investment (including IT) by businesses in specific under-capitalised sectors such as hotels and catering or small businesses, may be more effective but is still likely to be limited. Related to this, they also argue that the ability for government-policy-created adjustment of overall industrial structure is relatively small and indirect, though direct promotion of high productivity sectors such as construction is potentially possible through direct demand (i.e. government contracts). Crafts (2007) sees this as difficult, however, particularly without greater freedom over fiscal and industrial policy (which the Republic of Ireland enjoyed but which Wales does not). In addition, the further attraction and exploitation of resource transfer from multinationals into Wales - which, according to Hill and Munday (1992) was largely built on regional aid, relative wage levels and infrastructure spending - is becoming much more difficult (particularly given the rise of China). There is also a need to understand that policy focused in one area (i.e. productivity) may create deleterious effects for other areas also deemed important. For example, as Boddy (2006) points out, higher level skilled workers are more mobile and thus policy here runs the risk of encouraging more out-migration (though this can be ameliorated by a greater focus on the lower end of the skills value chain). Policies that increase the concentration of economic activity (e.g. in Cardiff and the other larger cities) to generate agglomeration effects will also adversely affect spatial equity within Wales.

Another important issue to take into account, when examining business productivity policy options, is the degree to which government policy can or should influence the situation. Crafts (2007) highlights, for example, that the differences may largely represent the outcomes from equilibrium regional disparities (see Rice and Venables, 2003), rather than market failure per se. In the equilibrium scenario for example, London, with its great agglomerations in key sectors such as financial and businesses services, consequently enjoys relatively high wages, and in-migration of skilled workers, as well as high relative house and untraded goods prices. According to Crafts (2007), therefore, the fact that real Gross Disposable Household Income per income in 2005 (which accounts for cost of living differences and is a measure of living standards) was $95.9 \%$ of the UK average (and only $12.1 \%$ below London) indicates that the differences are largely the consequence of market equilibrium rather than market failure. This does not explain, why the agglomerations occur in the first place, but does highlight a crucial need to understand the extent to which government policy can actually affect the situation. 
Business productivity raising policies are seen as necessary because of issues related to market failure, particularly regarding flows of information. For example, pure market interactions generally prove incapable of transmitting the qualitative information needed for developing new products in interaction between firms (Maskell, 2000). This 'market failure' for the exchange of knowledge centres around the need for the buyer to know the specific merit of the knowledge in question before purchase, while sellers are simultaneously unwilling to divulge these details as this effectively means the potential buyer will have acquired it gratis. Therefore under these conditions, no exchange will take place (see Arrow, 1970 for a full account of this issue). Market failure therefore provides a justification of policy interventions designed to facilitate better and greater knowledge exchange, either indirectly by enhancing networks and trust, or by taking a direct role as a knowledge broker and/or actual provider of various types of knowledge.

Given such issues concerning control, impact and availability of resources highlighted earlier, it is unsurprising that, as Roper et al. (2007) highlights for Scotland, the specific focus for new government policies is often placed on economic structure-enhancing and related issues - through enterprise, innovation and network development policies, particularly between industry and universities - in order to assist more generally in the creation of the necessary social infrastructure or change capital for productivity enhancement. Recent Scottish research conducted into innovation policy (www.scotland.gov.uk/Resource/Doc/170949/0047879.pdf) also highlights, however, a general problem in the use of universities more broadly because of potential mismatches between knowledge generation and the local needs / absorptive capacity of local small and medium sized enterprises (SMEs). This was in contrast with University-foreign multinational links, which in Wales could be seen as fitting with the previous Regional Innovation System highlighted by Cooke (2003). In addition, work by Cooke et al. (2005) and Cooke and de Laurentis (2006) emphasises the potential importance of cross-locational links in the development of successful firms in many knowledge-based industries. This must also be seen in relation to the resource constraints for both economic development policy in general, and HEI activity in particular.

In addition, although the statistical analysis shown earlier allows the decomposition of the business productivity issue into individual factors, in reality these factors will be overlapping. Policies to overcome the productivity gap may thus simultaneously affect more than one of its causes. It is also the case, however, that the WAG policies identified are often not framed specifically in terms of the business productivity-raising agenda (i.e. as part of a specifically named business productivity strategy). More broadly, for example, discussions with policy experts raised questions over the linkage between WAG policy (e.g. Innovation Action Plan) and Objective One policy outcomes. Clearly, an overall evaluation of the impacts is likely to only be viable sometime in the future, but this would seem to be best achieved within an overall productivity policy and evaluation framework. However, whilst the 2006 Wales Science Policy can be seen as a partial successor to the Innovation Action plan, there seems to be a specific need for an overarching reconstitution of an integrated innovation policy with the specific focus on productivity, possibly related / integrated with the Entrepreneurship Action Plan as well as other relevant policies.

The key WAG policy challenges for strengthening business productivity in Wales (identified from sections 1,2 and 3) would thus seem best to revolve around maximising the beneficial impacts from a specifically designed set of inter-related business-productivity raising policies focused on creating high-growth entrepreneurship, innovation and network enhancing outcomes and assisting more generally in the creation of the necessary social infrastructure or change capital for business productivity enhancement. Specifically, 4 identified areas for policy development are as follows: 
1. An overall policy-making process that successfully incorporates the full range of stakeholders involved in a regional economic development process, in ways that improve business productivity outcomes.

2. Effective industrial sector / cluster activities that build a viable networked approach between industry, universities and government to achieve business productivity raising outcomes.

3. Inter-related innovation creation, knowledge transfer and entrepreneurial utilisation activities that improve overall business productivity for the firms affected.

4. Best practice business development policy delivery that promotes improved entrepreneurial outcomes in terms of both the number and growth of these firms.

The 10 interventions discussed in section 5 unsurprisingly fall into one or more of these areas.

\section{Potential role of reviewed initiatives in filling gaps and other lessons offered}

* The following initiatives are to have the most immediate transferability potential in terms of applicability, complementarity and speed of implementation: Regional Growth Agreements; K-Plus Competence Centres; Hothouse Incubator Policies; Innovation Vouchers and (assuming a long-term evaluation framework of impacts) New Industrial Clusters.

* The specific areas where transferability was most relevant were in terms of networked policy making and implementation; and in innovation creation, dissemination and utilisation mechanisms, particularly via use of university facilities and knowledge bases and building firm innovation capacity.

* Complementarities and overlaps with existing WAG policies, in terms of elements of WAVE, Techniums, incubation and sectoral policies, in particular, were found.

* Specific lessons for policy development revolved mainly around creating and developing networks and network capital (particularly between universities and between universities and firms), providing incentive for university collaborations with other stakeholders, and the need for further development of targeted policy (spatial, sectoral, university-type and firm-size related).

Each of the reviewed initiatives is briefly summarised, followed by an in-depth exploration of their relevance and lessons from them. The methodology adopted utilises relevant secondary data analysis supported by interviews with experts from relevant areas of industry, government, or academia who were asked to comment on the potential policies and similar ones in Wales (where applicable). This approach follows that of Roper et al. (2007), Clifton et al. (2008), Pickernell, et al. (2008) and Welsh Economy Research Unit (2002). These views were also, fed back to the authors of the original potential policy summaries, to ensure that problems of misinterpreting the potential policy information did not occur. Broadly, the analysis revolved around a summary of the initiative, potential transferability to the Welsh situation, complementarities with current Welsh policy, as well as any issues which might require adjustment in the potential or existing Welsh policy.

\section{Broad productivity policy - providing a broad spatial regional growth framework for general policy making milieu and networking creation: Vastra Gotaland regional growth agreement, Sweden}

Overview

This intervention is of particular relevance because of the similar political and economic circumstances in which Vastra Gotaland (VG) and Wales found themselves in the late 1990s. Since then, however, Vastra Gotaland has undertaken a relatively successful transition from a predominantly 
industrial region toward one based upon more knowledge-intensive and higher-value added economic activities in both manufacturing and services; aims which WAG also wishes to follow. The principal instrument of the new growth-oriented spatial policy was the introduction of Regional Growth Agreements (RGAs) (tillväxtavtal) that emphasised the regional foundations of economic growth, localised learning and the effectiveness of decentralised spatial policy. RGAs were thus established to co-ordinate and adjust sectoral policies, to better exploit unique regional potential and mobilise regional actors to explore new approaches to regional and local development. The RGAs have since evolved into three year Regional Growth Programmes (RGPs) (tillväxtprogram) (2004-07) with a greater emphasis upon promoting clusters and innovation systems regionally. A number of specific lessons identified as of use to Wales are:

- A systematic and process-based approach to sustainable territorial development which emphasises the need for thorough analysis and strategic planning on an ongoing basis, and that feeds into an evolving development strategy over time.

- An inclusive and broadly-based approach to establishing the RGA partnership which provided a means for tapping into local knowledge, consensus-building and identifying priorities with regional and local growth potential. Adaptation has been necessary amongst public institutions and their staff, for example, to work within broader and more diverse partnerships.

- A focus on policy learning and capacity building through elements such as the new Centre for Regional Analysis at Göteborg University. An evaluation panel for the recent Vision Västra Götaland and postgraduate study for staff development to improve their capacity for strategic and long-term thinking, and connecting and integrating projects into coherent themes.

- The importance of alignment and co-ordination of strategies within a multi-layered governance structure, to achieve connection and complementarity between strategies and frameworks working at different territorial scales and, in some cases, areas.

- An approach to spatial planning, in particular, where regional balance is a key element in the new RGP dialogue, but with a desire that regional resources are maximised for the whole region. There is therefore a focus on maximising economic potential rather than having a resource redistribution approach. The competence networks established as part of the regional innovation system can thus be spread out and connect, for example, the rural areas. The handling of the contribution of dominant cities and their relationships with their broader regions is also instructive, particularly given the concerns about the balance of spatial development across Wales. Region VG is careful not to centralise too much in Goteburg and tries to use specific projects to connect and link growth developments across the wider region. This would appear to be an important issue in the context of the Cardiff city region and Wales. An opportunity for mutual policy learning across a range of productivity-raising activities is also possible in terms of clusters/sector, increasing workforce participation and inactivity.

\section{Evidence of policy effectiveness}

Available evidence of the policy's effectiveness conclude that it has been an important tool for coordination and co-operation between regional and local actors and played a contributory role alongside a favourable international macroeconomic context in the region's recent economic change, supporting its attempted transition toward a more knowledge-intensive economy. Västra Götaland had experienced a decade (1994-2004) of relatively strong growth and GDP and employment rates were $99 \%$ and $73 \%$ of the national average respectively (119\% of EU average). The number of jobs 
increased by 4300 from 1994, mostly in the city of Göteborg and its surrounding region. Västra Götaland has also had a strong performance in levels of R\&D investment and the growth of new technology-based firms in recent years, especially in the leading science parks in Göteborg. At the same time, productivity and investment levels have improved alongside new firm formation rates. Sectorally, the region has also become dominated by services (82\% GDP), suggesting a relative evolution away from the historical dominance in its economic structure of manufacturing industries. However, there is still a sizeable manufacturing sector (18\%). Regional public finances and property prices have also benefited from rising prosperity within the region.

\section{Elements of policy that are adoptable or adaptable to the Welsh context}

The Vastra Gotaland RGAs can therefore be seen as successfully combining elements already in existence in Wales, in terms of overall economic development (Wales a Vibrant Economy) and spatial strategy (Wales Spatial Plan), as well as sectoral and innovation policy elements. There thus appears to be a good basic existing platform on which to build. The policy making process in Vostra Gotaland also involves a greater recognition of the importance and integration of key stakeholders in knowledge and innovation (particularly universities) within regional contexts. This promotes both better policy making and greater "buy-in" to the decisions made, supported by analysis and research from a National Institute for Growth Policy.

This would seem to provide Wales with a general template within which to integrate a number of key policies, a more inclusive policy-making process, and specific lessons to learn, both positive (ideas to adopt / adapt) and negative (weaknesses to take account of). Evaluation by two policy experts (one examining the planning and spatial aspects, and the other the economic development aspects), reinforced this and highlighted a number of specific issues to take into account. Discussion with policy practitioners also highlighted that whilst there were a plethora of initiatives in Wales, there was question as to how well these currently fit together. Reconcilation of these types of policies is currently undergoing consideration, making the Vostra-Gotaland example extremely relevant to current debates. In terms of specific areas for adoption / adaptation:

- Although Wales and Vastra Gotaland are currently utilising very similar sets of policy ingredients, the overall outcomes appear to be different. In particular, successful adoption / adaptation of the Vastra Gotaland experience requires adoption of a policy mindset that moves away from top-down, economic redistribution-based focus and unintegrated policies, towards more of a bottom-up policy generated focus on maximising value added from regions based on their potentials.

- An explicitly articulated, "joined-up" approach to and designation of a "Productivity policy" was also seen as important, creating a structure that acknowledges and utilises the overlaps in different existing policies within a broad framework.

- In order to do this, a much more detailed overall economic analysis of areas of growth potential (within the framework highlighted by Vostra Gotaland) is a necessary first step.

- In addition, this policy needs to engage more directly with business than current policies (such as the Innovation Action Plan and aspects of Objective One) appear to have done. 


\section{Innovation and cluster policy - stakeholder networking and integration public infrastructure in hi-technology clustering sectors: Hokkaido new industrial cluster policy, Japan}

\section{Overview}

Hokkaido, has a larger population than Wales (5.6 million), a much larger "capital" (1.8 million), and an innovation system that comprises a wide number of actors, including 34 (national, private and public) universities and 32 public research institutions. In comparison to other Japanese regions, there has been a tendency for less engagement between Hokkaido's Universities and large firms; as well as a lower concentration of R\&D activity, most of which is conducted by SMEs. Like Wales, it has an industrial structure where agriculture, forestry and fisheries are relatively large, as are government services, whilst graduates face difficulties in obtaining employment. Broadly, therefore, Hokkaido and Wales face a similar need to develop an innovation system to help produce a more knowledgeintensive mix of industries and employment. In terms of Hokkaido's industrial cluster policy, the following lessons are of particular importance:

- Considering the strong R\&D element it is likely that the true costs and (more particularly) benefits may only become visible up to 20 or more years after the initiative is introduced. For example, on an annual basis, Japanese national government funding is equal to around $£ 50 \mathrm{~m}$ per annum during the first stages of the METI and MEXT programmes and equivalent to around $£ 60 \mathrm{~m}$ per annum during the second stages. Against this, the directly observable measurable outcomes appear rather modest. Observations thus far include only 2871 jobs and 7 Initial Public Offerings (IPOs) created in the Information Technology (IT) sector (2001- 2006); and 192 jobs, 25 bi-venture companies, 1 IPO, 9 products, 22 IP rights and 100 collaborative projects in the biotechnology sector (2002-2006). In the short run, therefore, these policies are likely to appear expensive with a consequent need for strong and continuing political support.

- Of the two initiatives examined (biotechnology and IT), biotechnology appears to be the more dynamic with the greatest growth potential, as well as having the most relevance to the Welsh Strategic Framework for Economic Development (WAG 2005: 13) and the outlined strategic sectors.

- Networking initiatives and interactions between different sets of actors are the key elements to how Hokkaido's regional innovation cluster is developing. This should include a broad range of firms, venture capital, the universities and government. The overall underlying consensus amongst actors in Hokkaido towards the cluster initiative may also be important, as this is recognised as a strength of the initiative. In order to help promote an underlying consensus, there is a perceived need to limit the number of organisations involved and employ personnel with private sector experience. This is also important because of the resulting supply side issues that success could create, for example, in terms of availability of human resources.

- Allowing researchers involved in technological projects to interact at an early stage with other actors in university, industry and government is of crucial importance, with support being provided in terms of information network structures and physical facilities in the form of incubation centres.

\section{Evidence of policy effectiveness}

Considering that both of the initiatives have a strong R\&D element, the available evidence of policy effectiveness is understandably at an early stage. As stated earlier, overall costs and benefits 
might not be visible for 20 years or so after the initiative is introduced. It is difficult to assess the overall significance that the initiative has had at this stage. However, over the long term, significant network effects (the creation or assistance of local firms through the implementation of joint projects and information support) may enhance the overall project performance. The evidence suggests that there have been changes in the IT and bio sectors in Hokkaido, but it is perhaps still too early to judge the proper role that policy has played. Nevertheless, available survey responses from participating firms have tended to endorse the cluster policies.

\section{Elements of policy that are adoptable or adaptable to the Welsh context}

Broadly, this example emphasises that an "innovation infrastructure" in terms of social (networking), physical (incubators), and intellectual (information) elements is important. It also reemphasises the overlaps between policies (in this case innovation and cluster / sector policies), thereby highlighting the importance of explicitly linking these together (as the Vastra Gotaland example showed). In Wales this would initially require mapping the current piecemeal of policies in this area, determining how they fit together (within a Vastra-Gotaland type spatial-productivitysectoral policy); where gaps exist in policy, institutions, and relationships; and how they might link together in future. Networking and early stakeholder involvement is important for many of the cluster types that Welsh policy is trying to encourage. This revolves around the need to generate "cooperation capital". Any potential Welsh policy based on the Hokkaido experience would also need to recognise the issues concerning the key role of HEI stakeholders and similar institutions, who often get more recognition for international research activities and much less for beneficial impact on the local economy (or co-operation with each other). A situation which was compared unfavourably with technology institutes in Norway, for example. In terms of the specific elements that are adoptable / adaptable, therefore:

- The support provided by government and university stakeholders needs to include information and network structures as well as physical facilities in the form of incubation centres. It is also crucial for this type of initiative that the researchers involved in the actual technological projects interact at an early stage with the other actors from university, industry and government.

- The requisite networking initiatives and interactions between different sets of actors should include from the start a broad range of stakeholder types, including firms and government, but also venture capital and universities. To promote greater consensus and market-focused outcomes, there is a need to strictly limit the number of organisations involved and to employ key personnel with private sector experience.

- Discussions with policy-making actors highlight that this approach may be best applied in the already identified "core" sectors of ICT, energy, environmental service and transport. Productivity improvements in these sectores are most able to spill over into the economy as a whole, to multiply the benefits. Such a focused approach, with public policy attention on the core activity of mitigating climate change through a variety of technologies with spillovers into the general economy (via food, energy, manufacturing processes, transports, etc.), was suggested by one commentator, as the best focus for adoption of this type of policy.

Overall, policies which encourage and incentivise university cooperation and collaboration (both with other universities and with industry) are important and should be encouraged. 


\section{University-located innovation creation: K-plus Competence Centres, Austria}

\section{Overview}

The Austrian Kplus-programme can be seen as just such a policy, inspired by a variety of similar programmes from around the world, such as the Swedish NUTEK-centres, the Australian Cooperative Research Centre (CRC) Programme and the Canadian Networks of Centres of Excellence Program. It provides additional exemplars and learning opportunities, as well as highlighting a popular policy that other governments are focusing resources upon. The aim of K-Plus specifically was to link industry and universities to increase the quality of research, rather than focusing on particular research areas. Whilst the programme resulted in a stronger focus on certain areas, few of these areas were new. Lessons highlighted from the Austrian experience, for Wales specifically, include:-

- Transferability potential of the programme is high, particularly given additional related examples.

- Critical mass in research at a high level can be actively stimulated by public policy in regions of similar size to the Cardiff region in particular. However, innovation policy makers should first talk to universities and industries established in Wales, to get a first impression of whether, and in what industries, this could be enacted.

- Care is required as to whether to emphasise science and knowledge of a pre-competitive nature or near-market innovation. Pre-competitive knowledge-building time horizons are longer than for innovation oriented research centres. Gains for economic development are likely to be higher when resources are concentrated on use-inspired research.

- Wales would need to ensure that necessary leverage over universities exists in order to design cooperative centres appropriate for the purpose required. Given that these competence centres can be set up as independent legal entities, leverage may involve attractive funding and research perspectives. Therefore, it is partly a question of adjusting research and funding incentives currently available to Welsh universities.

\section{Evidence of policy effectiveness}

The available data indicates that the Kplus centres have been quite effective in meeting the objectives of the overarching programme. At the innovation system level, a major success is the institutionalisation of a new culture of cooperation between science and industry. Evidence for a successful linking of both sectors comes from data on cooperative behaviour and from additionality surveys. Research collaboration is now of greater importance for Kplus firms than for non-Kplus firms; the share of contractual R\&D rose from 10\%, at the beginning of the programme (1997/98), to $22 \%$ at the first interim evaluation in 2001/2. Kplus industry partners also spend far more money on external research than innovative non-participating firms. In terms of innovation behaviour, survey data indicates that before Kplus, firms assessed the importance of contractual research at 2.53 (on a 5point scale, where $1=$ not important and $5=$ very important), whereas after participating the mean importance was 3.44. Importance of co-operative research increased from 2.56 to 3.38; whilst the importance of universities, or other higher education institutions, as an information source for Kplus partnering firms reached 2.00 (on a 0-3 scale) versus 0.62 for Kplus-non-partnering firms. Only $5 \%$ of firms said that they would have carried out projects without the respective competence centre; onethird would not have been able to carry out the project at all; while the rest would have carried out the projects, but with limited resources, scaled-down objectives and a different duration. At the firm level, private R\&D expenditures were given incentives, e.g. follow-up projects were often the result of a first cooperation within a Kplus-centre. The research projects within Kplus are higher-risk, technologically 
more complex and longer-term in comparison with intra-mural firm $\mathrm{R} \& \mathrm{D}$, pointing to a change in firms' innovation behaviour towards more strategic R\&D activities.

\section{Elements of policy that are adoptable or adaptable to the Welsh context}

The risks for firms participating in a collaborative research centre are relatively low, and thus may be seen as more palatable, producing spillovers of process in particular, as well as product innovation. Roper et al. (2007) provide valuable evaluation material (in their case of the NUTEK Swedish centres), of relevance here. Roper et al. (2007) suggests that experience from similar collaborative research centres elsewhere (e.g. Question Centre at Queens University Belfast) implies potential for additional spin-out and start-up companies being generated from this type of initiative. There is also potential for supporting mechanisms, such as creating enterprise fellowships to provide academics with opportunity to explore preliminary research undertaken in the collaborative research centres. If conducted in conjunction with access to entrepreneurship education and support for commercialisation, the consequent exposure of academics to industry-relevant research may also be important in leading to spin-out companies by academics. A problem with this approach, however, is that the focus of the Austrian programme was less on spin-outs and more on research in existing firms; upgrading; changing the innovation behaviour of the firms towards more strategic and larger scale R\&D; and towards routinely cooperating with outside knowledge sources in the innovation process. For university spin-outs, there are different programmes in Austria (AplusB) in essentially publicly funded incubators. There was thus the potential that firms financing/participating in Kplus centres (and thus possible similar entities in Wales) would not be supportive of attempts to generate spin-outs because it would complicate the sharing of IPR and lead to the emergence of new competitors. There is therefore the risk of firms withdrawing their support from the centres, unless the spin-outs have their business focus in totally unrelated areas.

Another related downside highlighted in the Roper et al. (2007) evaluation of the NUTEK example for Scotland, was that many Higher Education Institutions (HEIs) did not see the benefit of this policy specifically. Instead they saw it as duplicating what other policies were already doing. They were also concerned that insufficient numbers of firms would come forward to make such centres viable. In Wales, specific comment was made as to the applicability of the K-plus Centre approach, given that existing medium and large firm capacity for cutting edge, near-market innovation was relatively small. It was felt that if the creation of such centres were as well resourced as the K-plus centres appeared to be then this might require a pooling of resources currently being utilised for associated policies, and thus help assist in making the policy more system-oriented. It was pointed out, however, that this placed a major responsibility on any created centres to not merely reinforce existing technology foci, but to focus on innovations most likely to raise productivity.

In Wales the majority of Research is carried out in a very small number of universities, particularly Cardiff University. This creates a critical mass, but also potentially restricts the geographic spread of the benefits of the policy to Cardiff and surrounding areas. Comment was also made that in the current Welsh technology and innovation policy there was often evidence of historical policy "lock-ins" and path-dependencies. This meant that support was often focused on seperate individual "key" technologies, new-to-market breakthroughs, or physical facilities. It was felt that there was consequently too little focus on converging and combining existing technologies. These often less tangible process technologies and incremental product improvements, the knowledge of which is often brought in from outside, could be applicable to a wider range of firms. It was therefore deemed crucial that innovation policy be both more outward-looking and based on increased collaboration and combination of policies - areas currently seen as relatively weak in Wales. 
It was also commented that in many cases the triple helix actors of university, industry and government worked more as separate "islands" of innovation, with too little interactivity within a coherent system, and a consequent need for facilitation of these relationships. If Wales chooses to focus on those innovations most likely to raise productivity, then the Austrian model of the K-Plus type programme design will need to be adjusted. For example, rather than involving an open call for centres a much more focused approach will need to be taken. It is thus crucial that if contemplating a similar policy in Wales, it is integrated within a wider explicit policy agenda to promote synergy and complementarity rather than duplication. The K-Plus policy in Austria was used precisely to overcome the problem of universities and industry following distinctly different research paths. The incentive for the firms to participate was the relatively high levels of public funding (possibly due to the closeness to basic research) and research in common with university researchers. Some of the wider explicit policy agendas to promote synergy and complementarity could thus be achieved by a K-Plus type programme itself. In particular, the need to promote firm use of university links would seem of importance. Specific elements that are adoptable / adaptable are therefore:

- Adapting a K-Plus arrangement to be more in synergy with other innovation support measures in Wales, particularly those focused more directly on exploitation, could act as a stimulus for more project funding through knowledge transfer programmes (KTPs) and may also better fit with other policy initiatives examined in this document.

- This would need to be accompanied by identification (or capacity building) of medium and larger firms able to take advantage of the policy, with a specific initial focus on innovations (both singly and collectively) most likely to raise productivity quickly (and adaptation of the K-Plus system), where more long-term cutting edge research was seen to be being undertaken.

- If the policy is to generate wider geographical benefits, there is a need for further development of research collaborations between universities in Wales to provide critical mass, within an integrated policy, that encourages firm-university links.

This suggests a multi-strand approach, where university-based business creation (e.g. incubators) can emphasise the applicability of university knowledge; policies to actively promote firm links with universities (e.g. K-Plus type) can reinforce this use for existing firms; and policies to increase firms' R\&D capacity may assist in generating demand for these links. The next 3 policy options can also be seen as relevant to these strands.

IV. University-located hi-technology business creation, enterprise and innovation focus, with hitechnology skills retention secondary effect and relevance to WAG Technium and university incubator policy: Hothouse Business Incubator, Ireland

\section{Overview}

Hothouse is different from many UK incubator programmes in that the programme of support and the entrepreneurial environment, rather than the physical space itself, were seen as more important. Indeed, it was seen as more of a training and enterprise development programme by some commentators. The main highlighted lessons for Wales, from this type of policy, are as follows:

- The need to treat Hothouse and university incubator-related policies within the wider regional and national policy environment. Specifically, linking and coordinating enterprise policy with skills and education policy (which from the Vastra Gotaborg example requires policy dialogue, broad horizontal consensus on purpose, objectives and expected outcomes), joint implementation, and ongoing funding. 
- Policy requires concrete objectives and robust evaluation procedures established at the start, as well as resources to implement policy and evaluation.

- Third level colleges and university colleges in today's information and knowledge societies have a core role, and potentially part ownership, in enterprise policy. If these colleges fail to perceive this opportunity, then enterprise policy at both national and regional levels and its implementation may be deficient. Accepting more responsibility for enterprise policy can represent a 'mind change' for college management. Therefore, maximising the benefits of incubator programmes requires committed leadership and support from college managements based on recognition of their core role in education and training policy, but also in enterprise policy development and implementation.

- The role of management and operating ethos of the incubator is not necessarily fully dependent on the attitude of college management. Hothouse was more innovative and led development more than college management, highlighting the need for a culture and services ethos by management.

- Development of international links between Wales and Ireland, for example, for better and more efficient knowledge and resource transfer of policies, such as the Hothouse incubator, into which WAG-related policy could also be effectively and beneficially linked.

\section{Evidence of policy effectiveness}

GEM research shows that Ireland ranks 3rd highest in the EU in terms of early stage entrepreneurial activity and similarly 3rd highest in the OECD in terms of high expectation early stage entrepreneurs. Hothouse is generally perceived as contributing to that achievement. Forfás (the Irish national policy review agency) has highlighted that the Enterprise Platform Programmes (of which Hothouse is a strong part) run by the Institutes of Technology, 'are becoming an increasing source of high potential start-up businesses' (Forfás, September 2007), and recommends that public funding should be continued for the establishment of entrepreneurship centres linked to universities. In a review of the sources of high potential start-ups (HPSUs) over the period 2003 - 2007 approximately $23-25 \%$ of all HPSUs (360 companies in total) were participants in the Enterprise Platform Programme, including Hothouse (Enterprise Ireland, March 2008). Hothouse management reports hat 162 companies (74\%) out of a total of 218 companies that participated in their programmes continue to survive and trade. There is thus general evidence of policy effectiveness. However, effectiveness cannot be considered definitive since: the evaluations were often broad ranging and involved the participation of Hothouse; there are other potential causal variables for success; and, indeed, that the outcomes from HPSU's are not likely to be fully seen for some time.

\section{Elements of policy that are adoptable or adaptable to the Welsh context}

In terms of adoption / adaptation of the Hothouse programme in Wales, apart from the intensity of support activities, it was not clear to some commentators how specifically the Hothouse programme differs from many other university/college-business interfaces across the globe. Conversely, the author of the original paper argued that the Hothouse experience suggested that in a range of important factors there was the achievement of differentiation and results: (a) establishment of a distinctive value proposition for participants (b) brand and innovative promotion (c) professional delivery and a client oriented service culture (d) openness to third level graduates from all colleges (including nonnationals) (e) building and using effectively a well developed network of proven advisors, consultants, alumni, etc. These features are often not recognised and absent in other incubators around the world. 
The hothouse policy can thus be seen as linking together Technium, university incubator and related education and skills development policy, re-emphasising the need for a holistic integrated approach. In particular, comment was made that if there is a weakness in current Welsh initiatives, it is the lack of a systematic programme of support activities (training, mentoring and marketing) of the sort described in the Hothouse paper.

However, the issue remains as to whether these kinds of activities are better provided, as they appear to be in Ireland, in programmes linked to technical colleges and the newer universities whose overall missions are broader than those of traditional universities. This is a matter for debate and depends upon the relative capacities of different types of universities in Wales. There is also the issue of the extent to which HEIs should have control of the objectives of these programmes, relative to industry. For example, there are Techniums in North Wales run by independent companies (on behalf of WAG), whilst in the Swansea-based Techniums the University has a major say. Evaluation of their relative success would need to be conducted to determine the best approach. The question was raised as to whether it was vital that this type of activity be physically located on a campus. The main benefits were linked to a programme of activities rather than physical space, and Hothouse brand seemed to have very much an identity of its own, separate from the University and reliant upon the dynamism of the people involved. Hothouse does provide a benchmark against which to judge Technium and university incubator programmes for example, and from which individual elements can be adopted.

It must be recognised, however, that a policy such as Hothouse would require networking with successful firms and alumni, as well as willingness of universities to assist those from outside their own staff / alumni. The fact that participants were chosen on a competitive basis meant that a Hothouse type scheme may be seen as giving support to higher profile, motivated participants who are more likely to produce higher returns. Another benefit of policy adoption would be that the education and training programme-base of Hothouse could fit in with the resource concentration of WAG policy in this area. Conversely, Hothouse can also be seen as requiring a relatively large amount of resources and is likely to produce geographically concentrated effects. Thus, placing the policy within a framework of broader business support was seen as necessary in order to assess its success in raising productivity levels in Wales more generally. Specific mention was also made of the current, often piecemeal, approach to policy. A small number of very focused policy initiatives in Wales, even if successful, were likely to produce only small improvements in overall productivity performance because they could assist only a small number of firms. Finally, it was suggested that mutual learning from the Irish experience should be at the practical level, via mentoring of Welsh hothouse-type managers, rather than producing an official "public service target" type approach. This should not preclude, however, the Hothouse experience and demonstrated 'success factors', feeding into the design of new national policy on incubators, the absence of such a policy being a hindrance to individual incubators like Hothouse. Specific elements that are adoptable / adaptable are therefore:

- Due to perceived weakness in current Welsh innovation initiatives, in terms of the lack of a systematic programme of support activities to incubator and spinouts, adoption of the Hothouse policy of training, mentoring and marketing support would seem to represent an additional element to existing policies that could enhance their outcomes in terms of the creation of viable technologically advanced HPSUs.

- The Hothouse policy may be adaptable, not only by being sited on university campuses but by being spread more widely (though still within specialised spaces and utilising university expertise - though not necessarily university run), fitting in with wider business support, and skills and training measures to promote broader productivity improvements. 
- The adoption of branding policy with the Hothouse type approach, of being competitive in terms of gaining entry, may also assist in the identification of early stage high potential firms.

Overall, the Hothouse experience seems to provide valuable insight into programmes which can assist incubator policy more generally, and may potentially fill a gap in current Welsh policy.

\section{Promoting university-enterprise links: innovation voucher scheme in the Netherlands and the UK}

Overview

The main aims of the Innovation Vouchers scheme is to build relationships between SMEs and public research institutions, such as universities, to stimulate university-small business interaction, encourage innovation and direct knowledge transfer (of both locally created and internationally transferable knowledge and innovation), as well as acting as a catalyst for formation of longer-term, more in-depth relationships, effectively pump-priming funding to allow establishment of the initial relationships. The Dutch programme was seen as part of a suite of measures, rather than a stand-alone activity, and adoption of similar programmes in both Ireland and the West Midlands provide a range of comparator programmes from which to draw. In terms of the three examples given, the following lessons can be seen:

- Demand-led network-marketing of the programme is likely to be most effective and lead to over-subscription, with a consequent need to develop transparent and effective procedures for allocating support to firms which meet the eligibility criteria'.

- Related to this, is a need to determine targeting (or non-targeting) on the basis of technical (engineering or ICT-based innovations), and/or management (including leadership) based innovations.

- Resource ramp-up to meet the increased demand may also be required, either directly from government or from a "matched" arrangement, as an alternative / addition to tight choice criteria. This highlights again the critical importance of deciding how such a scheme would sit within an overall strategy with regards to productivity.

- There is a key need for careful articulation of the role of universities, given that the voucher scheme is likely (and desirably) part of a suite of activities that they are to be required to engage in as part of the overall productivity agenda.

- In terms of administration, it is suggested that "light touch" administration and simplicity in application and identification processes are important in the success of such a scheme. Development agencies, rather than universities, are also believed to be best placed to manage the programme - universities acting only as providers. This is to avoid conflicts of interest, focus activities, and allow linkage with other related policies.

\section{Evidence of policy effectiveness}

Evaluation evidence is at present restricted to the initial tranche of Dutch Innovation Vouchers distributed in 2004. An evaluation of the $1^{\text {st }}$ Innovation Voucher pilot scheme was based on data from the application forms and from telephone interviews with 71 voucher winners and 242 firms who were not allocated vouchers. The first 100 innovation vouchers were allocated randomly among 1044 applicant SMEs in September 2004. Around 80\% of firms in both groups had some prior knowledge of the research institutions, although a smaller proportion (around half) had not previously 
commissioned any research, primarily because of the expense of doing so. The overall satisfaction level among voucher winners was high although there was less overall satisfaction about the price/quality ratio. Seventy-six percent of voucher recipients did not need to add their own money to the value of the voucher. Estimates of additionality also suggested that around eight out of ten vouchers represent projects which would not have been commissioned without the voucher scheme, a high level of additionality relative to other innovation incentives. A subsequent assessment of the impact of the 2004 pilot intervention on the innovation behaviour of voucher winners was then conducted, although issues of sample selection create caveats about the results. The analysis is based on firms' innovation outputs in the period 2005-2006, for 47 SMEs with a 2004 voucher and 169 applicants that did not win a 2004 voucher. Significant positive effects are identified on process improvement although not for product innovation, product improvements or process innovation. There is also a strong positive additionality in terms of the number of new assignments which would not have been commissioned without the vouchers. Again, however, it must be stated that the nature of innovation may mean that the overall impacts (or lack of them) may require a more longitudinal evaluation.

\section{Elements of policy that are adoptable or adaptable to the Welsh context}

Discussions with policy-making actors highlighted this type of scheme as of particular interest for the future. There were also (from other contributors), however, a number of highlighted issues. First, reinforcing the need for the policy to be seen as one amongst a suite, it was stated that $£ 3 \mathrm{k}$ was unlikely to be sufficient for any but the smallest of companies, with a consequent need for other larger scale incentives for medium and larger SMEs (where the next initiative (NITEC) may be seen as providing some potential promise). Second, there were some concerns over the capacity of SMEs to take up the opportunities, but also universities to have sufficient number of academics with the necessary expertise and / or time, unless the scope of the vouchers could include managerial, process and product innovations. Third, the key element for success would seem to revolve around the brokerage of the scheme, with support for the view that an all-Wales body (such as the One Stop business service, Development Agency, or all Wales University organisation) act as coordinators. This raised the issue of whether there was currently the brokerage capacity for such an arrangement. Roper et al's (2007) Scottish innovation system study, for example, identified a potential support policy which would involve a group of full-time brokers to identify research needs in firms new to innovation and link these to partnership opportunities with higher education institutions. In the Roper et al. (2007) study it was recommended that grant support be provided to the university/college to work with the firm, the implementation success of any initiative would thus depend very strongly on the quality of those recruited as innovation brokers. In addition, however, it is also seen as important that conscious selectivity, which required background justification and detailed administrative procedures, is avoided, because this would conflict with 'light touch' administration and make the scheme more difficult to operationalise. It is important to note, therefore, that this support measure is meant to be small scale, easy to obtain, quick and not overburdened with administration, with a consequent absence of any attempt to maximise impact via detailed selectivity criteria. Specific elements that are adoptable / adaptable are therefore:

- It is likely to require an initial expansion of the innovations able to receive support (over and above those highlighted in the Dutch and West Midlands approaches) to include business management and technological innovations, in order to avoid university capacity problems and also to increase the scope for beneficial improvements.

- The schemes organisation should be coordinated by an All-Wales body of specialised innovation brokers, with universities facilitating the vouchers rather than running individual schemes, and minimal administration. 
- Given the needs of different sized firms, adoption of an Innovation vouchers scheme at $£ 3 \mathrm{k}$ per firm requires the scheme to be explicitly marketed as one amongst a suite of support, or alternatively a sliding scale of potential support depending on the firm size.

In addition, however, there is a crucial issue surrounding the initial innovation capacity of firms to be able to take advantage of the links. This highlights a need for decisions as to whether a supporting policy could therefore involve support for R\&D capacity building in SMES, as well as whether innovation vouchers may be suitable for micro and very small businesses whilst R\&D capacity building type policies may be more suitable for larger SMEs.

\section{$V I . R \& D$ capacity building in SMEs: the NITEC initiative to support $R \& D$ units in Portuguese SMES}

Overview

The NITEC programme described below is an example of Firm R\&D capacity building type of intervention. Although, to an extent, it can also be seen as an alternative to innovation vouchers, promoting in-house as opposed to collaborative activity. The NITEC programme involves support for creation of Research and Technological Innovation Teams in Companies. A NITEC was defined as a small (initially 3 and now 5), permanent team of people, fully dedicated to technology 'mastering' and development activities. According to a project-based action plan, those activities were expected to lead to the design of new products, processes and/or systems or the introduction of significant improvements in existing ones. The NITEC programme is also, however, aimed at addressing the low level of in-house technology and innovation capabilities in Portuguese firms, which had been identified as an important hindrance to a stronger co-operation between universities and Scientific and Technological (S\&T) organisations and Industry. Positive effects of NITECs were reported to include increased process effectiveness, and design and development capabilities leading to a higher turnover. It must also be expected that the main outcomes of the investment in NITECs may take some time to materialise, having in mind the characteristics of the activities performed. The key issues are therefore as follows:-

- Policy makers in Wales are likely to share, to a significant extent, the problem faced in Portugal by SME managers who often viewed technologies in terms of application, rather than something which they can innovate for competitive advantage. A key challenge for public innovation policy in Wales is therefore to assist in building up in-house capabilities.

- Although it also has complementary characteristics, NITEC may be seen as an alternative to the innovation voucher scheme previously discussed.

- A NITEC type scheme can also incentivise and enhance the value of relational assets with other companies (customers, suppliers, partners, or rivals) and with Science and Technology organisations such as universities.

\section{Evidence of policy effectiveness}

Available information suggests that the adoption of the NITEC incentive system has been relatively high during its first phase of implementation, with the number of applications and contracts exhibiting a growing trend. Overall, the efficiency of the NITEC initiative has also been positively evaluated. It was recognised that the support for the creation of the small R\&D teams is justified in terms of public policy, insofar as it has significantly contributed towards a positive change in the commitment and capacity of Portuguese companies to undertake R\&D and innovation, both internally and collaboratively. With regard to tangible outcomes, however, there is no statistical evidence about 
the consequences in terms of increased company competitiveness or turnover, for instance. However, information from academic research suggests some positive intermediary effects of NITECs from cost savings due to increased process effectiveness, and increased design and development capabilities (though there are also concerns about the effectiveness of the small $R \& D$ teams, insufficient selectivity in choosing the participating firms, and substitution of public for private activities). It should be taken into account, however, that the main outcomes of the investment in NITECs may take some time to materialise, given the activities performed.

\section{Elements of policy that are adoptable or adaptable to the Welsh context}

The NITEC programme appears overall to be a potential example of good practice, with at least partial relevance for innovation policy in Wales. Discussions with policy-making actors showed some interest, but perhaps less than for innovation vouchers, for example. Whilst in general terms, there seem few major transferability problems, issues remain over precise policy mechanisms, in particular: how such a policy would sit with other overlapping policies in this area, the relative benefits from such resources (e.g. how assistance would compare with companies that are already focused on knowledge and innovation), and also to what extent such an intervention may actually inhibit the benefits of firm churn in a free market. Roper et al. (2007) found, in their Scottish evaluation, however, that there was often a lack of recognition of the value of R\&D and misperception of innovation by many SMEs, and a consequent lack of belief in its ability to raise economic performance. Overall this seems to highlight the fundamental importance of raising innovation capacity and benefit recognition and industryuniversity networking, which will be the sine qua non of these types of policy. Policy experts argue, however, that this type of policy (as well as being seen as a type of KTP arrangement) may be particularly suitable for specific medium sized companies, where development of an appropriate R\&D base that did not currently exist might assist strongly in growth and thus productivity gains. Specific elements that are adoptable / adaptable are therefore:

- A NITEC type policy should be adapted to sit alongside current Knowledge Transfer Partnership arrangements (the nearest equivalent) and /or innovation vouchers (which could possibly focus on smaller firms and organisations). It should be specifically focused on medium sized firms with growth potential, where development of a competitive R\&D capability (of at least 5 individuals) would assist in the firm's growth and business productivity gains.

- It could also be used to promote medium-sized firm exemplars, which raise the recognition of the importance of innovation and growth through subsequent "graduation" of the benefiting firms into university-industry innovation relationships.

This also raises the issue of entrepreneurial behaviours more widely as stimulators of innovative policy. In the knowledge spillover theory of entrepreneurship (Acs et al. 2004) it is argued that knowledge developed in one institution (e.g. universities, etc.) may be commercialised by others (e.g. firms), and that entrepreneurship (particularly in the form of new firms) is one way that the 'economic agent with a given endowment of new knowledge' can best appropriate the returns from that knowledge. The complexity of such knowledge intensive entrepreneurship often creates barriers for firm creation, however. This may be result from (1) failure of private firms and public institutions to generate new knowledge; (2) failure of that knowledge to be disseminated efficiently; (3) failure of individuals to exploit new knowledge; (4) a range of other factors that make entrepreneurship difficult. Previous policies discussed can be seen as dealing with the first 3 factors. There still remains, however, the need to explore the role and importance of entrepreneurship promotion. 


\section{Benchmarking WAG policy: Appalachian Regional Commission (ARC) Entrepreneurship Initiative (EI), USA}

\section{Overview}

The Appalachian Regional Commission's Entrepreneurship Initiative is focused on how to foster the economic and cultural conditions that give birth to entrepreneurs, support innovation, and assist in developing and expanding successful enterprises. The ARC's Entrepreneurship Initiative is, however, one of the first large-scale regional entrepreneurial development efforts and the first federally funded regional entrepreneurship strategy; as a result its impact is perhaps easier to measure. Its focus was on six basic outcomes: more potential entrepreneurs, more entrepreneurs staying in the community to create their business, better informed and skilled entrepreneurs, faster growing businesses and greater business productivity. In terms of key issues:

- Entrepreneurship development initiatives should include assessment of existing capacity and capacity building activities as part of project design with emphasis placed on initiatives that demonstrate ability to form regional partnerships and collaborations. As with previous policy examples, the EI was heavily focused on building strong regional partnerships that included national, regional and local partners, particularly a wide range of new community-based organisations, such as youth clubs, faith-based organisations, microenterprise funds, and others. Many of these have subsequently assumed major local and regional leadership roles in promoting alternative economic development strategies.

- Entrepreneurship development investments should: focus on long term sustainability, be market driven and practice continuous improvement.

- There is a need for a robust, comprehensive applicable performance measurement system. Entrepreneurship development efforts have traditionally been assessed using metrics such as job creation or retention, leveraged investments etc. (as indeed were the original measures for the EAP in Wales). These do not, however, necessarily give a full picture and thus a more wide-ranging set of metrics may also need to be considered.

\section{Evidence of policy effectiveness}

In terms of evidence of policy effectiveness, the EI's limited scale and scope (investing approximately USD 42 million in 13 states over ten years) makes it difficult to draw any causal connections between ARC investments and broader regional economic trends. The final reports submitted to ARC did identify that the EI led to the creation of at least 9156 jobs, the retention of a further 3022 jobs, the formation of 1787 new businesses, and the provision of services to 8242 businesses. The public cost per job created was USD 4 693. ARC investments were made in 340 unique projects across the region at an average investment per state of USD 3.3 million and investment per capita of USD 1.82 million. The total ARC investment has leveraged an additional USD 72.8 million in private investment for those projects that have been closed, a figure that is projected to rise to USD 109.9 million when all projects in the portfolio have been completed. Qualitative impacts were identified as building a local "enterprise culture". Interviews with key stakeholders indicated that EI investments did contribute to the generation of new thinking and approaches to local economic development. Interviewed participants also noted that the programme helped raised the profile of entrepreneurship as a development strategy, and also helped facilitate networking and collaboration among practitioners. 


\section{Elements of policy that are adoptable or adaptable to the Welsh context}

The key specific EI lesson here would therefore seem to be the linking of entrepreneurship with innovation and network, with social capacity building and creation to facilitate this. The fact that many of the EI innovations have been implemented elsewhere in the US, overseas, and indeed in Wales (through the EAP) may limit the elements that are adoptable / adaptable for the Welsh context; though it may serve in some ways as an exemplar against which to benchmark WAG policy in legitimising entrepreneurship as a core aspect of regional economic development strategies. Discussions supported the view that EI can be seen as a general entrepreneurial milieu creating policy, in line with the WAG's Entrepreneurship Action Plan, but also highlighted limitations in its practical usefulness in broad application. In the ARC case and generally in the US, innovation policies tend to be focused on technology development and commercialisation and have a heavy, although unintended, urban or suburban emphasis. "Entrepreneurship" was therefore viewed by the ARC as an ideal rural development method, given that it implied a "home-grown" assets-based development strategy that could be applied in any environment, but was especially well suited to small towns in Appalachia. It therefore emphasised economic development outcomes but had an equally strong interest in community building, though the metrics used did not really capture the latter. This therefore suggests that to an extent the EI is more akin to a Rural Action Plan, rather than an Entrepreneurship Action plan per se, though rural areas of Wales tend to have a better entrepreneurship record (in terms of selfemployment at least) than urban areas. Discussion with policy-making actors in Wales also revealed that whilst there had been some planning for an "EAP II", this had been shelved, potentially in favour of a wider policy that brought together a number of interrelated enterprise, innovation and productivity issues. Specifically, in comparison with the EAP, the EI had relatively limited resources spread over a range of entrepreneurship, but also innovation and clustering activities. In contrast, the EAP was specifically aimed at entrepreneurship when it was put in place in 2000, but has not been specifically updated since, the perception being that the EAP was effectively superseded by the Innovation Action Plan (with specific elements of the EAP updated). EI may be better utilised as a comparator, with elements of any broader productivity-raising strategies (e.g. WAVE or the Vostra Gotaland example), or specific rural development initiatives which have a greater emphasis on capacity building. In terms of the specific elements that are adoptable / adaptable, this is a policy where only a limited number of selected elements may be suitable:

- Adapting the networking and entrepreneurship capacity building elements most focused on business productivity and small firm growth, suitable for a geographically focused policy on small towns in rural areas, within the rurally focused parts of the Spatial Plan and any Vostra-Gotaland type strategy.

- Use results from EI to benchmark relevant Welsh policy subsequently adopted.

\section{Benchmarking business support: No Wrong Door Model, USA}

\section{Overview}

The No Wrong Door model was created to deal with the issue of multiplicity of programmes, policies and support measures related to SME development. In this example, US communities have sought to enhance the "user-friendliness" of their small business support services through creation of local or regional systems of entrepreneur support. A "No Wrong Door" model seeks to create a more seamless and coordinated system of business support across a region or state, building a collaborative structure where organisations jointly market, share a customer database, make referrals within the system, have common customer intake procedures, and utilise the programmes operated by partner organisations. The key identified lessons are: 
- Generally the programmes could be transferred for use in Wales, given that facilitated basic software packages are available for purchase, and are being used in other regions in the US.

- The main obstacles to the "No Wrong Door" model result from different organisations' competition for resources, customers, and public recognition. This may therefore require well funded full time network coordinators, to build connections between various network partners, and funding to provide incentive payments to other network partners.

- There is also emphasis on fostering collaboration among network partners. Network operations improve when partners participate in regular meetings in person, via conference calls or via webinars. These sessions also help partners learn about each other's programs, and should also be used for joint professional development opportunities.

- Web site and database hosting is another issue to consider when implementing a No Wrong Door approach. Each partner organisation may operate its own website and internal databases, but the network sites are managed by one of the partner organisations that manages access to the data and ensures quality control over information and marketing materials.

\section{Evidence of policy effectiveness}

Preliminary evaluations through surveys of programme customers and partners indicate major improvements in customer satisfaction, significant cost savings for service provider organisations, and improvements in regional business productivity and growth. No independent analyses have yet been completed, however, and the short life span of the model thus far limits the ability to fully assess effectiveness and efficiency.

\section{Elements of policy that are adoptable or adaptable to the Welsh context}

In terms of direct adoptability / adaptability to the Wales context since devolution, it must be recognised that although the No Wrong Door approach was seen as offering a potentially organic, networked alternative to the current Welsh approach highlighted earlier, concerns were also raised that the necessary collaborative networks and software to coordinate activities might not work in practice. Overall, whilst concerns (highlighted earlier) were raised about existing policy in Wales, there were also perceived weaknesses in adopting the No Wrong Door model, as well as an acknowledgment that the One Stop Shop approach was the approach favoured for Business Support in Wales; the current strategy being seen as following in the footsteps of previous attempts such as Business Connect and Business Eye. Some commentators saw this as evidence of merely repeating past policies. Conversely, policy-making actors argued that the new approach aspired to having a No Wrong Door approach (in terms of being a bespoke demand driven as opposed to supply driven approach), growing into a service which would also link with overlapping activities, such as those related to universities. As such, the No Wrong Door model can be seen as a partial alternative approach to existing policy measures in Wales, but not one where adoptability is currently an option. Thus adoptability / adaptability is limited to:

- Use results from the No Wrong Door approach to benchmark the One Stop Shop approach of current Welsh policy. 


\section{Benchmarking Wales university collaboration activities: University Filial Centres, Finland}

\section{Overview}

The background of the University Filial Centre Network lies in executing universities' regional development function of answering the needs of a less favoured region. The empirical findings from the Finnish less favoured regions underline the notion that to create local knowledge spaces and systems in a thin knowledge environment, local actors need a) applicable national instruments (competitive funding, legislation, educational opportunities, etc), b) regional or local incentives and activeness, and c) dense global interaction, all within the locally embedded existence of active and skilled actors, as well as the advanced development of culture and mobilisation - often described as openness for new ideas and knowledge. The resultant policy was to promote these activities through regional entrepreneurship, by inducing universities to found new units, creating university filial ('University Consortiums' in the Finnish context.) centres (institutions), and share arenas as a form of innovation (policy) platforms under the university filial centre umbrella. The university filial centre umbrella was aimed at creating intersectoral, interdisciplinary and interactive aspects through the filial network, as well as promoting openness for many kinds of actors and ideas. The basic policy-related issues are as follows:

- There is an important indirect role for university filial centres as hosts (seen as more beneficial than government for reasons of hierarchy) to policy platforms, which serve as a public space or an interpretative space for ongoing local, but globally linked conversations about infusion of current technologies and future direction of technologies, markets and new services. This creates potentially very different outcomes in different areas.

- The major industry participants in collaborative technology programmes and initiatives actively look for difficult-to-describe new knowledge requiring deeply committed coalitions and research alliances with long-time spans. Industry representatives were concerned over the still unknown results and outcomes and how their companies were able to absorb new information and knowledge. This may also be seen to be in conflict with the closer to market outcomes focus proposed for K-plus centres.

- Overall, the linking of individual and independent knowledge organisations onto the same platform enhances knowledge sharing and accumulation in new ways, and attracts stakeholders previously excluded or reticent to engage in difficult to induce collaborative actions.

\section{Evidence of policy effectiveness}

The effectiveness of many of the university filial centres has been measured against the tasks set for them by their regional stakeholders, who support different though locally important schemes, approximately $2 / 3$ of the funding for the centres coming from external sources (mainly regional funds or stakeholders). Evaluations have highlighted the cost-efficiency of the centres in successfully meeting these expectations and other national choices to enhance the regional knowledge economy. Most evaluations, however, concern only one case region and partnership consortium at a time and evaluation of the entire system has tended to focus on the allocation of resources rather than the impact on the regional innovation systems.

\section{Elements of policy that are adoptable or adaptable to the Welsh context}

Filial activities are typically strongly affected by (usually) extremely high regional expectations. These often cast University Filial Centres as the main engines of economic growth of the region, 
responsible for unlocking existing knowledge structures. A key weakness, however, for both regions and University Filial Centres is the insecure financial situation, based on temporary funding and weak institutional roles within parent universities. In practical terms, given the very strong existing emphasis on the role of universities in many of the other potential initiatives, the benefits of this policy (and the organisational changes it would necessitate) would need to be weighed against other potential activities and seen in the light of an existing broad geographical coverage of universities around Wales, and competition between them. Discussion also revealed a current perceived weakness in the ability of universities in Wales to effectively network together to create beneficial cooperative outcomes, a perception that was also seen by policy-making actors for some (but not all) university activities. The filial centre system provides a knowledge platform, through which formation of local activeness may occur, and an instrument from which to build the local or regional constructed advantage (as Asheim proposed in 2006). From a policy transferability point of view it would seem to represent an addition to existing university structures, and an alternative (and ramp-up) to the existing cooperation and collaboration between universities, necessitating both incentives and further network facilitation from government, a need also highlighted, for Wales in particular, by Pickernell et al. (2008). Discussions with policy experts also highlighted a specific need for bodies such as HEFCW, or the University of Wales, to facilitate increased collaboration between universities in Wales and to overcome current perceptions of universities as competitors for the scarce resources likely to be available to instigate such a policy. Thus adoptability / adaptability is limited to:

- Currently this policy is most useful as a benchmark for policies with similar targeted outcomes of university involvement in local economies in Wales.

- In the longer term, there is potential for instigation of the filial elements for creation of "innovation public space" in towns (localities not currently served by universities), by utilising a group of universities involved in further network building between universities in Wales, or using alternative sets of stakeholders (e.g. a university with local government, local industry organisations etc.) to facilitate the dialogue within the space created.

\section{$X$. Issues relevant to Wales' sectoral policies: FATEC Initiative - advanced footwear technologies, Portugal}

Overview

FATEC is one illustrative project intervention out of an integrated long term strategy for the sector. In the "first round" of interventions, FATEC and other large dimension projects were developed, focusing on "hard" technological dimensions. These interventions allowed creation of the social capital needed to develop a next generation of integrated policies and projects, which now have a direct focus on skills and organisation. FATEC itself was developed during 2002-2005 by footwear companies, technology providers and institutional players, aimed at the technological intensification of the Portuguese footwear sector geographically concentrated in the North. It represents a case of locally organised collective action to change the competitive model of a traditional industrial sector, in which regionally-based intermediate institutions also play key roles. Within this policy and context there are a certain number of individual areas of interest identified:

- Procedural characteristics of FATEC may be useful to similar initiatives, given that it constitutes an integrated process of innovation from knowledge creation to technology commercialisation and successful delivery arrangements. FATEC lessons may also be used in "traditional" sectors (like agri-food) and spearhead sectors (like automotive, aeronautics or pharmaceuticals) focused on by WAG policy. 
- A (broader) regional dimension was appropriate for initial consortium design, allowing the most capable players (namely knowledge institutes) to be included and making frequent contacts and interaction between the partners possible. The transformation has been brought about by measures that have served to enhance previously weak co-operation between companies in the sector and through the strong leadership offered by the Portuguese Footwear Technological Centre (CTCP). FATEC also shows, however, that for this type of regional consortium it is important to involve the most able partners who can effectively contribute to the development of new business solutions, as opposed to a wider approach (which may be seen as necessary for broader policy creation and acceptance). The design of projects like FATEC may be preceded by smaller projects in order to create trust between players. The bottom-up approach draws together the main players in the sector, changing the regionally-based Portuguese footwear sector from one relying on imported components and machinery for the manufacture of the bulk low-added value products demanded by large multinational suppliers of world markets, into one able to design and manufacture small higher value batches for specific niches, thereby slowing but not halting the overall decline in employment in the sector. This may be an important area for further analysis, given that in many sectors in Wales "cooperation capital" between potential partners has previously been suggested to be relatively weak.

- Related to this, proximity (physical, institutional and social) is relevant to steer frequent contacts, in-house research and development, solutions' fine tuning, etc. Regional and wider dimensions, however, are often the appropriate scale to enlist relevant partners. Thus, it might very well be that a hypothetical initiative to develop new technology for the agro-food sector in rural areas of Wales, for example, can link with the participation of the research infrastructure and solution suppliers located in the region's most dynamic urban areas. Moreover, in some sectors where knowledge is very specific and hard to find, the constitution of temporary proximity platforms with partners from other worldwide regions can even be considered, if other institutional conditions allow for that.

- The FATEC project has also had the effect of motivating companies to move into new product areas and markets and given rise to new institutional learning processes. Previous research by Clifton et al. (2008) into the Welsh aerospace sector highlighted the need for reduced Government involvement in the governance of the sector to allow other participants, including higher education institutions and small and medium-sized companies, to play a bigger role in decision-making. Within the various Welsh sectors identified as offering strong growth possibilities, it would perhaps now be appropriate for Government to urge industry to reform its intra-sector structures so that Government can step back and play a more traditional role as the overall economic policy proponent. The emergence of stronger representative organisations across Welsh sectors - even acknowledging the realities of the overwhelming integration of Welsh business into wider UK and European structures - could be important, helping to create enhanced co-operation capital between companies and also with higher education institutions.

\section{Evidence of policy effectiveness}

The time that has elapsed since FATEC's conclusion in 2005 means that evidence of policy effectiveness is limited to partners' perception and documented information. In terms of basic outcomes, the consortium developed and produced 68 new systems and pieces of equipment, encompassing the 12 strategic areas of the footwear production cycle planned in the working groups. Each of the developed solutions has also been installed in the plants of the pilot footwear firms. Recent rises in Portuguese footwear exports as a share of total (declining) production, together with an average rise in price, also suggest that the industry is becoming more specialised in market niches. 
Many of the products and technologies developed under FATEC were exported to Italy and Germany, not only within the footwear industry but also in automotive components, food and furniture. The development cost of the new solutions was on average three times higher than the already stabilised and commercial solution, however, this was still considered to be moderate because the financial risk was shared between the consortium partners. Although direct causality is not possible to establish, FATEC firms (and others in the industry) also argued that the initiative contributed to endowing them with critical technologies for state-of-art product design, cutting, small series and just-in-time deliveries - key conditions to be competitive in footwear international niche markets

\section{Elements of policy that are adoptable or adaptable to the Welsh context}

In terms of adoptability / adaptability there are, however, several issues which may limit the relevance of the FATEC strategy approach to Wales. In contrast, to Portugal, Wales has a much greater ability to generate policies with a specific regional (within Wales) and sectoral focus. A weakness of the Portuguese system is that economic and innovation policies are traditionally designed at a national level, with regions lacking political power and focusing almost exclusively on land planning and the provision of cheap space and basic infrastructure. However, despite their lack of political power, regions are increasingly becoming involved in clustering, internationalisation and innovation systems policy. The latest generation of initiatives being planned by CTCP (the footwear trade association) will seek to deal with one of the weaknesses in the previous approach, namely the lack of training interventions within the sector. In this respect, Wales already has large-scale interventions in place, through its higher education institutions aimed at ensuring a flow of trained operatives into high technology sectors, such as aerospace. More importantly, Wales does not have significant one-product, largely domestically-owned, industrial clusters highly concentrated in one geographic area, such as footwear in Portugal. Companies operating in specific sectors in Wales, such as food and aerospace, also often lack the geographical proximity apparent in the case of the Portuguese footwear industry (where most participants are within 45 minutes travel time of each other). With the possible exception of the already well developed opto-electronics sector which is concentrated in north-east Wales, industry, even within the same sector, is widely spread throughout the main industrial regions of Wales and physical communications between north and south Wales are poor. The other very significant difference between the economic structures characterising Wales and Portugal is the absence in general of independent trade or technological associations, such as APPICAPPS (Portuguese Footwear, Components and Leather Goods Manufacturing Association) or CTCP (Portuguese Footwear Technological Centre). Welsh businesses will usually belong to UKbased associations, which may or may not have Welsh regional offices. Given their wider range of responsibilities, these associations are unlikely to provide the type of leadership for Welsh-orientated initiatives offered by the Portuguese bodies in Portugal. In the longer term, introducing policy of this sort for key industrial sectors in Wales would be predicated upon the emergence of Welsh industry bodies able to play a fuller partnership role than seems currently to be the case. Higher education institutions in Wales, whilst potentially offering considerable support to Welsh businesses, including training, also see themselves more as a part of a wider UK economy and research activities dedicated to Welsh industrial sectors are not a major priority for most. Thus adoptability / adaptability is limited to:-

- Currently this policy is most useful as one against which to benchmark policies with similar targeted outcomes for Wales.

- Procedural characteristics of FATEC may be adaptable to the Welsh context (e.g. in food) in terms of providing an integrated process of innovation from knowledge creation to technology commercialisation and successful delivery arrangements. 
Thus, whilst elements of FATEC might be potentially useful to WAG's sectoral policy (e.g. with regard to the food sector), it is also apparent that WAG policy is already very proactive in the key sectors of this area (highlighted earlier) and exists in a very different economic and policy environment.

\section{Conclusions and policy recommendations}

\section{What should policy responses be in terms of adaptations of the 10 initiatives in Wales?}

* From the Vostra Gotaland initiative: adoption of the overall policy-making process that incorporates the full range of stakeholders involved in a business productivity improvement process; the increased engagement consequently providing additional knowledge sources which also allow strengthened analysis of growth potentials

* From the Hokkaido cluster initiative: adoption of greater up-front concentrations on the "soft" information and network-related resources (alongside "hard" infrastructures) with a focused and initially limited group of key industry, university and government stakeholders in the industrial sectors / clusters deemed of greatest strategic importance to the Welsh business productivity policy agenda.

* From K-Plus, Hothouse, Innovation Vouchers and NITEC: an inter-related targetable (i.e. each of these policies suitable for firms of different sizes and existing innovation capacities) suite of innovation creation, knowledge transfer and utilisation activities that can assist in improving overall business productivity for the firms effected, and can sit within existing policy in this area (assuming a targeted approach, where any new policies are specifically focused on addressing identified gaps in the current scope of policy e.g. with regard to medium sized firms for example, or enterprise-related support to support Technium-type activities)

* From Entrepreneurship Initiative, No Wrong Door, University Filial Centres, and FATEC: in the short term, an opportunity to benchmark existing Welsh policy and in the longer term, possible areas for new policy adoption assuming further network and capacity building between stakeholders.

The common themes of the 10 initiatives seem to be that there are clear advantages to be gained from an integrated specific productivity focused strategy, within which resources can be allocated, and existing and potential new policies evaluated. The range of policies that fall within the broader business productivity agenda will also need to combine focused policies in terms of geographies, sectors, firms (in terms of size) and technologies, with broader innovation creation, combination, dissemination and utilisation measures. In Wales, it would seem, however, that a degree of network and stakeholder capacity building may be required if the full benefits from such collaborative policy making and implementation are to be realised, particularly if universities are deemed to be strong actors in this regard, but also with regard to industry associations, etc. It is also clear that subsequent policy evaluation mechanisms will need to be suitable in terms of the (often significant) expected length of time before the full outcomes (often subtle and nascent) are likely to be achieved. Benchmarking against similar policies or alternative policies having similar outcomes, from other jurisdictions, may be of use in any evaluative framework. Specifically, in terms of the 10 initiatives:

- From the Vostra Gotaland initiative: adoption of the overall policy making process that incorporates the full range of stakeholders involved in a business productivity improvement process; the increased engagement consequently providing additional knowledge sources which also allow strengthened analysis of growth potentials.

- From the Hokkaido cluster initiative: adoption of greater up-front concentrations on the "soft" information and network-related resources (alongside "hard" infrastructures) with a focused and initially limited group of key industry, university and government stakeholders 
in the industrial sectors / clusters deemed of greatest strategic importance to the Welsh business productivity policy agenda.

- From K-Plus, Hothouse, Innovation Vouchers and NITEC: an inter-related targetable (i.e. each of these policies suitable for firms of different sizes and existing innovation capacities) suite of innovation creation, knowledge transfer and utilisation activities that can assist in improving overall business productivity for the firms effected, and can sit within existing policy in this area (assuming a targeted approach where any new policies are specifically focused on addressing identified gaps in the current scope of policy e.g. with regard to medium sized firms for example, or enterprise-related support to support Technium-type activities).

- $\quad$ From Entrepreneurship Initiative, No Wrong Door, University Filial Centres, and FATEC: in the short term, an opportunity to benchmark existing Welsh policy and in the longer term, possible areas for new policy adoption assuming further network and capacity building between stakeholders.

Ultimately, the overlapping nature of the problem of relatively poor business productivity performance in Wales and its potential solutions means that rational comprehensive planning is often inadequate for the range of issues that arise. The issues themselves are inherently difficult to clearly define, contain many interdependencies and multi-causal aspects, and are socially complex with many stakeholders. This means that entrenched value differences are likely to exist, with relationships that are unstable and evolving, the knowledge base for defining the nature of problems and the scope of possible solutions both patchy and disputed (Head 2008). This would suggest that business productivity policies fall within the remit of 'wicked problems' (Rittel and Webber 1973) the solutions for which are largely a social process (Roberts 2000) ongoing over a long period of time. An OECD (2001) publication, "Governance in the 21st Century", unsurprisingly therefore highlighted that nurturing social capital - based on networks and mutual recognition of worth - is both a key outcome and requirement of tomorrow's broader governance environment. The policies evaluated here emphasise the importance of this approach. In particular, and echoing the OECD (2001), the governance modes highlighted involve a much wider range of active participants, with more flexible and dynamic control methods. Fostering shared values is thus a crucial part of making this type of network decision making workable - emphasising the approach of the Vostra Gotaland initiative - and is important when contemplating implementation of policies related to the Hokkaido, Austrian K-Plus, Hothouse, and Innovation voucher initiatives in particular. Successful policy creation and implementation will increasingly depend on using the richest sources of knowledge about both the specific problem and solution, rather than relying on top-down established policy-making structures, a situation which creates profound challenges for policy makers. 


\section{References}

Abbey, J., Davies, G., and Mainwaring, L (2008), Vorsprung durch Technium: Towards a System of Innovation in South West Wales, Regional Studies, 42 (2), 281-293.

Adams, J., and Robinson, P. (2005), Regional Economic Policies in a Devolved United Kingdom, Seminar Paper 3, Welsh Assembly Government, Cardiff.

Alden, (2006), Regional Planning, An Idea whose time has come?, International planning Studies, 11 (3-4), 209-223.

Arrow, K. (1970), Essays in the theory of risk-bearing Amsterdam, North-Holland.

Asheim B.T. (2006) Constructing Regional Advantage: Principles - Perspectives - Policies. DG Research Expert Group On 'Constructing Regional Advantage'. Rapporteur Professor Asheim. Final Report On February, 2006. EC. 2006

Boddy, M. (2006), Understanding productivity variations between Wales and the rest of the UK, Report to the Economic Research Advisory Panel, Welsh Assembly Government, Cardiff.

Breunig, R. and Wong M-H. (2007), The Role of Firm Dynamics in Australia's Productivity Growth, The Australian Economic Review, 40 (1) 90-96.

Bristow, G., (1999) Towards an Economic Analysis of Wales: industrial Structure Sub-Group Report, WDA Economics Panel, Cardiff.

Bristow, G. (2005) Everyone's a Winner: problematising the discourse of regional competitiveness, Journal of Economic Geography, 5, 285-304.

Bristow, G., Hartwell, S., Meadows, G., Morgan, K. (2007) Objective One in Wales: An Assessment and Lessons for the future, Report for the BBC, Cardiff.

Bristow, G., Entwistle, T., Hines, F., Martin, S. (forthcoming), International Journal of Urban and Regional Research.

Brooksbank, D., Pickernell, D., and Morse, L., (1998) Reviving the Valleys of South Wales: Case Study evidence of a link with low pay, European Urban and Regional Studies, 5 (3) 277-281.

Brooksbank, D.J., Clifton, N.C. Jones-Evans-D. and Pickernell, D.G.,(2001) The End of the Beginning?: Welsh Regional Policy and Objective One, European Planning Studies, 9 (2), 255-274.

Clifton, N., David, R., Ehret, O., and Pickernell, D., (2008) Auditing Welsh Industry A clusters based approach-Aerospace, Report for the Welsh Assembly Government Small Grants Scheme, Cardiff, Welsh Assembly Government.

Coe, D.T. and Helpman, E. (1995) International R\&D Spillovers, European Economic Review 39 (5), $859-87$. 
Cooke, P. (2003). The Regional Innovation System in Wales: Evolution or Eclipse in Cooke, P, Heidenreich, M. \& Braczyk, H. (eds) (2003) Regional Innovation Systems (2 Edition), London, Routledge.

Cooke, P. Clifton N. and Oleaga, M. 2005 Social capital, firm embeddedness and regional development, Regional Studies, 39 (8): 1065-1077.

Cooke, P and De Laurentis, C. 2006 forthcoming in Cooke, P., De Laurentis, C., Tödtling, F., Trippl, M. Regional Knowledge Economies: Markets, Innovation and Clusters, (Edward Elgar).

Crafts, N. (2007) Productivity and Living Standards in Wales: A Comparative Perspective, Paper presented to Welsh Economic Research Advisory Panel, $28^{\text {th }}$ June,. Welsh Assembly Government, Cardiff.

Etzkowitz, H. and Leyesdorff, L (2000), The dynamics of innovation: from National Systems and "Mode 2" to a Triple Helix of university-industry-government relations, Research Policy, 29, 109-123.

Gwartney, J., Lawson, R., and Holcombe, R. (1998), The Size and Functions of Government and Economic Growth, Prepared for Joint Economic Committee Washngron D.C.

Hall, R.E., and Jones, C.I. (1999), Why do Some Countries Produce so much more putput per worker than others? Quarterly Journal of Economics, February, 83-116

Head, B. (2008) Public Management Research: towards relevance Keynote Presentation IRSPM Conference, Brisbane, Australia.

Hill, S., and Munday, M. (1992), The UK Regional Distribution of Foreign Direct Investment: Analysis and Determinants, Regional Studies, 26 (6), 535-544.

Maskell, P. (2000), Social Capital, Innovation, and Competitiveness, in Baron, S. Field, F. and Schuller, T. (eds.) Social Capital: critical perspectives, Oxford, Oxford University Press.

Morgan, K. (1997) The Learning Region: Institutions, Innovation and Regional Renewal, Regional Studies, 31 (5), 491-503.

OECD (2001) Governance in the $21^{\text {st }}$ Century, OECD, Paris.

Pagell,, M and Krause, D.R. 2005 Determining When Multiple Respondents Are Needed In Supply Chain Management Research: The Case Of Purchasing And Operations, Academy of Management Conference Proceedings , Honolulu, August 5-10: B1-B5

Patton, M. Q. (1990). Qualitative evaluation and research methods (2nd ed.). Newbury Park, CA: Sage Publications

Pickernell, D., (1999) Inward Investment, diffusion of knowledge and new working practices, Local Economy, 14 (2) 144-160.

Pickernell, D., Packham., G., Thomas, B. and Keast, R., (2008) University Challenge? Innovation Policy and SMEs in Welsh Economic Development Policy: Towards a New Framework, International Journal of Entrepreneurship and Innovation, 9 (1) 51-62. 
Rice, P., and Venables, A.J. (2003) Equilibrium Regional Disparities: Theory and British Evidence, Regional Studies, 37, 675-686.

Rittel, H. J. W., \& Webber, M. (1973), Dilemmas in a general theory of planning, Policy Sciences, 4, 155-169.

Roberts, N.C. 2000 Wicked problems and network approaches to resolution. International Public Management Review, 1(1):1-19.

Roper, S., Love, J., Scott, J., Cooke, P., Clifton, N., and Hewitt-Dundas, N., (2007) The Scottish innovation System : Review and Application of Policy, Scottish Executive, Department of Enterprise, Transport and Lifelong Learning, Edinburgh, (www.scotland.gov.uk/Resource/Doc/170949/0047879.pdf)

Schwartrz , R.G. and Teach, 2000 Research Note: Entrepreneurship Research: An Empirical Perspective, Entrepreneurship Theory and Practice, 24 (3) :77-81

Senyard, J., Pickernell, D., Clifton, N., Kay, A., and Keast, R. (2007) Developing a Framework for Knowledge Creation, Dissemination and Utilisation for SMES: A case study of Biotechnology, Proceedings RENT-Research in Enterprise and Small Business XXI Conference, pages pp. 131, Cardiff, Wales.

Stiroh, K.J. (2001) What drives productivity growth?, Federal Reserve Bank of New York Economic Policy Review March, 37-59.

Van Ark, B., O’ Mahony, M., and Ypma, G., (2007), The EU KLEMS Productivty Report, European Commission, Brussels.

Welsh Assembly Government (2008) Welsh Assembly Government Final Budget Allocations 20082011, WAG, Cardiff.

Welsh Economy Research Unit (2002) Welsh Growth Sector Analysis 2002, Cardiff, Welsh Economy Research Unit. 


\section{Acknowledgements}

In the process of preparing this paper general advice or comment on policy was obtained from a number of policy actors and experts on the Welsh productivity policy situation. I would therefore like to thank the following for their input:

Professor Jeremy Alden

Dr. Gillian Bristow

Professor David Brooksbank

Dr. Nick Clifton

Professor Phil Cooke

Jarlath Costello

Rhys David
Professor Steve Hill

Adrian Healey

Professor Dylan Jones-Evans

Professor Lynn Mainwaring

Professor Max Munday

Dr. Gary Packham

Dr. Martin Rhisiart 